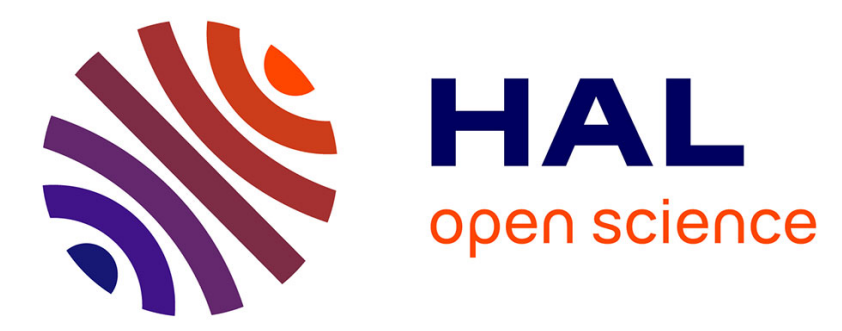

\title{
Prédiction transfusionnelle au cours de la chirurgie de la scoliose pédiatrique après mise en place d'un protocole d'épargne transfusionnelle par érythropoïétine et antifibrinolytiques
}

Claire Dupuis

\section{To cite this version:}

Claire Dupuis. Prédiction transfusionnelle au cours de la chirurgie de la scoliose pédiatrique après mise en place d'un protocole d'épargne transfusionnelle par érythropoiétine et antifibrinolytiques. Médecine humaine et pathologie. 2015. dumas-01205297

\section{HAL Id: dumas-01205297 https://dumas.ccsd.cnrs.fr/dumas-01205297}

Submitted on 25 Sep 2015

HAL is a multi-disciplinary open access archive for the deposit and dissemination of scientific research documents, whether they are published or not. The documents may come from teaching and research institutions in France or abroad, or from public or private research centers.
L'archive ouverte pluridisciplinaire HAL, est destinée au dépôt et à la diffusion de documents scientifiques de niveau recherche, publiés ou non, émanant des établissements d'enseignement et de recherche français ou étrangers, des laboratoires publics ou privés.

\section{(1) (1) $\$$}

Distributed under a Creative Commons Attribution - NonCommercial - NoDerivatives 44.0 


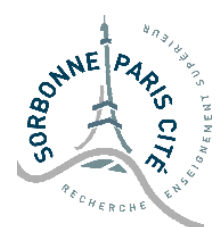

\section{AVERTISSEMENT}

Cette thèse d'exercice est le fruit d'un travail approuvé par le jury de soutenance et réalisé dans le but d'obtenir le diplôme d'Etat de docteur en médecine. Ce document est mis à disposition de l'ensemble de la communauté universitaire élargie.

Il est soumis à la propriété intellectuelle de l'auteur. Ceci implique une obligation de citation et de référencement lors de l'utilisation de ce document.

D’autre part, toute contrefaçon, plagiat, reproduction illicite encourt toute poursuite pénale.

Code de la Propriété Intellectuelle. Articles L 122.4

Code de la Propriété Intellectuelle. Articles L 335.2-L 335.10 


\section{UNIVERSITÉ PARIS DESCARTES \\ Faculté de Médecine PARIS DESCARTES}

Année 2015

$N^{\circ} 21$

\section{THÈSE \\ POUR LE DIPLÔME D'ÉTAT \\ DE \\ DOCTEUR EN MÉDECINE}

Prédiction transfusionnelle au cours de la chirurgie de la scoliose pédiatrique après mise en place d'un protocole d'épargne transfusionnelle par érythropoïétine et antifibrinolytiques

Présentée et soutenue publiquement

le 7 avril 2015

Par

Claire DUPUIS

Née le 5 mars 1983 à Dieppe (76)

Dirigée par M. Le Professeur Souhayl Dahmani

Jury :

M. Le Professeur Brice Ilharreborde

Président

M. Le Professeur Gilles Orliaguet

Membre

Mme Le Docteur Julie Hilly

Membre 

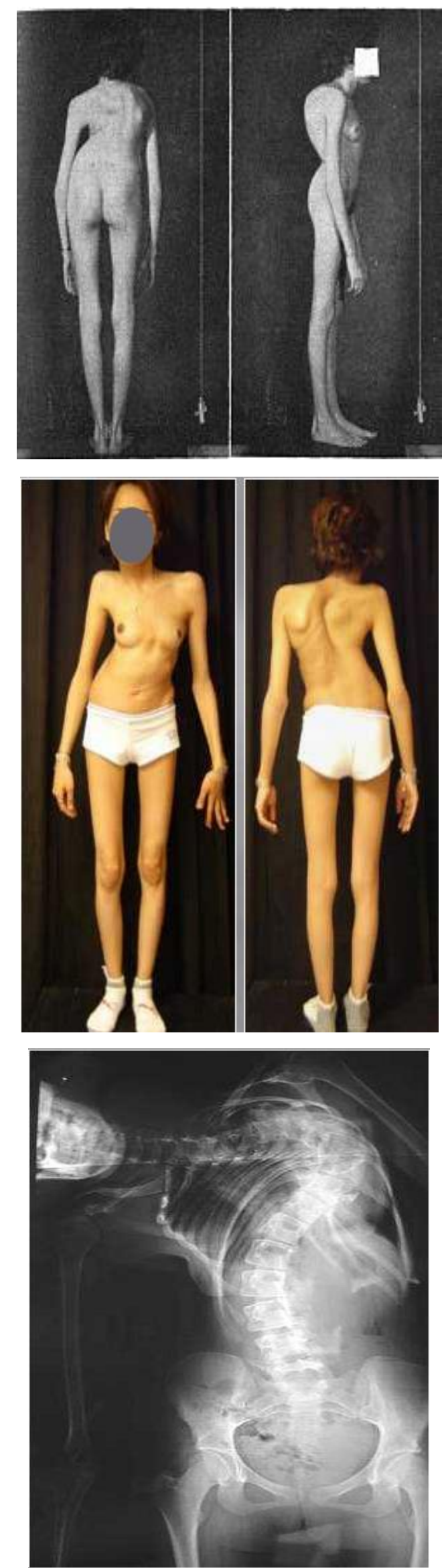
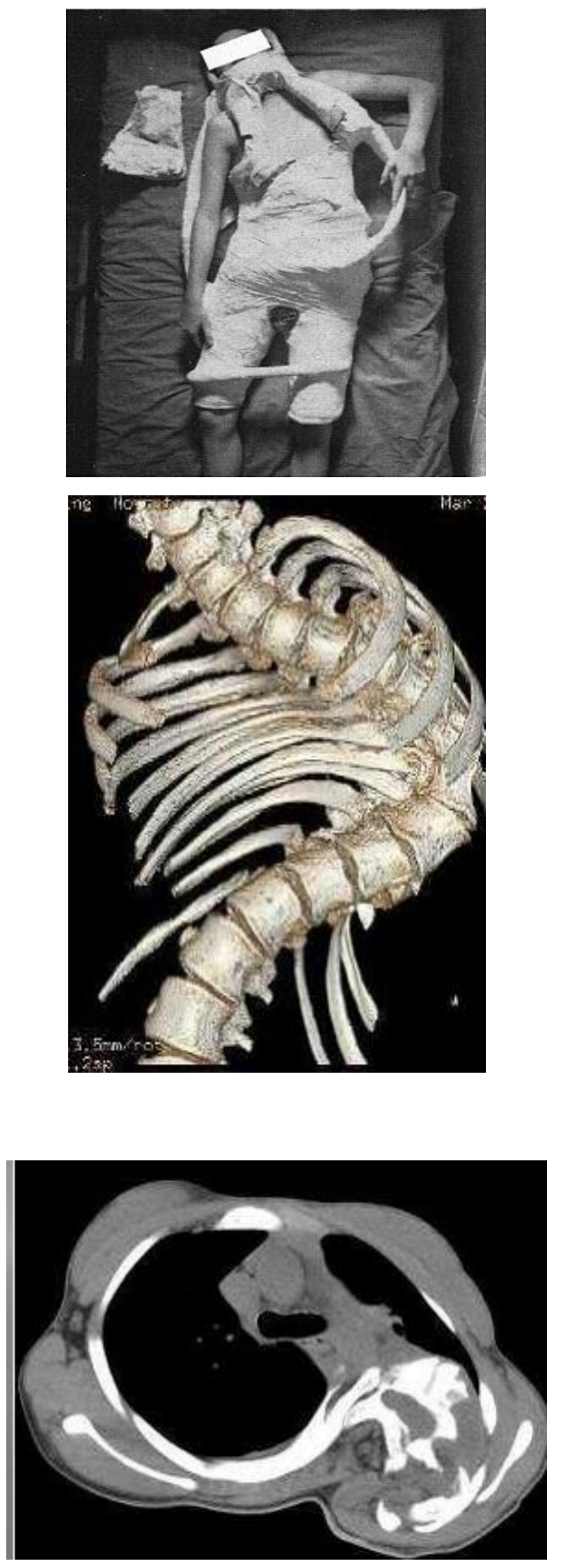


\section{REMERCIEMENTS}

A ma famille et mes amis...

Je tiens à remercier

Le Pr Souhayl DAHMANI pour m'avoir offert ce sujet de thèse.

L'ensemble des équipes médicales et paramédicales que j'aurais croisées tout au long de ce cursus et qui m'auront transmis chacun à leur manière leur passion, celle de l'anesthésie réanimation. 


\section{Table des matières}

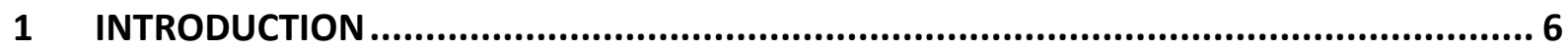

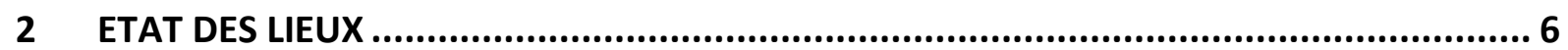

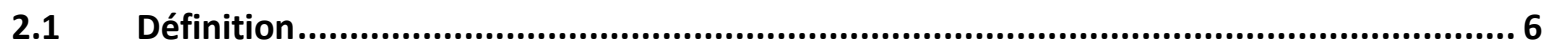

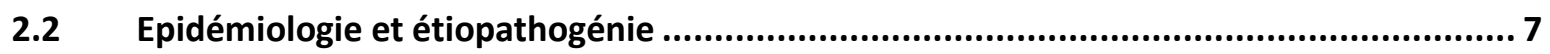

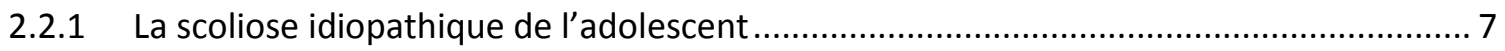

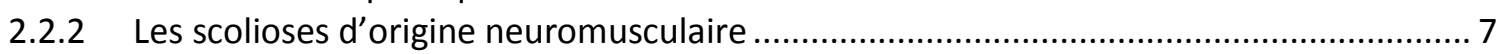

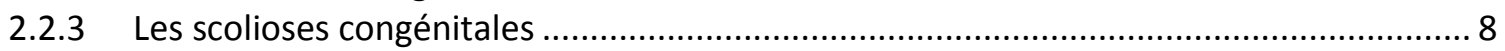

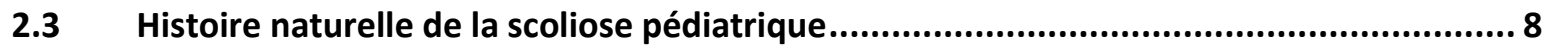

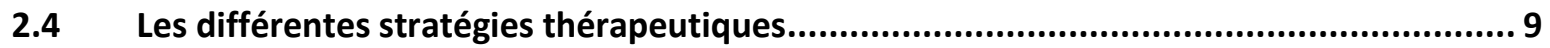

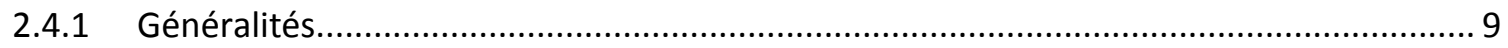

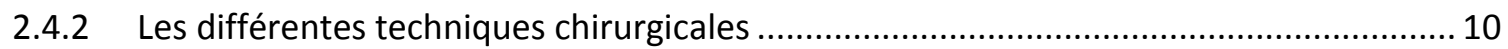

2.4.3 Spécificités anesthésiques et réanimatoires de cette chirurgie....................................... 12

2.5 Les facteurs de risques de saignements et transfusionnels au cours de la chirurgie de la

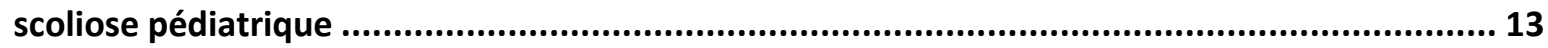

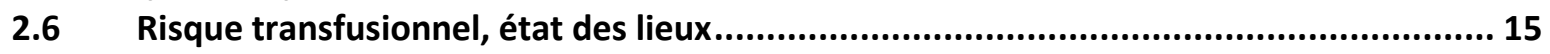

2.7 Les différentes stratégies d'épargnes transfusionnelles ....................................... 17

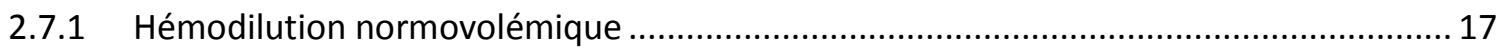

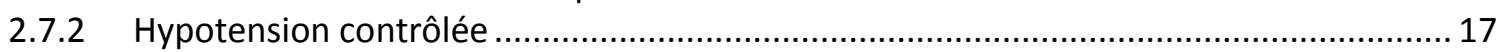

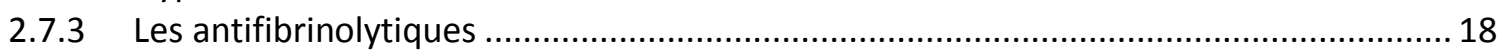

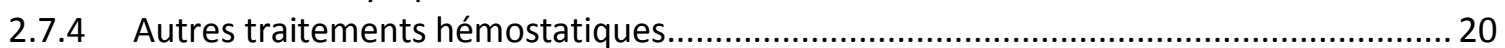

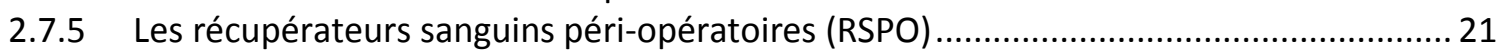

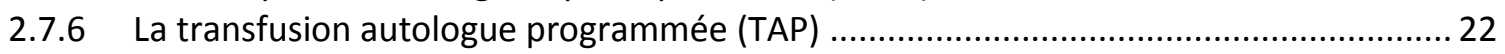

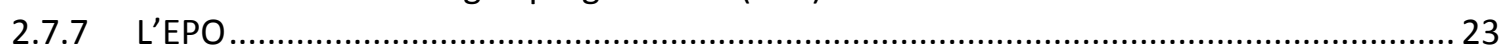

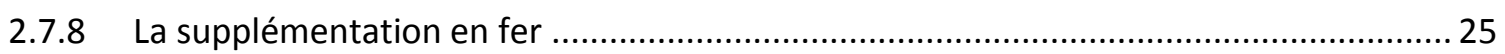

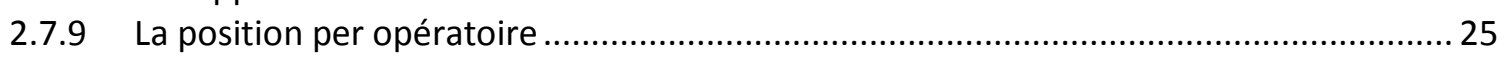

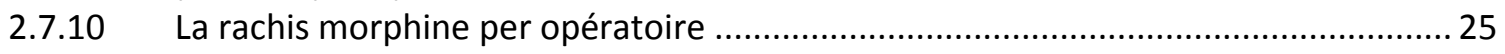

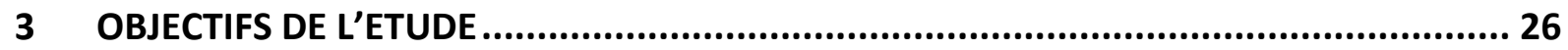

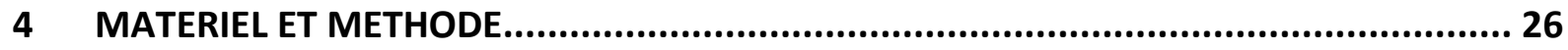

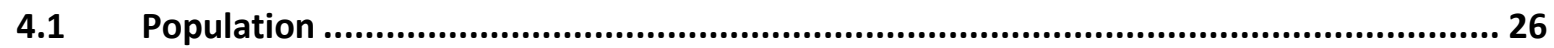

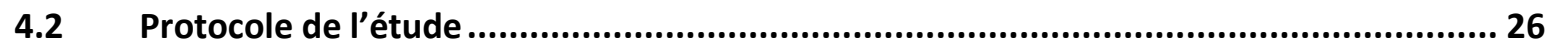

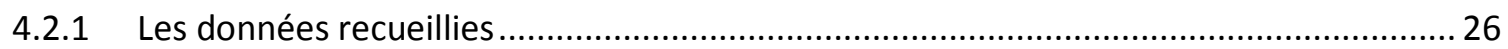

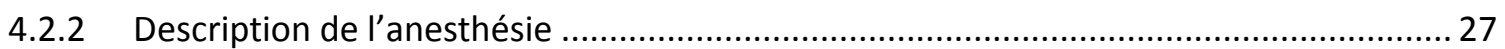

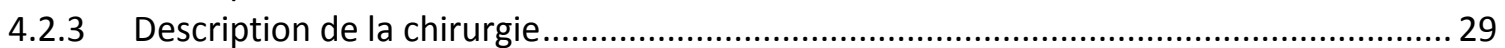

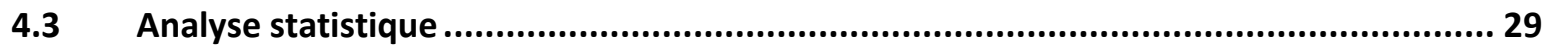

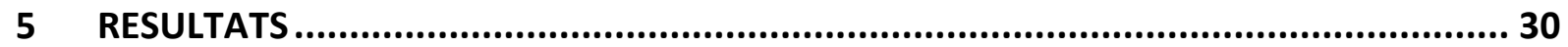

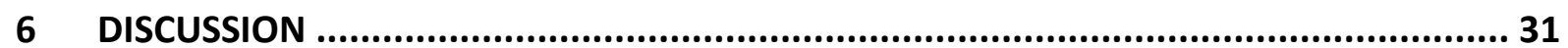

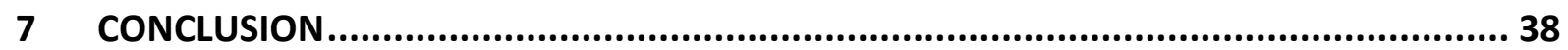

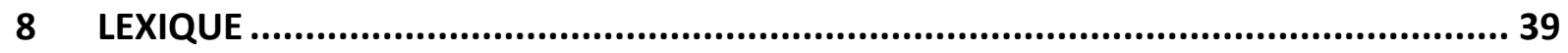

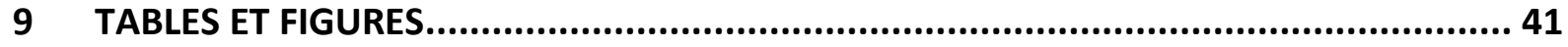

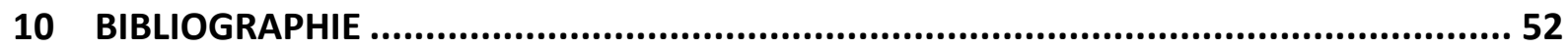

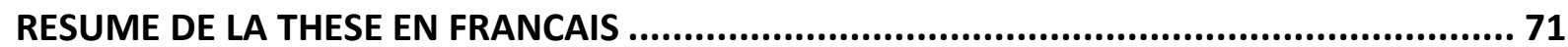

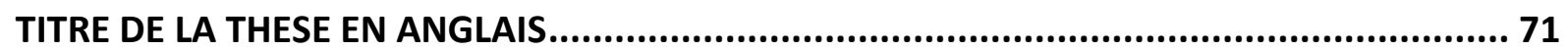

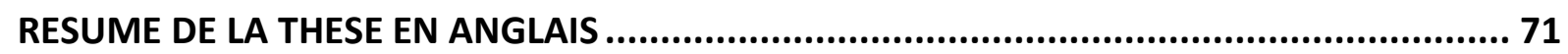

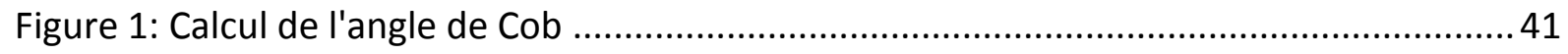

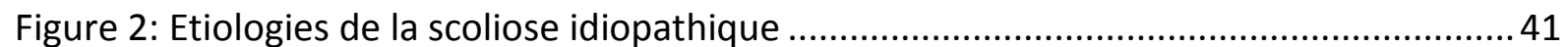


Figure 3: Paralysie cérébrale

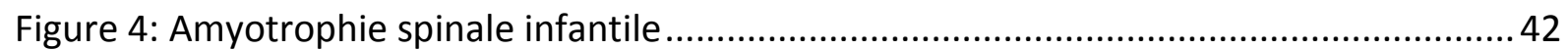

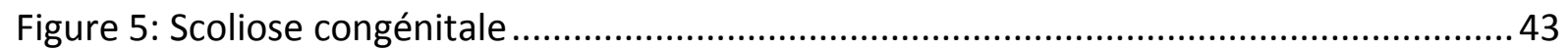

Figure 6: Score de Risser : illustration des 6 stades de Risser permettant d'évaluer l'âge

osseux.....

Figure 7: Les techniques d'arthrodèse par voie postérieure: A: Luque et Gavelston; B:Cotrel-

Dubousset.

Figure 8: Risque transfusionnel en 2012

Figure 9: Evolution du risque résiduel de transmission d'infections virales par transfusion

entre 1992 et 2005 en France (données de l'institut national de veille sanitaire). .45

Figure 10:Evolution des principaux effets indésirables chez le receveur de produits sanguins

labiles. 46

Figure 11: Evolution des causes de décès du receveur de produits sanguins labiles..............46

Tableau 1: Etiologies de la scoliose pédiatrique..... 44 Tableau 2: Nombre de décès secondaire à la transfusion en 2012 en France au Royaume Uni et aux Etats Unis

Tableau 3: Effets indésirables liés aux transfusions. Incidence sur la période de 2006-2010. 45

Tableau 4: Caractérisques de la population.

Tableau 5: Transfusion et remplissage péri-opératoire.

Tableau 6: Résultats de l'analyse univariée des facteurs associés à la transfusion péri opératoire.

Tableau 7: Résultats de l'analyse multivariée des facteurs associés à la transfusion péri opératoire.

Tableau 8: Résumé des études portant sur les différentes techniques d'épargne transfusionnelle en chirurgie de la scoliose pédiatrique. 


\section{INTRODUCTION}

Les pertes sanguines sont une des principales causes de morbi-mortalité en chirurgie de la scoliose pédiatrique. L'épargne transfusionnelle vise à diminuer l'exposition aux produits sanguins labiles (PSL) tout en garantissant la sécurité du patient. Ces techniques reposent sur la transfusion autologue programmée (TAP), l'optimisation pré-opératoire de la masse érythrocytaire et des réserves en fer, la diminution du saignement et la récupération de sang péri-opératoires. Les pratiques ne sont pas uniformisées. Ainsi, les pratiques anglaises restent très hétérogènes et sont différentes des nôtres (1). En France, les dernières stratégies utilisées conjointement depuis quelques années sont l'érythropoïétine (EPO), l'acide tranexamique (AT) et les récupérateurs sanguins per opératoire (RSPO). Aucune étude n'a recherché les facteurs associés au risque transfusionnel dans ces conditions en chirurgie de la scoliose pédiatrique.

L'objectif principal de cette thèse est donc la recherche des facteurs de risque de transfusion au cours de la chirurgie de la scoliose pédiatrique après mise en place de nouvelles stratégies d'épargne transfusionnelle.

Dans une première partie, les généralités concernant la scoliose pédiatrique à savoir son épidémiologie, son histoire naturelle et ses différents types de traitements sont rapportées. Puis, une mise au point sur les stratégies d'épargne transfusionnelle et sur les facteurs associés au risque transfusionnel et de saignement au cours de la chirurgie de la scoliose pédiatrique est effectuée. Enfin, les résultats de l'étude de cohorte réalisée au sein de notre établissement pédiatrique cherchant ces facteurs de risque sont présentés puis discutés.

\section{ETAT DES LIEUX}

\subsection{Définition}

La scoliose est une déformation du rachis dans les trois plans de l'espace. Le diagnostic de scoliose est porté sur la radiographie thoracique en mesurant l'angle de Cobb qui doit être supérieur à $10^{\circ}$ (figure $n^{\circ} 1$ ). La scoliose pédiatrique est une entitée à part entière. Ces étiologies sont nombreuses. Elle est le plus souvent idiopathique, qualifiée d'infantile, de juvénile ou de l'adolescent en fonction de l'âge au moment du diagnostic, à savoir respectivement inférieur à 4 ans, entre 4 et 10 ans et au-delà de 10 ans. Les autres scolioses sont dites secondaires. Elles sont alors soit d'origine neuromusculaire, soit 
congénitale, soit secondaire à un processus tumoral, soit post traumatique (2). (Tableau $\left.n^{\circ} 1\right)$.

\subsection{Epidémiologie et étiopathogénie}

\subsubsection{La scoliose idiopathique de l'adolescent}

La scoliose idiopathique de l'adolescent est la principale étiologie, elle représente 70 à $80 \%$ des scolioses (3). Elle survient chez les adolescents en bonne santé. Elle concerne 1 à $3 \%$ des enfants entre 10 et 16 ans. La prévalence d'une courbure supérieure à $20^{\circ}$ est de 0,3 à $0,5 \%$ alors que des courbures supérieures à $40^{\circ}$ sont décrites dans moins de $0,1 \%$ de la population, avec une prédominance des scolioses dans la population féminine (4). L'origine de la scoliose idiopathique reste peu connue, probablement multifactorielle avec des prédispositions génétiques (3) (figure $n^{\circ} 2$ ). Ainsi, il y a une augmentation de la prévalence des scolioses au sein d'une même famille. Une méta analyse regroupant 100 paires de jumeaux montre une corrélation plus importante en terme de courbure entre monozygotes qu'entre dizygotes (5). La scoliose est une maladie complexe pouvant être expliquée par plusieurs gènes. Initialement, des études de gènes candidats ont été menées. Celles évaluant les gènes codant pour les protéines du tissu conjonctif ont été décevantes $(6,7)$. A d'autres niveaux des associations ont été retrouvées, notamment avec le TGF $\beta 1$ (Tumor Growth Factor) (8), ou dans le cadre du métabolisme phosphocalcique, avec le récepteur à l'œstrogène ESR1 $(9,10)$. Plus récemment, des études pangénomiques ont été réalisées permettant de mettre en avant une association avec la protéine G 126 présente dans le cartilage (11), avec le gène LBX1 (12), mais également avec le locus $17 q 24.3$ près du gène SOX9 jouant un rôle dans la chondrogénèse et du gène KCNJ2 (13). En dehors de la génétique, il est reconnu que la mélatonine joue un rôle dans la survenu de la scoliose $(14,15)$. La responsabilité d'une anomalie des muscles para vertébraux est également évoquée. L'origine de la scoliose est multifactorielle avec la part liée à l'environnement à déterminer.

\subsubsection{Les scolioses d'origine neuromusculaire}

Elles représentent 15\% des scolioses environs (figure 2 et 3). La baisse du tonus des muscles du tronc en est à l'origine. Elles sont d'évolution plus rapide et surviennent à un âge plus jeune. On distingue les scolioses secondaires à un déficit neurologique, avec les encéphalopathies, des scolioses secondaires à une myopathie. La dystrophie musculaire de Duchenne est la cause de myopathie la plus étudiée avec un taux d'incidence annuel de 3300 naissances. C'est une maladie liée à l'X, résultant de mutations de la dystrophine 
entraînant à partir de l'âge de 2 à 6 ans une fatigabilité musculaire au niveau proximal essentiellement, avec progressivement une perte de la marche. La scoliose commence alors à apparaitre avec une aggravation de la courbure au moment de la puberté. L'utilisation de la corticothérapie précoce a permis de repousser l'âge de la perte de la marche et limiter l'incidence des scolioses dans cette population. Un tiers de ces patients présente un déficit cognitif. Des défaillances d'organe peuvent également être présentes avec un atteinte cardiaque à type de cardiomyopathie dilatée et de troubles du rythme, une atteinte respiratoire avec syndrome restrictif et à un stade ultime une hypertension artérielle pulmonaire (HTAP). L'amyotrophie spinale est également pourvoyeuse de scoliose (figure $\left.n^{\circ} 4\right)$. C'est une pathologie génétique de transmission autosomique récessive responsable d'une amyotrophie par dénervation. Son expression clinique est très variable avec des formes précoces rapidement létales et des formes pauci symptomatiques. La scoliose arrive également au moment de la perte de la marche avec un retentissement respiratoire dans les cas extrêmes. Les autres causes retrouvées sont entre autre la poliomyélite et la syringomyélie.

\subsubsection{Les scolioses congénitales}

(Figure $n^{\circ} 5$ ) Ce sont des anomalies du développement embryologique du squelette axial qui peuvent engendrer des erreurs de formation ou de segmentation des vertèbres. Une agression survenant vers la septième semaine post conception est généralement l'évènement déclencheur. Plusieurs facteurs tératogènes ont été impliqués: I’hypoxie, l'hypercapnie, certains médicaments tel l'acide valprö̈que, l'alcool, le tabac. Ces anomalies rachidiennes ont également été décrites dans le cadre de syndromes polymalformatifs (16). Mac Master a proposé une classification des scolioses congénitales en 1982 (17) en distinguant: $1 /$ les synostoses costales, 2 /les défauts unilatéraux partiels de formation de vertèbres (vertèbres trapézoïdes), 3/les défauts unilatéraux complets de formation de vertèbres (hémivertèbres), 4/les défauts de segmentation avec les barres et les fusions vertébrales, 5/les inclassables. Le développement de ces scolioses est progressif. II peut être sévère entre autre, en cas d'anomalie de développement costal associé pouvant aboutir à des «syndromes d'insuffisance thoracique » (18).

\subsection{Histoire naturelle de la scoliose pédiatrique}

Les données permettant de retracer l'histoire naturelle de la scoliose pédiatrique sont issues d'études de cohorte constituées dans les années 1950. Les patients ne 
bénéficiaient alors pas de prise en charge médicale, orthopédique ou chirurgicale. Ces études ont pour principale limite un recrutement très hétérogène ne distinguant pas les différents types de scoliose (3). Une étude a suivi prospectivement le cas de 102 patients avec au total 133 courbures sur 40,5[31-53] ans. Soixante-huit pourcents des patients avec scoliose idiopathique présentèrent une progression de leur courbure malgré la maturation osseuse. Ainsi, les courbures de plus de $50^{\circ}$ progressaient d'environ $1^{\circ}$ par an à l'étage thoracique, de $0,5^{\circ}$ par an à l'étage lombaire. II n'y avait pas de progression à l'étage thoracique si la courbure était inférieure à $30^{\circ}$ (19). Les facteurs prédictifs de progression de la courbure sont l'âge à la découverte de la maladie, le stade pubertaire, la quantité du cartilage de croissance résiduel évalué par le score de Risser (figure $n^{\circ} 6$ ) (20), l'importance de la courbure, la localisation de la courbure et le nombre de courbures (21). Les patients les plus « immatures » à savoir les plus jeunes, non pubères, avec un score de Risser bas ont donc un potentiel d'aggravation de leur scoliose plus important. Les principales complications de la scoliose sont : 1/les douleurs dorsales, 2/les complications cardiorespiratoires, et $3 /$ le préjudice esthétique avec ses répercussions sur le plan psychique et sociale $(22,23)$. Kafer et coll. (2) décrit ainsi des cas historiques avec des complications cardio-respiratoires extrêmes allant du syndrome restrictif avec hypoxie et hypercapnie jusqu'à I'HTAP. Une des premières études est celle de Nachemson et coll. publiée en 1968 (24). Il suivait 130 patients dont $45 \%$ avec scoliose idiopathique. En plus des complications cardio respiratoires extrêmes, les patients présentaient également des atteintes neurologiques à type de compressions médullaires et radiculaires. Les principales causes de décès étaient de cause cardio-vasculaire. Les formes idiopathiques sont généralement moins agressives car survenant chez des patients plus âgés. La scoliose idiopathique est plus féminine à contrario des scolioses d'origine neuromusculaire (25). Une étude rapporte et compare le devenir de 117 patients avec scoliose idiopathique à celui de 62 témoins après 50 années d'observation (22). II n'y avait pas de différence en termes de mortalité ni d'altération de la qualité de vie. Les patients scoliotiques se plaignaient plus de gêne respiratoire mais celle-ci était modérée. Elle était corrélée à l'importance de la courbure et à sa localisation apicale. Les douleurs dorsales étaient plus importantes.

\subsection{Les différentes stratégies thérapeutiques}

\subsubsection{Généralités}

Les objectifs du traitement sont de ralentir la progression de la courbure (traitement médicale et orthopédique) et dans les cas les plus avancés de corriger la courbure 
(traitement chirurgicale) avec pour objectif la prévention des complications à court et à long terme. Les indications thérapeutiques prennent en comptent l'étiologie de la scoliose et les facteurs de risque de progression de la scoliose. Ainsi, les exercices physiques et les programmes de réhabilitations intensives sont proposés pour des scolioses peu avancées. Puis, lorsque la courbure dépasse les $25^{\circ}$, est proposée le port d'un corset $(3,4)$. L'indication opératoire chez l'adolescent est retenue pour un angle de Cobb supérieur à $50^{\circ}$ au niveau thoracique et supérieur à $40^{\circ}$ au niveau lombaire. Ces seuils ont été retenus à partir des résultats des études observationnelles montrant un risque associé d'évolutivité résiduel important même au-delà de la puberté (21). Plusieurs études ont été réalisées pour évaluer l'impact de ses stratégies. Une méta analyse comprenant 1910 patients traités par corset ou uniquement médicalement pour 129 patients montre la possibilité de ralentir la progression de la courbure et d'éviter la chirurgie (26). En 1995, une étude prospective de faible niveau de preuve retrouve une efficacité des corsets en cas de courbure entre $25^{\circ}$ et $35^{\circ}(27)$. Ces résultats ne sont cependant pas confirmés dans une autre étude montrant l'incapacité de prévenir par corset la progression de la courbure et la prévention de la chirurgie pour $42 \%$ des patients d'une cohorte de 102 patients (28). Un essai randomisé à haut niveau de preuve publié en 2013 marque un tournant dans cette controverse en prouvant l'efficacité d'un port prolongé du corset dans la prévention de la scoliose avec un succès de la pratique dans $72 \%$ dans le groupe traitement pour seulement $48 \%$ dans le groupe sans intervention (avec après ajustement sur le score de propension un odd ratio (OR) de 1,93[1,08-3,46]) (29). Par ailleurs aucune étude avec haut niveau de preuve ne prouve la supériorité du traitement chirurgical (30). Les scolioses neuromusculaires sont à considérer différemment sur le plan thérapeutique uniquement en cas de perte de la marche. L'atteinte de la jonction sacro-lombaire (bassin oblique) peu alors amené à étendre I'arthrodèse au sacrum avec une morbi-mortalité péri-opératoire plus élevée. Le traitement de la scoliose congénitale ne peut être que chirurgical dès la preuve de l'aggravation de la scoliose et sans même attendre les valeurs angulaires envisagées pour les autres étiologies.

\subsubsection{Les différentes techniques chirurgicales}

Il existe principalement deux techniques d'instrumentation par voie postérieure

(figure $n^{\circ} 7$ ). Ces techniques sont obtenues par avivement des processus articulaires et des lames vertébrales, et mise en place d'un greffon osseux. 


\subsubsection{L'instrumentation de Luque}

Cette technique par fixation segmentaire a été mise au point par Luque en 1976. Elle est basée sur un réalignement du rachis par 2 tiges pré-cintrées, fixées par des fils à chaque niveau vertébral. La technique classique dite de « Luque-Galveston » correspond à une instrumentation de Luque associée à une fixation iliaque par la technique de Galveston. La difficulté de cette technique est de faire passer un fil métallique dans le canal rachidien à chaque étage avec un risque neurologique et vasculaire non négligeable, n'autorisant pas son utilisation pour les scolioses idiopathiques. Par ailleurs, cette technique altère la mobilité rachidienne. Cette technique est donc avant tout utilisée pour les patients non marchant donc dans le cadre des scolioses d'origine secondaire sévères.

\subsubsection{Instrumentation de Cotrel-Dubousset}

Cette instrumentation a été élaborée au début des années 1980 par Cotrel et Dubousset (31). Cette technique d'ostéosynthèse rachidienne segmentaire postérieure permet une bonne réduction des courbures scoliotiques ou cyphotiques et une fixation rigide, supprimant toute contention post-opératoire, tout en assurant une arthrodèse vertébrale. Aucun élément d'ostéosynthèse ne pénètre en totalité dans l'espace souslamaire, diminuant le risque d'hémorragie ou de lésion médullaire. Ce Matériel comporte 2 tiges cylindriques, rugueuses, indépendantes, placées dans la concavité et la convexité, cintrables pour redessiner un profil rachidien normal. Les tiges sont fixées à des crochets lamaires ou pédiculaires étagés par des boulons, permettant la correction progressive de la déformation et le maintien de la correction, renforcée par 2 tiges transversales en haut et en bas solidarisant les 2 tiges qui de plus assurent la dérotation vertébrale. Les segments rachidiens laissés libres par les appuis sont avivés permettant l'arthrodèse.

\subsubsection{Les techniques de redressements par voie antérieure}

La voie d'abord antérieure permet un abord des vertèbres de la convexité et se fait par thoracotomie, thoraconéphrolombotomie ou lombotomie. La fixation du matériel d'ostéosynthèse s'effectue à la face latérale des corps vertébraux et la réduction de la courbure s'effectue par rapprochement des vertèbres vers une plaque métallique ou une tige. Les complications respiratoires sont plus fréquentes. L'abord antérieur peut être isolé en cas de courbure peu sévère et peu étendue. Cet abord peut également être associé à une voie postérieure. Ces deux temps peuvent être réalisés le même jour ou plus souvent avec un intervalle de 10 à 15 jours. 


\subsubsection{Les techniques d'instrumentation sans arthrodèse}

Elles s'adressent aux patients avec des scolioses sévères et précoces permettant à la croissance de se poursuivre. Les implants sont de taille réglable.

\subsubsection{Spécificités anesthésiques et réanimatoires de cette chirurgie}

La chirurgie de la scoliose a de tout temps été un challenge sur le plan anesthésique.

Ainsi, Thomas en 1957 décrivait la prise en charge anesthésique d'une scoliose idiopathique en soulignant bien les difficultés rencontrées (32). L'intubation était difficile en raison de l'immobilisation du rachis cervicale dans un corset complexe et de l'absence de curarisation afin de prévenir le risque d'hyperthermie maligne et de rhabdomyolyse. Une technique d'épargne sanguine était mise en place avec l'instillation de noradrénaline au niveau du site opératoire. L'anesthésie de la scoliose pédiatrique doit donc prendre en compte les spécificités d'une part liées à la chirurgie et d'autre part liées au terrain. Les principaux challenges à relever et prévenir sur le plan anesthésique au cours d'une telle chirurgie sont donc : $1 /$ une potentielle intubation difficile en fonction de la localisation de la courbure, 2/les hyperthermies malignes chez les patients atteints de polyneuromyopathies, 3/les hyperkaliémies associées à la succinyl choline, 4/les instabilités hémodynamiques en raison des pertes sanguines mais également des cardiopathies potentiels, des troubles de conduction et du rythme pré-existants, 5/le monitorage de la plaque motrice, 6/les lésions de la moelle épinière et en post-opératoire la douleur et les difficultés de sevrage ventilatoire. Les complications médicales post-opératoire propres à la chirurgie de la scoliose (33) comprennent le syndrome de sécrétion inappropriée d'hormone antidiurétique (SIADH), l'embolie graisseuse, les lithiases biliaires, les pancréatites, le syndrome de la pince mésentérique, les iléus post-opératoires et les coagulopathies. Une revue de 19360 patients ayant bénéficié d'une chirurgie de la scoliose pédiatrique s'est focalisée en 2011 sur leur morbi-mortalité (34). La mortalité globale de ces patients était estimée à $0,13 \%$, secondaire soit à une détresse respiratoire aiguë, soit à une hémorragie per opératoire, soit à un sepsis d'origine pulmonaire. La mortalité chez les patients avec scoliose d'origine neuromusculaire était plus importante $(0,34 \%)$ que la mortalité des patients avec scoliose d'origine idiopathique $(0,02 \%)$. Les complications graves concernaient $10 \%$ des interventions, $18 \%$ en cas d'origine neuromusculaire et $6 \%$ pour les scolioses idiopathiques. Les complications neurologiques survenaient dans $1 \%$ des cas et étaient complétement régressives dans $66 \%$ des cas. Elles étaient particulièrement fréquentes en cas de scoliose congénitale. Elles 
étaient secondaires soit à une atteinte directe nerveuse à type de compression soit secondaire à une ischémie. Les complications respiratoires à type de pneumonies, atélectasies, bronchospasmes, épanchement pleural, exacerbation de pathologie respiratoire pré-existante et ventilation prolongée survenaient dans $1 \%$ des cas. Elles étaient impliquées dans un tiers des décès et étaient surtout présentes en cas de pathologie respiratoire pré-existante ou de trouble de la déglutition. Les complications hémorragiques représentaient la deuxième cause de mortalité. La morbi-mortalité est secondaire à I'hypovolémie, à l'anémie aiguë et à leurs conséquences sur la moelle et sur les fonctions cardio-respiratoires. Elle est également liée aux complications des PSL.

Dans ce contexte, différents axes de recherche ont été établi. L'interaction des agents hypnotiques avec les potentiels évoqués a été étudiée (35). La gestion de l'analgésie postopératoire a été l'objet de plusieurs essais dont ceux soulignant le bénéfice de la rachianalgésie morphine en tant qu'épargneur sanguin (36-40). Enfin, une grande partie de la littérature concerne le risque de saignement, le risque transfusionnel et les différentes techniques d'épargne transfusionnelle utilisables en chirurgie de la scoliose pédiatrique.

\subsection{Les facteurs de risques de saignements et transfusionnels au cours de la chirurgie de la scoliose pédiatrique \\ Les pertes sanguines sont difficilement évaluables au cours de la chirurgie de la scoliose} et représentent ainsi une des premières limites des études évaluant les risques de saignements et de transfusions au cours de cette chirurgie. Les pertes sanguines sont variables et sont comprises généralement entre 1000 et $2000 \mathrm{~mL}$ mais peuvent aller jusqu'à $4000 \mathrm{~mL}$ (41). Le saignement est avant tout lié à l'étendu de la dissection des muscles paravertébraux, des gestes osseux et des lésions possibles sur les vaisseaux dont les plexi veineux vertébraux. Ainsi, les saignement semblaient plus importants lors de la phase d'insertion des vis pédiculaires, de la correction de la déformation et d'avivement osseux pour la préparation de la greffe (42).

Dans la littérature sont souvent recherchés de manière intriquée les facteurs de risque de saignements et transfusionnels. Le premier à s'être intéressé à la question est Dorsey, qui dans son éditorial datant de 1993 (43) pointait le doigt sur l'importance de rechercher les facteurs associés aux saignements au cours de la chirurgie de la scoliose pédiatrique, réflexion faisant suite à la constatation de pertes sanguines plus importantes en cas de scoliose d'origine neuromusculaire. 
Peu d'études ont été réalisées jusqu'à présent. Une partie des connaissances provient des essais randomisés évaluant les nouvelles techniques d'épargne transfusionnelle. Ainsi, l'étude de Vitale et coll. de 1998 (44) évaluant l'EPO, montrait que le risque transfusionnel était associé aux scolioses d'origine neuromusculaire, à l'angle de Cobb et au nombre d'étages fusionnés. Leur autre étude de 2007 (45) retrouvait les mêmes facteurs avec en plus une fusion lombo-sacrée, la durée de la chirurgie et un traitement par EPO. L'étude de Neilipovitz et coll. (46) montrait que l'origine neuromusculaire était associée aux pertes sanguines. Une autre étude montrait également que le degré de minéralisation osseuse était indépendamment associé à la quantité des pertes sanguines (42). Guay et coll. en 1994 (47), avec pour technique d'épargne transfusionnel utilisée laTAP, I'hémodilution et l'hypotension contrôlée, retrouvaient une corrélation entre les pertes sanguines et le nombre de vertèbres fusionnées $(r=0,66, p<0,0001)$, ou la durée de la chirurgie $(r=0,46$, $p=0,0105)$. Dans l'étude de Meert et coll. de 2002 (48), la chirurgie était réalisée avec RSPO, hémodilution et hypotension contrôlée. Les facteurs associés au risque transfusionnel étaient un petit poids, une origine neuromusculaire et le nombre de vertèbres fusionnées. Enfin, Vitale en 2002 (49), s'était lui aussi spécifiquement intéressé aux facteurs de risques transfusionnels dans une cohorte où seulement une partie des patients recevaient de l'EPO. De son analyse multivariée ressortait cinq facteurs indépendant associés au risque transfusionnel à savoir I'EPO (OR : 0,29[0,135-0,624]; $p=0,0015)$, une origine neuromusculaire (OR : 2,02[1,069-3,819]; $p=0,03)$, l'angle de cobb (OR : 1,015[1,005-1,025]; $p=0,004$ ) et la réalisation d'une fusion lombo-sacrée (OR : 2,174[0,91-5,192], $p=0,08$ ).

Pour résumer, les deux principaux facteurs de risque hémorragique sont la scoliose neuromusculaire et le nombre d'étages fusionnés, et donc de manière plus générale, on peut distinguer les facteurs de risques liés à l'étiologie de la scoliose de ceux liés à la chirurgie. Ces derniers regroupent donc le nombre d'étages fusionnés mais également la technique chirurgicale et la durée de la chirurgie, soulignant l'importance de l'expérience du chirurgien. Concernant le risque transfusionnel, il est donc associé à l'étiologie de la scoliose. En fonction des études, la fréquence de la transfusion dans la chirurgie de la scoliose idiopathique est comprise entre 25 et $45 \%$ et entre 45 et $75 \%$ chez les patients avec une scoliose d'origine neuromusculaire. Les patients les plus jeunes présentent également un risque augmenté d'être transfusé, les répercussions des saignements et des expansions volémiques dans ces populations étant plus importantes $(48,50)$. Enfin, l'anémie pré opératoire représente un facteur de risque indépendant de morbi-mortalité et de 
transfusion péri-opératoire en chirurgie non cardiaque de l'adulte. Deux études observationnelles de grandes envergures montraient chez l'adulte en chirurgie non cardiaque qu'une anémie pré-opératoire était indépendamment associée à la morbimortalité post-opératoire $(51,52)$. Nuttall et coll. dans la chirurgie du rachis de l'adulte montraient également que le taux d’hémoglobine pré-opératoire était associé au risque transfusionnel (53).

\subsection{Risque transfusionnel, état des lieux}

L'exposition à des produits homologues reste toujours source de complications potentielles. Les incidents transfusionnels font ainsi l'objet de rapports permettant des statistiques annuelles dans la plupart des pays. Les dernières données sont colligées dans le tableau $n^{\circ} 2$ et 3 et représentées dans les figure $n^{\circ} 8$ et $9(54)$.

Tout d'abord, l'introduction des tests ADN mais également la déleucocytation des dons et la sélection des donneurs a permis une diminution du risque de transmission concernant le VIH, le VHB, le VHC et l'HTLV en France (55) (figure $n^{\circ} 9$ ). Des cas de transmission de nouveaux agents émergeant tel le West Nile virus, le virus JC, la maladie de Chagas, le paludisme ou encore la Dengue ont été rapportés mais restent encore très peu nombreux. Le risque de transmission bactérienne reste toujours aussi important. Ainsi le rapport anglais SHOT (Serious Hazard Of Transfusion) de 2009 (56) soulignait que sur les 66 infections post-transfusionnelles rapportées entre 1996 et 2009, 40 étaient d’origine bactériennes. Les complications non infectieuses restent de loin les plus fréquentes. On distingue les complications immunes des non immunes. Ainsi, l'hémolyse posttransfusionnelle, la réaction fébrile et le TRALI (Transfusion-Related Acute Lung Injury) sont les complications immunes les plus fréquentes. Les incidents de surchargs posttransfusionnel ou TACO (Transfusion-Associated Circulatory Overload) est la principale complication non immune. Il est par ailleurs acquis que la transfusion engendre une immunomodulation pourvoyeuse de risque infectieux accru, de retard de cicatrisation et de risque de progression tumorale (57).

Les dernières guidelines américaines concernant le seuil transfusionnel rapporte les dernières statistiques en terme de risques transfusionnels aux Etats Unis d'Amérique (58). Ainsi, Entre 2007 et 2008, l'incidence de l'infection par le VIH parmi les donneurs était de $3,1 / 10^{5}$ personnes/an avec un risque transfusionnel associé de 1:1 467000 ou 0,68 par Million de CGR (Concentré en Globule Rouge) transfusés. Au décours de cette même période, l'incidence de l'infection par le VHC parmi les donneurs était de 5,1/10 
personnes/an avec un risque transfusionnel de 1:1 149000 ou 0,87 par Million de CGR transfusés. Entre 2006 et 2008, l'incidence de l'infection par le VHB parmi les donneurs étaient de 3,41 à 3,43 pour $10^{5}$ personnes/an avec un risque transfusionnel de 1/282 000 à 1/357000 soit 2,8 à 3,6 par million par CGR transfusés. Le taux de TRALI en 2009 était de $0,81[0,44 ; 1,49]$ pour $10^{4}$ CGR transfusés. Le risque de TACO est estimé à $6 \%$ en réanimation en cas de transfusion (59), et à $1 \%$ au cours de la chirurgie de la hanche (60). La Food and Drug Administration (FDA) rapporte un taux de 12,5 décès par an entre 2005 et 2010. Le risque de décès pour hémolyse était de 1:1 250000 ou 8 pour 10 million de CGR transfusés. La réaction hyperthermique était estimée à 1,1\%. En France, Le rapport d'hémovigilance de l'année 2012 rapportait une diminution globale de la mortalité imputable à la transfusion de PSL, elle était en baisse sur la période 2000-2012. L'incidence sur cette période était de 2,5 décès par un million de PSL transfusés. Les effets indésirables sont rapportés dans le tableau $n^{\circ} 3$ et les figures $n^{\circ} 10$ et 11 .

Les trois principales causes de mortalités secondaires à la transfusion sont le TRALI, le TACO, et les incidents hémolytiques. En 2012, en France, ont été rapportés 13 décès liés à la transfusion dont 5 pour surcharge (TACO), 4 pour hémolyse et 2 pour infection bactérienne transmise lors de la transfusion (61). Au Royaume-Uni, 9 décès ont été déclarés dont 6 pour surcharge (TACO) (62). Aux Etats Unis d'Amérique, on comptait 38 décès dont 17 pour TRALI, 8 pour hémolyse et 8 pour surcharges (TACO) (63).

En pédiatrie l'incidence des effets indésirables graves est significativement supérieure par rapport à la population adulte, notamment chez le nourrisson (54). Ils étaient liés essentiellement à une erreur humaine avec des accidents de surcharge, de compatibilité inadéquate ou à des réactions d’hémolyse immuno-hématologique. Les complications allergiques étaient également présentes.

Il est important de garder à l'esprit l'ordre de grandeur des risques graves associés à la transfusion de PSL. Ces risques sont de l'ordre de $1 / 10^{5}$ à $1 / 10^{7}$ transfusions. L'enquête SFAR INSERM sur la mortalité liée à l'anesthésie a montré que les trois principales causes de décès liés à l'anesthésie étaient l'hypovolémie liée à l'hémorragie, les complications ischémiques myocardiques liées à l'anémie aiguë et l'inhalation de liquide gastrique. Le risque associé à la mauvaise gestion des hémorragies aiguës selon cette étude est estimé à $1 / 10^{4}$. La prise en compte des risques associés à la transfusion ne doit donc pas masquer les risques liés à l'hypovolémie, à l'anémie ou au retard de la transfusion dans les situations d'hémorragie per opératoires (64). 


\subsection{Les différentes stratégies d'épargnes transfusionnelles}

La mise en place des stratégies d'épargnes transfusionnelles en chirurgie hémorragique réglée a pour objectif principal la diminution de la consommation des PSL afin d'une part de diminuer le risque transfusionnel, d'autre part de diminuer le coût associé à la transfusion et de pallier à une éventuelle pénurie de PSL. Ainsi, la stratégie d'épargne transfusionnelle pour être mise en place doit assurer la sécurité du patient en n'induisant pas de morbi-mortalité, doit être acceptable sur le plan organisationnel et technique, et doit présenter un rapport coût bénéfice satisfaisant. Les différents axes d'action des stratégies d'épargne transfusionnelle sont la transfusion autologue programmée (TAP), l'optimisation de la masse érythrocytaire pré-opératoire, la diminution des saignements per opératoire, la récupération de sang péri-opératoire. Ces techniques ont d'abord été évaluées chez l'adulte en chirurgie cardiaque et orthopédique lourde, puis en pédiatrie d'abord cardiaque puis pour la chirurgie de la scoliose pédiatrique.

\subsubsection{Hémodilution normovolémique}

C'est une technique qui était utilisée de manière courante avant d'être définitivement abandonnée. Etudiée au cours de nombreuses chirurgies, deux méta-analyses ont été rédigées. La première, de Bryson et coll. publiée en 1998 (65) a réuni 24 essais randomisés. Les résultats étaient en faveur d'une réduction du risque d'être transfusé (OR:0,31[0,15;0,62]) et d'une réduction du volume de sang administré (différence en unité de sang administré : -2,22Ui, $[-3,57 ;-0,86])$. Néanmoins, l'analyse du sous-groupe des essais avec protocole transfusionnel ne montrait pas de différence en termes de risque transfusionnel, de volume de sang administré. La deuxième méta-analyse de Segal et coll., publiée en 2004 et regroupant 42 essais randomisés (66), ne montrait pas de différence en terme de risque d'être transfusé (Risque Relatif[RR];0,96[0,90-1,01]). La conclusion de cette méta-analyse était que cette technique n'apportait qu'un bénéfice très modeste, pour une sécurité incertaine.

\subsubsection{Hypotension contrôlée}

Cette technique également abandonnée était habituellement utilisée en complément de l'hémodilution. Les objectifs de pression artérielle moyenne étaient entre 50 et $60 \mathrm{mmHg}$ (milimètre de mercure). Cette technique devait être évitée en cas d'hypovolémie, d'hypertension intracrânienne ou de défaillance d'organe préalable. Elle a été décrite initialement dans les années 1960, une des études princeps étant celle de McNeill et coll. 
publiée en 1974 (67). II montrait alors une réduction de 40\% de la transfusion sanguine per opératoire au cours de la chirurgie de la scoliose. En 2003, Lim et coll. (68) retrouvait un intérêt à associer hémodilution et hypotension contrôlée afin de diminuer la transfusion au cours de la chirurgie du rachis. Copley et coll. utilisait également l'hypotension contrôlée dans son essai évaluant l'hémodilution (69). Les complications de ces méthodes ont peu été rapportées dans la littérature. Un risque certain de souffrance myocardique, d'acidose lactique et de souffrance médullaire existe. Ces méthodes n'ayant pas démontré une supériorité en terme d'épargne transfusionnelle sont abandonnées.

\subsubsection{Les antifibrinolytiques}

Les trois principaux antifibrinolytiques sont l'aprotinine, l'acide aminocaproique (EACA) et l'acide tranexamique (AT).

L'aprotinine est un petit polypeptide alcalin (6,5 kiloDalton), extrait de tissu bovin. II appartient à la famille des SERPINS. II neutralise entre autre la trypsine, le plasmine, et la kallikrein. Son activité s'exprime en unité inhibitrice de la kallikrein (KIU). Son mécanisme d'action prête encore à discussion. Il semblerait cependant que ses activités antifibrinolytiques, de restitution de la fonction plaquettaire et d'inhibition de la phase de contact de la coagulation permettent de limiter le saignement per opératoire. L'aprotinine peut bloquer le récepteur PAR (PAR 1 ou platelet protease activated receptor 1 ) de la thrombine. Il joue ainsi un rôle anti thrombotique. Sa pharmacocinétique est complexe avec une grande variabilité inter-individuelle.

$\mathrm{L}^{\prime}$ acide tranexamique (Exacyl ${ }^{\odot}$ ) et l'acide aminocaproïque (Amicar ${ }^{\odot}$ ) sont deux molécules de synthèse de la même famille. Ce sont des analogues de la lysine, inhibant l'activation du plasminogen en plasmine. Ces molécules ont un faible poids moléculaire, sont hydrophiles, d'élimination rénale sans biotransformation et de faible coût.

Ces molécules sont utilisées à partir des années 60 initialement en chirurgie cardiaque puis en chirurgie orthopédique lourde et enfin en pédiatrie. Ainsi, l'acide tranexamique a été évaluée en chirurgie cardiaque pédiatrique en 1996 (70) et 1997 (71) avant de l'être en chirurgie de la scoliose pédiatrique. Les trois molécules ont alors été testées.

Concernant l'aprotinine, seul trois essais de petits effectifs ont été réalisés pour la scoliose pédiatrique. En 2001, Cole et coll. (72) montraient dans un essai randomisé une diminution des pertes sanguines (545+/-311,9 vs 929,9+/-771,7 en $\mathrm{mL}$ ) et du nombre de CGR transfusé $(1,1+/-1$ vs $2,2+/-1,7)$ pour les 23 patients recevant l'aprotinine versus les 21 contrôles, puis en 2008 Kasimian et coll. (73) retrouvaient des résultats similaires à savoir 
une diminution des pertes sanguines (715 vs 2110 en $\mathrm{mL} ; \mathrm{p}=0,007$ ) et du nombre de CGR transfusés $(1,25$ vs 3,16 Ui; $p=0,001)$. L'aprotinine a cependant été retirée du marché en novembre 2007 aux Etats Unis et en juillet 2008 en France pour effet indésirable. Cette décision faisait suite aux rapports de 9 décès imputables à l'aprotinine dans les suites d'une chirurgie cardiaque (74), et à deux études de haut niveau de preuve : un essai contrôlé randomisé en chirurgie cardiaque (75) arrêté prématurément pour surmortalité dans le bras aprotinine, et une autre étude observationnelle montrant elle aussi une surmortalité liée à cette molécule (76). A noter, une méta-analyse Cochrane publiée en 2011 (77) regroupant 250 essais et 250000 patients toute chirurgie confondue, montrait l'efficacité de toutes les molécules mais aussi la supériorité de l'aprotinine par rapport aux deux autres molécules en termes de réduction des pertes sanguines (aprotinine : $R R=0,66[0,6-0,72]$; acide tranexamique : $R R=0,9[0,53-0,7]$; acide amino caproique : $R R=0,81[0,67-0,99]$; aprotinine versus $[A T+E A C A]: R R=0,9[0,81-0,99]$. Contre placébo, aucun surrisque n'était retrouvé avec I'aprotinine que ce soit en terme d'infarctus du myocarde ( $R R=0,87[0,69-1,11])$, d'accident vasculaire cérébral ( $R R=0,82[0,44-1,52])$, d'insuffisance rénale $(R R=1,1[0,79-1,54])$ ou de mortalité ( $R R=0,81[0,63-1,06])$ avec néanmoins un surrisque de mortalité lorsque l'aprotinine était comparée aux deux autres molécules ( $R R=1,39[1,02-1,89])$.

L'acide amino caproïque a peu été évalué. On retrouve dans le domaine de la scoliose pédiatrique deux études concernant cette molécule. L'étude rétrospective de Thompson et coll. de 2008 (78) regroupant 34 patients dans le groupe contrôle pour 62 patients dans le groupe traitement montrait l'efficacité de cette molécule en terme de réduction des saignements et de la quantité de sang transfusé. Dhawale et coll. (79) montraient uniquement une diminution des saignements mais pas d'impact sur la transfusion.

L'acide tranexamique est donc la molécule la plus étudiée et la plus utilisée à l'heure actuelle en chirurgie de la scoliose pédiatrique. Les résultats des principales études divergent en raison d'une part de la dose d'acide tranexamique à administrer et d'autre part de l'hétérogénéité des populations incluses dans les études. Ainsi, un des premiers essais contrôlé, celui de Neilipovitz et coll. (46) publié en 2001, ne montrait pas de différence significative en terme de pertes sanguines (en $\mathrm{mL}: 2703+/-1292$ versus $2453+/-1526$ dans le groupe traitement, $p=0,58$ ). Dans cette étude, les doses administrées étaient plus faibles (10 $\mu \mathrm{g} / \mathrm{kg}$ en dose de charge puis $1 \mu \mathrm{g} / \mathrm{kg} / \mathrm{h}$ ) avec une population hétérogène (scoliose idiopathique et secondaire). Tous les autres essais retrouvaient une diminution des saignements per opératoires et une diminution du volume sanguin transfusé. Ainsi Sethna et 
coll. (80) en 2005 comparaient 23 patients sous acide tranexamique à 21 témoins. Ils utilisaient dans leur étude une dose de charge de $100 \mu \mathrm{g} / \mathrm{kg}$ puis $10 \mu \mathrm{g} / \mathrm{kg} / \mathrm{h}$ et retrouvaient une diminution des pertes sanguines de $41 \%$ et une diminution du besoin transfusionnel de 42\%. Dans une cohorte de patient avec scoliose d'origine neurogénique, Shapiro et coll. (81) en 2007 mettaient également en évidence avec les mêmes doses une diminution de $42 \%$ des pertes sanguines et une diminution de $46 \%$ du volume transfusé. Dans une étude récente, Yagi et coll. (82) dans une cohorte de patient avec scoliose idiopathique, montraient également une diminution des pertes sanguines et du volume sanguin transfusé. Enfin, la méta-analyse de Tzortzopoulou et coll. (83) confirmait l'efficacité de la molécule. Aucun effet secondaire n'a par ailleurs été décrit avec l'acide tranexamique.

\subsubsection{Autres traitements hémostatiques}

\subsubsection{La desmopressine}

La desmopressine ou 1-deamino-8-D-arginine vasopressin ou DDAVP a également été testée afin de réduire les pertes sanguines en per opératoire de la chirurgie de la scoliose pédiatrique. C'est un analogue synthétique de la vasopressine. II permet d'augmenter le facteur VIII, le facteur de Willebrand, le tPA (tissue Plasminogen activator) et le taux de prostacycline. II a initialement été testé en chirurgie cardiaque avec deux méta-analyses publiées. La première de I'International Study group of Peri-Operative Transfusion (ISPOT) (84), concluait à l'absence d'efficacité pour réduire l'incidence de la transfusion en per opératoire (OR : 0,98[0,64-1,50]; $p=0,92)$. La deuxième méta-analyse (85) regroupant 16 études pour un total de 1215 patients montrait une réduction des pertes sanguines $(114,1[84,5-144] \mathrm{mL})$, sans diminution ni d'unité de CGR transfusé $(0,12[-0,04 ; 0,28])$, ni de la mortalité, ni du taux de reprise chirurgical pour saignement. Une autre méta-analyse de 2004 de Carless et coll. (86) regroupait les 19 essais (1 987 patients) effectués en chirurgie adulte. Le taux de patients transfusés ne diminuait pas (RR de 0,96[95\% Cl 0,87-1,06]). II y avait cependant une diminution des pertes sanguines (-241,78 ml,[95\% IC -387,55; -96,01]), et une diminution du nombre de CGR transfusés $(-0,3 \mathrm{Ui}$, [95\% IC $-0,60 ;-0,01])$. Seulement trois études ont été réalisées spécifiquement en chirurgie de la scoliose pédiatrique. La première date de 1987 (87) et montrait une réduction du saignement et de la quantité de sang transfusé. Les deux autres études étaient non concluante $(88,89)$. Devant ces résultats peu convaincants, la desmopressine n'est plus utilisée en pratique courante. 


\subsubsection{Inhibiteurs du facteur VII activé}

Le facteur VII activé (VIIa) recombinant est produit à partir de cellules de bébés hamsters. De fortes doses de cette molécule permettent la génération de thrombine de manière dépendante ou indépendante de la voie du facteur tissulaire. Peu d'études évaluent le facteur VIla avec cependant de nombreux cas rapportés dans la littérature. La seule étude retrouvée concernant la chirurgie de la scoliose est celle de Kolban et coll. (90). Rétrospectivement dans une cohorte de 52 patients, ils démontraient une diminution des pertes sanguines per opératoire ( $1081,4 \mathrm{~mL}$ vs. $1513,4 \mathrm{~mL}, p=0,003)$, post-opératoires (1 881,9 $\mathrm{mL}$ versus $2317,6 \mathrm{~mL}, \mathrm{p}=0,032$ ) et une diminution du nombre de CGR transfusés en per opératoire $(p=0,042)$ mais pas en post-opératoire. II n'y avait pas de différence en terme de survenue d'effets secondaires (thrombose veineuse profonde, embolie pulmonaire et infarctus du myocarde).

\subsubsection{Les récupérateurs sanguins péri-opératoires (RSP0)}

La récupération sanguine péri-opératoire (RSPO) sans lavage a été développée dans les années 60 par Dyer et Klebanoff. Wilson et Taswell ont ensuite mis au point la récupération sanguine péri-opératoire avec lavage, permettant l'élimination du plasma, des leucocytes et des plaquettes. La RSPO s'intègre dans une stratégie d'épargne sanguine. Les indications sont les chirurgies cardio-vasculaires, orthopédiques, rachidiennes, neurologiques et la chirurgie de transplantation (91). De nombreuses études ont été publiées à ce sujet, elles se sont intéressées essentiellement aux chirurgies cardiaques, vasculaires, orthopédiques et obstétricales chez l'adulte, et démontrent la réduction de la transfusion en per opératoire. Ainsi la dernière méta-analyse de Carless et coll. publiée en 2010 , reprenant tous les types de chirurgies chez l'adulte montrait une réduction du risque de transfusion de $38 \%(R R=0,62[0,55 ; 0,70])$, et une diminution du nombre de CGR transfusés $(-0,68[-0,88 ;-0,49])$ grâce à cette technique (92). En pédiatrie les résultats sont moins convaincants, une des limites étant la taille du bol imposant un volume de saignement minimal pour être utilisé. Ainsi, au cours de la chirurgie de la scoliose, Bowen (93) montre une diminution du risque d'être transfusé ( $55 \%$ versus $6 \%$ dans le groupe avec RSPO, $p<0,05$ ) uniquement si la durée de la chirurgie était supérieure à 6 heures et les pertes sanguines de plus de $30 \%$ de la masse sanguine (ou supérieure à $360 \mathrm{~mL}$ ). Dans l'étude de Weiss et coll. (94), les patients ne pouvaient être retransfusés seulement si les pertes sanguines dépassaient les $500 \mathrm{~mL}$. La technique ne permettait alors pas de diminuer le risque transfusionnel. Dahmani et coll. (95) au cours de la chirurgie de la craniosténose 
démontraient une réduction du volume sanguin transfusé $(413[250 ; 540]$ versus $317[150 ; 410] \mathrm{mL}$ dans le groupe RSPO, $p=0,02$ ) et une diminution du nombre de CGR transfusés $(2[1 ; 2]$ versus $1[1 ; 2], p=0,04)$. En chirurgie cardiaque, Golab et coll. dans une population de 122 patients de moins de $10 \mathrm{~kg}$ montraient une réduction du volume sanguin allogénique transfusé (96). Les complications associées au RSPO restent rares, avec principalement une contamination bactérienne du sang récupéré, des troubles de la coagulation, les embolies gazeuses, la coagulation intravasculaire disséminée (CIVD), le Blood salvaged syndrome associant une CIVD à une détresse respiratoire aiguë dans un contexte d'activation plaquettaire et leucocytaire en cas de lavage insuffisant, une hémolyse aiguë et la transmission de cellules malignes.

\subsubsection{La transfusion autologue programmée (TAP)}

Cette stratégie consiste à prélever du sang du patient dans les semaines précédentes la chirurgie programmée à risque hémorragique, afin de mettre en réserve des CGR et des PFC pour la période péri-opératoire. Elle a été largement utilisée dans les années 1980 permettant de diminuer la transfusion homologue (97). Les premières études soulignaient son intérêt en termes d'épargne transfusionnel. Ainsi, la méta-analyse de Forgie et coll. (98) regroupant 61 études mais n'incluant que 6 essais randomisés dans l'analyse finale montrait une réduction du risque d'exposition au sang homologue en cas de TAP $(O R: 0,17[0,08-$ $0,37]$ ). Les patients bénéficiant de la TAP étaient cependant davantage transfusés (TH+TAP), (OR : 3,03[1,70-3,59]). Garcia et coll. (97) montraient rétrospectivement pour les 680 adultes bénéficiant $d$ 'une chirurgie rachidienne un taux de transfusion de $71 \%$ dont $80 \%$ sans transfusion homologue. En pédiatrie, cette stratégie était envisageable pour les enfants de plus de $20 \mathrm{~kg}$ et si les pertes étaient estimées à plus de $20 \%$. Plusieurs études ont été rapportées avec des résultats intéressants. Ainsi, Hibino et coll. (99) montraient que le don de 2 fois $10 \mathrm{~mL} / \mathrm{kg}$ avant une chirurgie cardiaque permettait de réduire la transfusion de sang homologue de 44,4\% à 4,3\%. Lauder et coll. (100) dans sa revue incluant 17 études, montraient que 63 à 94\% des patients pouvaient ne pas être transfusés. Les résultats ont ensuite été plus contrastés montrant surtout un surcoût de cette pratique $(100,101)$. L'étude de Bess et coll. (102) était une des premières à noter la non rentabilité de la TAP. Son étude incluant 123 enfants opérés de scoliose idiopathique, retrouvait un taux d’hématocrite pré-opératoire diminué et un taux de transfusion plus élevé dans la population bénéficiant d'une TAP. Les patients du groupe TAP étaient transfusés pour un taux d'hématocrite plus élevé alors que le taux d'hématocrite menant à la décision de 
transfusion homologue était identique dans les deux groupes. Par ailleurs, pour $51 \%$ des enfants, les dons n'étaient au final pas utilisés soit transfusés de manière non adaptée. Ensuite, une tentative d'optimisation en prescrivant de l'EPO en pré-opératoire a été essayée. Colomina et coll. (103) montraient ainsi la meilleure réalisation du don de sang autologue sous EPO avec un avantage si les pertes sanguines étaient supérieures à $50 \%$ de la masse sanguine, l'EPO seule étant suffisante en cas de perte sanguine estimée à $30 \%$. Les résultats n'étaient cependant pas concluants pour les patients avec une scoliose d'origine neuromusculaire (104). En résumé, le TAP semblait intéressant en raison de la suppression du risque d'accident hémolytique et de transmission virale. Elle présente cependant des limites la faisant remettre en question. Premièrement, il persiste toujours les risque liés à la surcharge, aux erreurs d'identité de patient et de groupe $A B O$ ainsi que les risques bactériens et allergiques. Par ailleurs, elle ne garantit pas l'absence de transfusion homologue (105). Ensuite, le rapport coût bénéfice n'est pas en sa faveur. Le coût direct d'une unité de sang autologue est supérieur à celui d'un CGR. Par ailleurs, de nombreux dons sont non utilisés voire transfusés sans justification. Enfin, sa lourdeur de mise en place n'est pas adaptée à la population pédiatrique en raison des contraintes à la fois physique (volume sanguin disponible restreint, immobilisation prolongé nécessitant le recours à une sédation) et morale.

Dans ce contexte, à l'heure actuelle, l'optimisation de l'hémoglobine en pré-opératoire est la principale stratégie, avec utilisation d'érythropoïétine $(54,106,107)$ et optimisation des réserves en fer.

\subsubsection{L'EPO}

L'EPO est une hormone régulatrice de l'érythropoïèse, permettant ainsi la synthèse de l'hémoglobine et le passage des réticulocytes dans la circulation tout en stimulant leur différenciation en globules rouges matures (103). L'EPO est produite à $90 \%$ par les cellules interstitielles péri-tubulaires du rein. Sa synthèse est régulée par l'hypoxémie et de nombreux facteurs influençant l'oxygénation des tissus périphériques. L'érythropoïetine humaine recombinante (EPO) est une forme biosynthétique de l'hormone naturelle ayant la même structure biochimique et les mêmes effets biologiques. Sa synthèse est effectuée par des cellules d'ovaires de hamster génétiquement reprogrammées. L'EPO a tout d'abord été utilisée en néphrologie pour la prise en charge des anémies chroniques des patients insuffisants rénaux chroniques. Puis, son champ d'action s'est étendu à l'optimisation du taux d'hémoglobine per et post-opératoire des chirurgies à fort potentiel hémorragique à 
savoir initialement la chirurgie orthopédique de l'adulte puis cardiaque, hépatique pour finalement être utilisée en pédiatrie en particulier au cours la scoliose pédiatrique $(102,103,108)$. Les effets secondaires de l'EPO sont par ordre de fréquence l'hypertension artérielle, des céphalées, des syndromes grippaux, Les effets thrombo-emboliques sont rares et sont décrits au-delà de $15 \mathrm{~g} / \mathrm{dL}$ en chirurgie orthopédique de l'adulte sans impact sur la mortalité (109). Initialement utilisée afin d’optimiser la transfusion autologue programmée $(103,110)$, rapidement l'EPO a été utilisée seule (111). C'est à Goodnough et coll. que l'on doit l'étude princeps marquant l'introduction de l’EPO en pratique transfusionnelle chirurgicale (110). II ressortait de ce travail la possibilité d'augmenter de volume de CGR recueillis (+41\%) si le TAP était accompagné de l'administration d'EPO, sans pour autant dans cette étude diminuer le nombre de patient non transfusés en homologue. Dans les suites, ont été réalisées plusieurs études évaluant l'administration d'EPO dans le cadre d'une TAP ou non. La majorité de ces essais sont inclus dans la méta-analyse de Laupacis et coll. (108) qui permettait de démontrer le bénéfice de l'EPO en chirurgie orthopédique et cardiaque de l'adulte. Il y avait une baisse significative du risque de transfusion en chirurgie orthopédique (11 essais EPO +TAP, OR : 0,42[95\% IC 0,28-0,62; $p<0.0001$ ] ; 3 essais EPO seul, OR : 0,36[95\% IC 0,24-0,56; $p=0,0001]$ ), et en chirurgie cardiaque (5 essais EPO et TAP, OR : $0,25[95 \%$ IC 0,08-0,82; $p=0,02]$ et 2 essais EPO seul, OR : 0,36[95\% IC 0,24-0,56; $p=0,0001]$ ). En 2001, Sonzogni et coll. montraient l'efficacité de la combinaison EPO et TAP en chirurgie cardiaque de l'adulte (112). Enfin, L' étude multicentrique de Price et coll. (113), portant sur 204 patients, confirmait que c'était uniquement dans le groupe de patients dont la concentration initiale d'hémoglobine était comprise entre 10 et $13 \mathrm{~g} / \mathrm{dL}$, que l'EPO diminuait significativement le risque relatif d'exposition au sang homologue. Vingt-huit pour cent de ces patients recevaient du sang homologue dans le groupe placebo contre $14 \%$ avec l'EPO. L'EPO a par la suite été évaluée dans le cadre de la chirurgie de la scoliose pédiatrique (44,49,114,115) . Ainsi, dès 1998, Vitale et coll. (44), montraient rétrospectivement avec 175 malades une réduction du taux de patients transfusés (de $31 \%$ à $18 \%$; $<<0,05$ ), néanmoins les analyses des sous-groupes montraient des résultats divergents. En cas de scoliose idiopathique, le traitement était efficace ( $4 \%$ versus $23,5 \%, p=0,006)$, mais non en cas de scolioses d'origine neuromusculaire ( $55 \%$ versus $43,6 \%, p=0,41)$. Dans une deuxième étude, avec plus de patients, Vitale et coll. rapportaient des résultats similaires ( $11 \%$ des transfusions dans le groupe EPO pour $25 \%$ dans le groupe sans). Shapiro montrait également I'intérêt de l'EPO pour optimiser le TAP au cours de la chirurgie de la scoliose (114). En 2007, 
vitale et coll. (104) restreignaient sa cohorte aux scolioses d'origine neuromusculaire et ne montraient pas de bénéfice pour l'EPO. Sur le plan médico-économique, le coût associé à I'utilisation de l'EPO est élevé : 40000 Ui d'EPO sont facturés 316,42 €. La dose d'EPO à administrer en pré opératoire n'est pas très bien définit. Le schéma initial était de $300 \mathrm{Ui} / \mathrm{kg}$ par jour pendant 10 jours (116) puis Goldberg et coll. ont montré qu'un protocole basé sur 4 injections hebdomadaires de $600 \mathrm{Ui} / \mathrm{kg}$ permettait une même efficacité tout en diminuant le coût (117). Enfin, Rosencher et coll. montraient la faisabilité d'injection de 4000 Ui hebdomadaire. Le protocole actuellement suivi est un bolus de $600 \mathrm{Ui} / \mathrm{kg}$ une fois par semaine (118)

\subsubsection{La supplémentation en fer}

Aucune donnée réalisée spécifiquement en pré-opératoire de chirurgie pédiatrique n'est présente dans la littérature. Les études ont été menées en chirurgie carcinologique colo-rectale et en orthopédie. Leur niveau de preuve est faible. II en ressort que la supplémentation en fer pré-opératoire est efficace chez les patients en situation de carence martiale $(119,120)$. Un bilan martial doit être donc prescrit lors de la première consultation.

\subsubsection{La position per opératoire}

La position est primordiale en chirurgie du rachis afin de limiter la pression au niveau des veines péridurales et ainsi limiter les pertes sanguines per opératoire ; ceci étant bien démontré dans l'étude de Park et coll (121). Le choix de la table dite de Jakson est donc important.

\subsubsection{La rachis morphine per opératoire}

Il a été montré grâce à trois essais qu'une rachis analgésie effectuée en début d'intervention avec une dose de $5 \mu \mathrm{g} / \mathrm{kg}$ de morphine réduisait les pertes sanguines périopératoire $(36,39,40)$.

De ces données, il en ressort qu'aucune stratégie individuellement n'a fait preuve de son efficacité entre autre pour la chirurgie de la scoliose d'origine neuromusculaire en terme d'épargne transfusionnel. La stratégie d'épargne transfusionnel doit donc être réfléchie et réunir les techniques les plus efficaces, les moins délétères, tout en gardant un ratio coût bénéfice acceptable. En chirurgie de la scoliose pédiatrique, Hassan et coll. présentaient une stratégie transfusionnelle comprenant une évaluation pré-opératoire du seuil d'hémoglobine et de l'hémostase, la mise en place d'une supplémentation en fer et de cures d’EPO pré et post-opératoires en fonction du taux d'hémoglobine. La récupération de sang 
per opératoire et sa restitution était systématique. Les patients recevaient de l'acide tranexamique (un bolus de $100 \mathrm{mg} / \mathrm{kg}$ puis $10 \mathrm{mg} / \mathrm{kg} / \mathrm{h}$ ) et des seuils transfusionnels restrictifs étaient respectés. Dans leur étude la transfusion de PSL concernait 1,7\% des scolioses idiopathiques et $36 \%$ des scolioses neuromusculaires (50).

\section{OBJECTIFS DE L'ETUDE}

A l'hôpital Robert DEBRE, la stratégie d'épargne transfusionnelle a été modifiée en 2010 avec arrêt des techniques de transfusion autologue programmée. L'hémoglobine est optimisée en pré-opératoire par l'administration d'EPO et d'une supplémentation martiale. Les pertes sanguines sont diminuées en per opératoire par l'administration d'acide tranexamique, la réalisation d'une rachi-analgésie morphine et l'utilisation d'un récupérateur sanguin per opératoire (RSPO).

Dans ce contexte, les objectifs de cette thèse étaient d'évaluer l'impact de notre stratégie globale d'épargne transfusionnelle en termes de pertes sanguines et de besoins transfusionnels, et de redéfinir les facteurs de risque transfusionnel au cours de la chirurgie de la scoliose pédiatrique. Pour cela, nous avons réalisé une étude de cohorte rétrospective observationnelle.

\section{MATERIEL ET METHODE}

\subsection{Population}

II s'agissait donc d'une étude rétrospective, monocentrique réalisée à l'hôpital universitaire Robert DEBRE, Assistance publique des hôpitaux de Paris, Université Paris Diderot, de janvier 2001 à Décembre 2012. Les patients inclus avaient moins de 18 ans et étaient opéré pour la première fois de leur scoliose pédiatrique. Toutes les données étaient extraites directement à partir du dossier médical archivé. Les chirurgies étaient réalisées uniquement par deux chirurgiens spécialisés dans la scoliose pédiatrique.

\subsection{Protocole de l'étude}

\subsubsection{Les données recueillies}

Les données alors recueillies pour chaque patient étaient ses caractéristiques de base (le sexe, l'âge, le poids, la taille, l'index de masse corporel (IMC)), la cause de la scoliose à savoir idiopathique, congénitale, d'origine neuromusculaire ou autres, le score ASA (American Score Anesthesiology). La sévérité de la scoliose était évaluée via l'angle de Cobb 
de sa courbure principale. Concernant la chirurgie, étaient recueillis le nombre d'étages fixés à l'étage thoracique, lombaire et sacrée, la réalisation d'une gibbectomie et la durée de la chirurgie depuis l'incision jusqu'à la fermeture. Etaient recueilli les taux d'hémoglobine préopératoires, en post-opératoire immédiat, et de J1 à J5. Etaient noté si un vasopresseur était administré en per opératoire, la quantité de remplissage reçue en cristalloïdes et colloïdes, la quantité de CGR, plasma frais congelés (PFC) et les plaquettes transfusées, le volume restitué de sang traité récupéré et traité par le récupérateur sanguin per opératoires, si le patient avait reçu de l'EPO, de l'acide tranexamique, une rachi-anesthésie morphine, et enfin la quantité de sang perdu par les redons durant les 24 heures post-opératoire en salle de réveil. Les pertes sanguines per opératoires étaient estimées par la variation d’hémoglobinémie péri opératoire : $\Delta \mathrm{Hb}$. Son calcul est basé sur les équations présentées par Nuttall (122), s'appuyant sur les travaux de Brecher (123). Cette variable permet une estimation des pertes sanguines péri opératoires :

$\Delta \mathrm{Hb}=\mathrm{Hb}$ pré op $-\mathrm{Hb}$ post op $+\mathrm{Hb}$ transfusé

Hb transfusée $=$ QHbtransfusée $x$ VST

$\mathrm{QHb}$ transfusée $=\mathrm{QHb}$ transfusée $\mathrm{CGR}+\mathrm{QHb}$ récupération

$\mathrm{QHb}$ récupération $=$ Hte récupération $\times \mathrm{V}$ récupération $\times \mathrm{TCMH}$

$\%$ Hte récupération $=0,5$ (donnée fabriquant) et $\mathrm{TCMH}=\mathrm{Hb} / \mathrm{Hte}$

$\mathrm{Hb}$ : hémoglobine; Hte : hématocrite; QHb : quantité d'hémoglobine ; VST : Volume sanguin total ; QHb récupération : la quantité d’hémoglobine restituée au patient grâce à la récupération de sang per opératoire ; $\mathrm{TCMH}$ : Teneur corpusculaire moyenne en hémoglobine.

\subsubsection{Description de l'anesthésie}

Les patients bénéficiaient d'une prise en charge protocolée. Une première consultation d'anesthésie permettant d'initier le traitement par érythropoïétine (EPO) sur un mois avec pour objectif un taux d'hémoglobine supérieur à $15 \mathrm{~g} / \mathrm{dL}$. Les patients recevaient ainsi de l'Eprex ${ }^{\circledR}$ (JANSSEN-CILAG, Issy-Les-Moulineaux, France), si le taux d'hémoglobine était inférieur à $15 \mathrm{~g} / \mathrm{dL} 48$ heures avant l'injection à la dose de $600 \mathrm{Ui} / \mathrm{kg}$, avec une stratégie débutée 5 semaines avant la date de la chirurgie. Tous les patients bénéficiaient d'une chirurgie première élective de leur scoliose sous anesthésie générale avec intubation orotrachéale en décubitus ventrale sur la table de Jackson. Un monitorage standard était installé et l'induction était effectuée en décubitus dorsal après pré-oxygénation et injection soit de $2-3 \mathrm{mg} / \mathrm{kg}$ de diprivan, ou induction sous $6 \%$ de sévoflurane, $0,2 \mu \mathrm{g} / \mathrm{kg}$ de sufentanyl 
et $0,5 \mathrm{mg} / \mathrm{kg}$ d'atracurium. Une seconde voie veineuse périphérique, un doppler œsophagien et un cathéter artériel invasif pour les patients avec dysfonction cardiaque préexistante, une sonde thermique et une sonde urinaire étaient posées. Une antibioprophylaxie par céfazoline en première intention était administrée. Ensuite, tous les patients étaient positionnés en décubitus ventral avec monitorage continue de la moelle épinière par potentiel évoqué somesthésique. L'anesthésie était maintenue soit par du Sévoflurane avec des objectifs de concentration alvéolaire minimale (CAM) entre 0,5 et 1,5 ou soit par une perfusion continue de diprivan avec des objectifs d'indice bispectral entre 40 et 60 . L'analgésie per opératoire était assurée par du Sufentanyl administré en continu (0,2 $\mu \mathrm{g} / \mathrm{kg} / \mathrm{h})$ et une rachianalgésie par morphine $(0,5 \mu \mathrm{g} / \mathrm{kg})$ délivrés par le chirurgien après l'incision. Les patients étaient curarisés par de l'atracurium avec des objectifs de train de quatre en per opératoire nuls. Ils recevaient par ailleurs de la kétamine à visée antihyperalgésique. En per opératoire, les patients recevaient de l'acide tranexamique (Exacyl ${ }^{\circledR}$, Sanofi-Aventis, Paris, France) avec une dose de charge de $50 \mathrm{mg} / \mathrm{kg}$ en 20 minutes débutée après l'induction suivie d'une perfusion continue à la seringue électrique de $10 \mathrm{mg} / \mathrm{kg} / \mathrm{h}$. Une dose maximale de $4 \mathrm{~g}$ par jour était administrée. Un dispositif de récupération sanguine intra-opératoire de type Haemonetic Cell Saver $5^{\circledR}$ (Haemonetic corporation, Braintree, MA, USA) était installé pour tous les patients avec décision de traitement et retransfusion seulement si les pertes sanguines étaient supérieures à $800 \mathrm{~mL}$. Le monitorage hémodynamique était assuré par un doppler œsophagien et une prise de pression non invasive. Le remplissage était effectué avec un cristalloïde (Ringer lactate), ou un colloïde (une gélatine, Plasmion ${ }^{\circledR}$, Fresenius Kabi France, Louviers, France) ou un hydroxy éthyl Amidon (HEA) 130/0.4, Voluven ${ }^{\circledR}$, FRESENIUS KABI FRANCE, Sèvres, France). L'analgésie postopératoire était standardisée avec de la morphine administrée par PCA (Patient Controlled Analgesia) (analgésie autocontrôlée par le patient), du paracétamol (paracétamol $15 \mathrm{mg} / \mathrm{kg} / 6$ heures), des anti-inflammatoires non stéroïdiens (kétoprofen $1 \mathrm{mg} / \mathrm{kg} / 8$ heures) et du néfopam $(0,25 \mathrm{mg} / \mathrm{kg} / 6$ heures). Les redons permettaient de monitorer les pertes sanguines en post opératoires. Les objectifs transfusionnels étaient : un taux d'hémoglobine supérieur à $10 \mathrm{~g} / \mathrm{dL}$, un taux de plaquette supérieure à $50000 / \mathrm{mm}^{3}$, et un TP supérieur à $40 \%$. Les patients étaient pour la plupart extubés dans les heures suivant l'intervention en salle de réveil ou ils étaient surveillés 24 heures. Ils étaient ensuite surveillés en unité de soin continu. 
Cette étude est approuvée par le comité local d'éthique (Comité d'évaluation de l'éthique des projets de recherche biomédicale - CEERB Paris Nord) et le recours au consentement n'était pas nécessaire du fait du caractère non interventionnel et observationnel de l'étude.

\subsubsection{Description de la chirurgie}

Les étages de fusion étaient sélectionnés selon les mêmes critères pendant toute la durée de l'étude. Les patients atteints d'une scoliose idiopathique bénéficiaient d'une fusion postérieure grâce à un matériel hybride incluant des câblages sous laminaires par des Clamps Universels ${ }^{\circledR}$ (Zimmer Spine, Bordeaux, France) sur le rachis thoracique, des tiges de fusion postérieure et des vis pédiculaires distales (lombaires) Java ${ }^{\circledR}$ (Zimmer Spine, Bordeaux, France). Des tiges en alliage de titane 5.5 étaient utilisées pour tous les cas et étaient profilées en fonction du profil sagittal recherché et reliées par deux connecteurs transverses. Les tiges étaient tout d'abord introduites dans les vis pédiculaires avant d'effectuer la correction lombaire. La translation postéro-médiale était la première technique utilisée pour effectuer la correction thoracique. Lors de la rotation in situ, la compression et/ou la distraction étaient effectuées pour améliorer la mise à niveau du rachis non instrumenté à la fois en proximal et en distal. L'intégrité de la moelle épinière était monitorée en per opératoire grâce aux potentiels évoqués somesthésiques et moteurs. Les patients atteints de scolioses neuromusculaires étaient opérés par la même technique associée à une fixation pelvienne par des tiges intra-sacrées comme décrit par la technique de Jackson modifiée. Les patients atteints de scolioses congénitales (hémi-vertèbre ou barre unilatérale non segmentée) étaient traitées par une épiphysiodèse convexe circonférentielle combinée à une arthrodèse postérieure instrumentée (deux niveaux au-dessus et en-dessous). Les épiphysiodèses antérieures étaient effectuées par thoracoscopie ou lombotomie. Les deux techniques étaient pratiquées en position latérale.

\subsection{Analyse statistique}

Les résultats étaient exprimés en médiane et interquartiles (IQS), ou nombre et pourcentage. Une analyse uni- puis multivariée étaient réalisées pour rechercher les facteurs indépendamment associés au risque transfusionnel. Les variables catégorielles étaient comparées par le test du Chi2 ou le test de Fisher; les variables continues par le test de Student ou de Wilcoxon en fonction de la normalité de leur distribution. Les variables avec une $p$ value $<0,2$ dans cette première analyse étaient intégrées dans le modèle multivarié. Pour cela, les variables continues étaient au préalable dichotomisées en utilisant le point en haut à gauche de la courbe ROC (Reiceving Operator Characteristics) de prédiction de 
transfusion (point J). Au final, les variables avec une $p$ value $<0,05$ étaient considérées comme indépendamment associées au risque d'être transfusé. Les analyses statistiques étaient réalisées à l'aide du logiciel SPSS 20.0 (IBM Company, Chicago, Illinois, USA).

\section{RESULTATS}

Au final, 147 patients étaient inclus dans l'étude. Aucune donnée n'était manquante. Toutes les interventions étaient réalisées par les deux mêmes chirurgiens. Les caractéristiques principales des patients sont rapportées dans le tableau $n^{\circ} 4$. L'âge moyen des patients étaient de 15 +/- 3 ans avec un IMC associé moyen de 19+/-4. L'angle de Cobb de la courbure principale était de $58^{\circ}+/-16$. La scoliose était idiopathique pour $79,6 \%$ des patients, secondaire à une myopathie dans 5,4\% des cas, une encéphalopathie dans $6,1 \%$ des cas, d'origine neuromusculaire dans $11,6 \%$ des cas, congénitale dans $6,1 \%$ des cas et post-traumatique pour 2,7\% des patients. En terme de techniques d'épargne transfusionnelle, 93,2 \% des patients recevaient de l'EPO en pré opératoire et tous les patients recevaient de l'acide tranexamique en per opératoire. Le RSPO était utilisé pour 54 (36,5 \%) des patients. La durée moyenne de la chirurgie était de 227+/-65 min. Le nombre moyen d'étages fusionnés était de 13+/-3. Vingt-six pour cent des patients bénéficiaient d'une gibbectomie. Les données correspondant au remplissage et à la transfusion per opératoire sont colligées dans le tableau $n^{\circ} 5$. En per opératoire, $17 \%$ des patients étaient transfusés pour $2,7 \%$ en post-opératoire soit au final $18,4 \%$ des patients. Les patients avec une scoliose d'origine idiopathique ne recevaient du sang que dans 9,4\% des cas, ceux avec une scoliose d'origine neuromusculaire dans $76,4 \%$ et en cas de scoliose congénitale dans $22 \%$ des cas. Le volume sanguin moyen administré était en per opératoire de $77+/-213 \mathrm{~mL}$ et au total de $95+/-265 \mathrm{~mL}$. Le taux d'hémoglobine préopératoire était de 14,6+/-1,3 g/dL et diminuait à 10,8 g/dL à la fin de l'étude. Trente-six pour cent des patients se voyaient restituer du sang récupéré en per opératoire avec un volume moyen de 129+/-240 mL. Quarante-quatre patients, soit 51\% des patients, recevaient des colloïdes durant I'intervention. De l'analyse univariée dont les résultats sont rapportés dans le tableau ${ }^{\circ} 6$, il en ressortait que les patients transfusés $(n=27)$ par rapport aux patients non transfusés avaient un poids inférieur (en kg 40[23-90] pour 52[10-96], p <0,0001), avec un indice de masse corporelle inférieur (18[11-31] pour 20[10-31]), présentaient plus de comorbidités avec un score ASA 3 pour 40,7\% d'entre eux versus 5\% chez les patients non transfusés ( $p<$ $0,0001)$. Ils présentaient plus de scolioses neuromusculaires $(13(48,1 \%)$ pour $4(3,3 \%), p<$ 
0,0001). Leur nombre d'étages fusionnés était plus important (16[11-17] pour 13[3-17], $p<$ $0,0001)$, et une fusion sacrée était plus souvent pratiquée $(9(33,3 \%)$ versus $2(1,7 \%), p<$ 0,0001). Ils recevaient plus souvent des colloïdes en per opératoire $(25(92,6 \%)$ versus 59 $(57,5 \%), p<0,0001)$ et la durée de la chirurgie était plus longue (285[140-520] versus 210[80-330], $p<0,0001)$. La valeur la plus en haut à gauche de la courbe ROC de prédiction de la transfusion était ensuite utilisée pour dichotomiser les variables continues associées au risque transfusionnel en analyse univariée. Les seuils retenus étaient alors : 16 pour l'IMC, 15 pour le nombre d'étages fusionnés, et 255 minutes pour la durée de la chirurgie. Au final, 4 facteurs étaient indépendamment associés au fait d'être transfusé au décours d'une chirurgie de la scoliose pédiatrique (tableau $\left.n^{\circ} 7\right)$ : un IMC supérieur à $16(\mathrm{OR}: 0,144[0,024-$ $0,864]$ ), une origine neuromusculaire de la scoliose (OR : 11,7[1,6-86,7]), l'administration de colloïdes (OR : 15,6 [1,43-169,9]) et une durée de chirurgie supérieure à $255 \min (\mathrm{OR}:$ 7,5 $[2-28,1])$. Le modèle comprenant ces 4 variables permettait de prédire le fait d'être transfusé avec une aire sous la courbe de 0,93[IC 95\%:0,86-0,98]. L'exactitude de ce modèle était de $93,2 \%$ (98,2\% pour prédire la non transfusion et $69,6 \%$ pour prédire la transfusion).

\section{DISCUSSION}

On retient de cette étude que seulement $18,4 \%$ des patients étaient transfusés avec une répartition différente en fonction de l'origine de la scoliose : 9,4\% pour les scolioses idiopathiques, $76,4 \%$ pour les scolioses d'origine neuromusculaire et $22 \%$ pour les scolioses congénitales. En termes de stratégie d'épargne transfusionnelle, 93,5\% des patients recevaient de l'EPO, tous se voyaient administrer de l'acide tranexamique en per opératoire et le RSPO n'était restitué que pour 36,5\% des patients. Enfin, les facteurs indépendamment associés au risque transfusionnel étaient l'indice de masse corporelle, une origine neuromusculaire de la scoliose, le fait d'avoir reçu des colloïdes en per opératoire et la durée de la chirurgie. Ni le nombre d'étages fusionnés, ni une fixation sacrée, ni la stratégie d'épargne transfusionnelle, ni l’hémoglobine préopératoire n'étaient associés au risque d'être transfusé.

Tout d'abord, cette étude confirme les résultats obtenus dans l'étude de Hassane et coll.(50) à savoir une réduction du risque transfusionnel principalement pour les scolioses d'origine idiopathique. Dans la littérature, les risques transfusionnels sont compris entre 15 et $25 \%$ pour les scolioses idiopathiques et entre 40 et $70 \%$ pour les scolioses d'origine 
neuromusculaire (cf tableau ${ }^{\circ} 8$ ). Ainsi, en 2002, Meert et coll.(48) dans une cohorte n'incluant que des patients avec scoliose idiopathique, retrouvaient une incidence transfusionnelle de 59\% mais la stratégie d'épargne transfusionnelle était différente (TAP, RSPO, hypotension et hémodilution). Sethna et coll.(80), dans une population mixte (idiopathique et neuromusculaire), une incidence transfusionnelle de $60 \%$ dans le groupe recevant de l'acide tranexamique et de $71 \%$ dans le groupe contrôle, étaient rapportés, sachant que les doses d'acide tranexamiques étaient alors plus faibles. Les études se focalisant sur les patients avec scolioses d'origine neuromusculaire dont celle de Shapiro et coll.(81) avaient des seuils transfusionnels élevés. La première conclusion de ces résultats est donc que notre stratégie d'épargne transfusionnelle n'est toujours pas optimale pour la prise en charge des patients avec scoliose d'origine neuromusculaire.

Ensuite, nous confirmons une fois de plus que la scoliose d'origine neuromusculaire est un facteur indépendant de risque transfusionnel. Ce résultat avait déjà été trouvé à plusieurs reprises $(48,49,124)$. Sachant ce sur risque de saignement et de transfusion, des auteurs se sont focalisés sur cette population pour évaluer leurs stratégies d'épargne transfusionnelle. Il est intéressant de noter que seuls les anti fibrinolytiques se sont avérés efficaces $(72,73,78,79,81)$, a contrario de l'EPO dans l'essai de Vitale en 2007 (104). La cause de cette majoration des pertes sanguines et du risque transfusionnel a été discutée à plusieurs reprises. Il en ressort plusieurs hypothèses. Concernant la chirurgie, l'exérèse est généralement plus étendue allant de l'étage thoracique jusqu'au sacrum, l'arthrodèse s'étendant en moyenne sur 13 à 16 étages, avec une fixation sacrée. Les patients sont par ailleurs généralement plus jeunes au moment de la chirurgie, avec un IMC moindre, rendant plus difficile l'intervention. L'os est également plus ostéoporotique imposant des modifications de techniques chirurgicales (" sublaminar wiring " versus « laminar hooks ») prolongeant la procédure (125). Sur le plan médical, il a été suggéré une anomalie de la coagulation pour expliquer l'importance des pertes sanguines. Deux études ont abordé le sujet. Kannan et coll. (126) comparaient le profil d'évolution de l'hémostase entre 14 patients avec scolioses idiopathiques et 11 patients avec scolioses d'origine neuromusculaire. Au décours de la chirurgie, le TP était en tout temps plus allongé chez les patients avec atteinte neurologique. Néanmoins, dans les deux groupes, il tendait à diminuer durant la chirurgie. Il en était de même pour le facteur VIla, à contrario du TCA et du TT qui restaient dans les normes. Les patients ne présentaient pas de déficit en vitamine $K$. Les 
DDimères étaient augmentées dans les deux populations. La majoration des saignements semblait donc être secondaire à une activation de la voie extrinsèque de la coagulation. Dans la deuxième étude (127), à baseline, tous les indices étaient dans la limites de la normales mais ils étaient plus allongés de manière significative chez les patients encéphalopathes. Une fois $15 \%$ de la masse sanguine perdue, le TP et le TCA étaient allongés seulement chez les patients ces mêmes patients, résultats en faveur d'une atteinte de la fonction plaquettaire. Les autres arguments avancés dans la littérature sont une exposition aux antibiotiques modifiant la flore intestinale indispensable à la formation de la vitamine $\mathrm{K}$, mais aussi une exposition plus importante aux anti-épileptiques dont l'acide valproïque connu pour être source de thrombocytopénie, thrombocytopathie et des déficits en facteurs de la coagulation (128). Les patients ont par ailleurs un os plus ostéoporotique, facteurs indépendant de majoration des pertes sanguines (42). Leur fibrose musculaire empêcherait également l'hémostase. Le tonus veineux de ces patients serait également altéré en raison de la dysfonction des mitochondries des cellules musculaires lisses.

Le deuxième facteur indépendant associé au risque transfusionnel dans notre étude est l'exposition à un colloïde. C'est la première fois que ce résultat est rapporté dans cette population, sachant qu'il n'avait par ailleurs jamais été recherché auparavant. Ceci, nous amène donc à ouvrir une discussion sur l'impact des colloïdes sur l'hémostase. Les colloïdes administrés dans notre étude étaient soit un HEA 130/0,4 (Voluven ${ }^{\circledR}$ ), soit une gélatine (Plasmion ${ }^{\circledR}$ ). Les colloïdes peuvent altérer l'hémostase de manière indirecte ou directe. Indirectement, ces solutés entrainent une hémodilution, facteur indépendant associé à une majoration des saignements. Ainsi, Rosencher et coll. (129) montrait dans une étude clinique réalisée en chirurgie de la prothèse de hanche que le taux d'hématocrite est corrélé au volume des pertes sanguines et émet plusieurs hypothèses pour expliquer ce phénomène. D'une part, la diminution du nombre de globule rouge permet aux plaquettes de circuler au centre des vaisseaux. Celles-ci n'interagissant plus avec le sous endothélium, ne peuvent plus participer à l'élaboration du clou plaquettaire. D'autre part, les globules rouges sont capturés par les filaments de fibrine et leur rupture occasionnelle induit une libération d'adénosine diphosphate (ADP) qui est un inducteur de l'agrégation. Parallèlement les érythrocytes agissent directement sur le métabolisme de l'acide arachidonique plaquettaire, sur le relargage des eicosapentaenoates et sur la synthèse de thromboxane, également puissant inducteur de l'agrégation. Cette dernière est donc majorée en présence d'érythrocytes, et elle diminue si le nombre des érythrocytes est réduit. Enfin, un troisième 
composant est à prendre en compte : les globules rouges, en mettant à disposition leurs membranes phospholipidiques, vont favoriser la génération de thrombine et, inversement une chute de l'hématocrite peut limiter théoriquement cette production.

Ensuite, certains colloïdes peuvent interagir directement avec l'hémostase. L'albumine n'a pas d'effet délétère dans ce sens. Les gélatines semblent neutres même si plusieurs essais montrent un lien avec l'hémostase. Ainsi, un travail de De Jonge et coll. chez des volontaires sains comparait l'effet de la perfusion de $1000 \mathrm{~mL}$ de gélatine fluide modifiée à 4\% (Gelofusine ${ }^{\circledR}$ ) au même volume de sérum physiologique (130). Le temps de saignement était allongé dans le groupe gélatine et, après correction du facteur dilution, était observé une diminution de l'activité du facteur Willebrand et des complexes thrombineantithrombines. La gélatine fixerait le facteur Willebrand. Néanmoins, la très large utilisation des gélatines et l'absence d'accidents rapportés permet de conclure à un faible risque hémorragique directement induit par ces produits. Ensuite, les dextrans absorberaient d'une part le facteur de Willebrand, et d'autre part altèreraient la polymérisation de la fibrine. Ils ne sont plus utilisés en France (131). Enfin, les hydroxy éthyl amidons (HEA) fixeraient le complexe facteur VIII, facteur de Willebrand (132) et empêcheraient la polymérisation des molécules de fibrine. Cette fixation est proportionnelle à la quantité de molécules d'amidon circulantes. Elle facilite l'élimination de l'HEA induisant ainsi un déficit quantitatif qui va produire, comme pour les dextrans, un syndrome de type Willebrand de type I-like. Il est reconnu que cet effet est conditionné par la dose administrée, le poids moléculaire, le degré de substitution, et le ratio $\mathrm{C} 2 / \mathrm{C} 6$. Ce mécanisme d'action permet de mieux comprendre les accidents observés avec les amidons de haut poids moléculaire (Hetastarch, non commercialisé en France) (133) et, relativement, les interactions avec l'hémostase de l'HEA 200/6\%/0,62 (Elohès ${ }^{\circledR}$ ), surtout quand il était utilisé de manière prolongé. Ainsi, un travail de Treib et coll. a pu montrer qu'après 10 jours d'hémodilution avec différents hydroxyéthylamidons à la dose de un litre par jour, ceux d'entre eux qui avaient le poids moléculaire in vivo le plus élevé s'éliminaient le plus mal et étaient responsables d'une chute importante du taux de facteur Willebrand (132). Un HEA de plus faible poids moléculaire in vivo est à présent largement utilisé en Europe : I'HEA 130/6\%/0,4 (Voluven $\left.{ }^{\odot}\right)$. II a fait preuve d'une certaine neutralité vis-à-vis de l'hémostase. Il a fait l'objet de nombreuses études que ce soit in vivo ou in vitro. Initialement, il était comparé à l'HEA 200/6\%/0,5. Un des premiers travaux montrait en chirurgie orthopédique majeure une réduction des pertes sanguines et de la transfusion homologue (134). Dans cette étude, le taux de facteur VIII était 
significativement moins diminué et le temps de céphaline activé (TCA) était moins allongé, à la $5^{\text {ème }}$ heure post-opératoire dans le groupe Voluven ${ }^{\circledR}$. Un travail réalisé en chirurgie cardiaque n'a pas montré de différence entre une gélatine de référence et le Voluven ${ }^{\circledR}$ vis à vis des pertes sanguines et de la transfusion de culots globulaires (135). Chez des patients traumatisés crâniens, de l'HEA 130/0,4 était administrée à des doses répétées jusqu'à une dose maximale de $70 \mathrm{ml} / \mathrm{kg} / \mathrm{j}$ alors que le groupe contrôle était traité avec un HEA 200/0,5 à la dose maximale de $33 \mathrm{ml} / \mathrm{kg} / \mathrm{j}$ avec un complément par de l'albumine pour atteindre une dose totale de $70 \mathrm{ml} / \mathrm{kg} / \mathrm{j}$ (136). Il n'était mis en évidence de différence entre les deux groupes en termes de mortalité ou de majoration du risque hémorragique ou transfusionnel, dans cette situation clinique réputée pour sa complexité. En 2001, Franz et coll. mettait en évidence l'implication de tous les amidons dans la diminution de l'expression de la glycoprotéine plaquettaire GPIIb-IIla et dans l'altération de l'hémostase primaire évaluée par le PFA 100. Seul I'HEA 130/0.4 (Voluven ${ }^{\circledR}$ ) échappait à ce type d'altération (137). Un effet plus marqué de l'HEA 130/0.4 sur des données thromboélastographiques a pourtant été récemment montré par Mittermayr et coll. comparativement à des cristalloïdes, conduisant à un apport complémentaire de concentrés de fibrinogène chez ces patients (138). La polymérisation de la fibrine pourrait être modifiée avec l'HEA 130/0.4 (139). Schramko et coll. (140), étudiait en chirurgie cardiaque l'impact du type de soluté (HEA 130/0.4, gélatine, ringer acétate) et la relation effet dose sur la coagulation. Les patients recevaient des bolus successifs de $7 \mathrm{~mL} / \mathrm{kg}$ et à chaque étape, la coagulation était monitorée par thromboélastométrie. Le temps de formation du thrombus ainsi que sa fermeté étaient altérés de manière identique pour les colloïdes alors que les données pour le Ringer Acétate n'étaient pas modifiées. Dans un esprit de synthèse de l'ensemble de ces études, plusieurs revues systématiques ont été publiées. La méta-analyses de Kozeck Langenecker et coll. de 2008 (141) en chirurgie cardiaque réunissant 459 patients dans 7 études clinique et comparait les HEA 130/0.4 aux HEA 200/0.5 montrant la diminution des saignements dans le groupe avec le degré de substitution le plus faible. II n'y avait pas de différence en termes de mortalité. La revue de Raja et coll. (142) comparait également les mêmes solutés et réunissait 3 études in vitro et 9 études in vivo. Le Voluven ${ }^{\circledR}$ ne semblait pas impacter la coagulation, en particulier sur la formation et la durée du thrombus. La revue systématique de Hartog et coll. (143), comparait en thrombo-élastométrie les effets du Voluven ${ }^{\circledR}$ soit à un cristalloïde, soit à de l'albumine au travers de 17 études in vitro et 7 in vivo. Il résultait de ce travail une tendance à une réduction de la taille et de la fermeté du thrombus dans le 
groupe Voluven ${ }^{\circledR}$. En raison de ces résultats, et de l'invalidation de certains essais pour fraude, les études évaluant cette molécule se poursuivent. Skhirtladze et coll., en 2014 (144),comparaient en chirurgie cardiaque l'albumine à $5 \%$, aux Voluven ${ }^{\circledR}$ et au ringer lactate. Les pertes sanguines étaient identiques dans les trois groupes mais les groupes des patients recevant un HEA étaient plus transfusés (35\% dans le groupe Ringer Lactate, $62 \%$ dans le groupe albumine et $64 \%$ dans le groupe HEA $(p=0,0003))$. Enfin, Rasmussen et coll. (145) comparaient le ringer lactate au Voluven ${ }^{\circledR}$ au cours de la chirurgie de la cystectomie, et mettait en évidence dans le groupe Voluven ${ }^{\circledR}$ une réduction de la dureté du thrombus $(p<0,001)$ et une augmentation d'environ $50 \%$ des pertes sanguines (en Litre : $2,2[0,5-5,0]$ versus $1,4[0,5-2,4],(p<0,038))$. La sécurité du Voluven ${ }^{\oplus} n^{\prime}$ est donc pas totalement établit. Les résultats de notre étude sont un argument de plus pour garder une certaine méfiance vis-à-vis de ce produit, et préconiser un usage exclusif des cristallö̈des au cours de la chirurgie de la scoliose pédiatrique.

Enfin, notre étude montre pour la première fois qu'un indice de masse corporel bas, c'est-à-dire inférieur à 16 est un risque de transfusion au cours de la chirurgie de la scoliose pédiatrique. Meert et coll., en 2002, retrouvaient le poids comme étant indépendamment associé au risque transfusionnel. Une des explications apportées étaient une modification de la technique chirurgicale, la gestion de la volémie et des seuils transfusionnels souvent plus libéraux (48). L'IMC apporte en plus du poids la notion de dénutrition. II est connu que le statut nutritionnel des patients est associé au pronostic (146). Un état de dénutrition préopératoire augmente la morbidité (infection, retard de cicatrisation), la mortalité, la durée de séjour. Encore une fois, une étude récente concernant la chirurgie de l'hydrocéphalie retrouve ce résultat (147). En pédiatrie, une étude menée en chirurgie cardiaque congénitale fait les mêmes constatations (148). Le statut nutritionnel est également d'une importance primordiale en réanimation. Ceci est très bien rappelé dans l'étude de Mehta et coll. montrant que le respect des protocoles d'alimentation est également associé à la morbimortalité des patients (149). Cette morbidité peut prendre différentes formes à savoir une dysfonction myocardique, une dysfonction vasculaire avec atteinte de la fonction endothéliale, une dystrophie musculaire avec ces répercussions potentielles sur le sevrage ventilatoire, une déminéralisation osseuse, une lypolyse, une résistance à l'insuline, un déficit protéique avec ces conséquences sur le système immunitaire. L'axe corticothrope peut également être mis au repos. La majoration des pertes sanguines peut donc s'expliquer par plusieurs arguments. Le plus communément avancé est la déminéralisation osseuse, 
facteur indépendamment associé au risque hémorragique. D’autres facteurs majorent les saignements comme la dystrophie des tissus ou l'atonie vasculaire. Ces patients par conséquent plus instables sur le plan hémodynamique et tolère moins bien l'anémie, le recours à la transfusion peut être plus précoce. Dans ce contexte, les patients à risque de dénutrition pré et post opératoire se présentant en consultation de chirurgie pour la scoliose pédiatrique doivent être dépistés et une évaluation de leur statut nutritionnel alors effectuée. En pédiatrie, le carnet de santé et la courbe de croissance sont les premiers éléments à analyser ainsi que le calcul de l'IMC. II n'existe pas de recommandation précise sur les moyens de mesure du statut nutritionnel chez l'enfant, à contrario de chez l'adulte avec l'index de pronostic nutritionnel de Buzby (150). Quatre scores ont été récemment évalués dans une même étude et n'étaient pas corrélés aux mesures anthropométriques (151). Le dosage de marqueurs de l'inflammation tel le fibrinogène, la CRP, et les indices de nutrition comme l'albumine et la préalbumine pourrait être réalisé pour initier le bilan. Un avis spécialisé semble recommandé pour tous les cas suspects. II faut distinguer les patients avec scolioses d'origine idiopathique généralement ASA 1 ou probablement de simples compléments alimentaires dans le mois précédant la chirurgie suffiraient à pallier le déficit. Le cas des patients avec scoliose d'origine neuromusculaire est nettement plus complexe. Leur dénutrition est généralement déjà diagnostiquée. Leur renutrition reste cependant un challenge à part entière (152). Il a longtemps été présupposé qu'une renutrition mal menée chez ces patients ne permettait que d'augmenter la masse grasse(153). Néanmoins, une étude récente rapporte une augmentation de la protéinémie sans majoration de la masse grasse, mais malheureusement sans reminéralisassions osseuse associée(154). Le rôle des corticoïdes doit également entrer dans la réflexion. Pour conclure, il est rare que l'état de dénutrition soit découvert en consultation d'anesthésie. Une prise en charge multidisciplinaire est primordiale. Le temps nécessaire à une renutrition pré opératoire doit être pris. La décision d'intervention chirurgicale après échec de renutrition doit donc faire l'objet d'une concertation pluridisciplinaire où le rapport bénéfice risque de la chirurgie doit être pesé.

Les points positifs de cette étude est son collectif important, opéré sur une période relativement courte par deux chirurgiens expérimentés, permettant d'évaluer une prise en charge homogène tant sur le plan anesthésique que sur le plan chirurgical. C'est la première étude évaluant l'ensemble de ces techniques d'épargne transfusionnel de manière concomitante à savoir l'EPO en pré opératoire, l'acide tranexamique, la rachi morphine et le 
RSPO. Dans l'étude de Hassane et coll(50)., moins de 30\% des patients au final recevaient de I'EPO en préopératoire. Par ailleurs, le caractère rétrospectif de notre étude ne semble pas être une limite car aucune donnée n'est manquante.

Une des limites est le nombre restreint de patient avec scoliose d'origine neuromusculaire empêchant la recherche des risques transfusionnels propre à cette population.

\section{CONCLUSION}

De cette étude nous retenons comme principaux résultats :

1/Une efficacité de la stratégie d'épargne transfusionnelle dans la catégorie des patients avec scoliose d'origine idiopathique. Une étude de rapport coût bénéfice doit donc être réalisée. Se discute dans cette catégorie de malades de restreindre les stratégies d'épargne transfusionnelle, entre autre en réévaluant l'intérêt du système de RSPO. Des objectifs abaissés d'hémoglobine permettraient également de diminuer le nombre d'injections préopératoire d'EPO et donc de limiter le coût. A contrario, la stratégie semble toujours insuffisante dans la population des patients avec une scoliose d'origine neuromusculaire. La recherche doit donc continuer pour limiter les saignements chez ces patients.

2/Les colloïdes sembleraient être associés à un sur risque transfusionnel. D’autres études sont en attente pour confirmer ce résultat. En raison de l'innocuité des cristalloïdes et leur performance identique, il semblerait donc légitime de recommander leur usage exclusif au décours de la chirurgie de la scoliose pédiatrique.

3/L'indice de masse corporelle est également un facteur indépendant de risque transfusionnel. L'anesthésiste lors de la consultation doit donc veiller à identifier les patients possiblement dénutris. La lecture du carnet de santé et le calcul de l'IMC sont donc indispensables. Un avis spécialisé doit être demandé pour chaque cas suspecté. Un bilan nutritionnel comprenant fibrinogène, $\mathrm{CRP}$, albumine et pré-albumine pourrait être prescrit. Toute une réflexion doit être entamée afin de protocoler le dépistage et la renutrition de ses patients en différenciant les patients avec une scoliose d'origine idiopathique dont une prise en charge par l'anesthésiste pourrait suffire des patients avec scolioses d'origine neuromusculaire pour lesquels un suivi spécialisé est indispensable. Un report de leur chirurgie doit être discuté en réunion de concertation pluridisciplinaire si besoin. 


\section{LEXIQUE}

\begin{tabular}{|c|c|}
\hline ASA & American Society of Anesthesiology \\
\hline ADP & Adenosine Diphosphate \\
\hline AT & Acide Tranexamique \\
\hline BIS & Indice Bispectral \\
\hline CAM & Concentration Alvéolaire Minimale \\
\hline CEERB & Comité d'évaluation de l'éthique des projets de recherche biomédicale \\
\hline CIVD & Coagulation intra vasculaire disséminée \\
\hline CGR & Concentré en globule rouge \\
\hline DDAVP & 1-deamino-8-D-arginine vasopressin \\
\hline EACA & Acide Amino caproique \\
\hline EPO & Erythropoïétine \\
\hline GVH & Graft versus Host \\
\hline FDA & Food and drug association \\
\hline $\mathrm{H}$ & Heure \\
\hline $\mathrm{Hb}$ & Hémoglobine \\
\hline Hte & Hématocrite \\
\hline HEA & Hydroxyl Ethyl Amidon \\
\hline HTAP & Hypertension artérielle pulmonaire \\
\hline IMC & Indice de Masse Corporelle \\
\hline IQS & Interquartile \\
\hline $\mathrm{Kg}$ & Kilogramme \\
\hline ISPOT & International Study group of Peri-Operative Transfusion \\
\hline$\mu g$ & Microgramme \\
\hline $\mathrm{Mg}$ & Milligramme \\
\hline OR & Odd Ratio \\
\hline PCA & Patient Controlled Analgesia (analgésie autocontrôlée par le patient) \\
\hline PFC & Plasma Frai Congelé \\
\hline PSL & Produit sanguin labile \\
\hline ROC & Reiceving Operator Characteristics \\
\hline $\mathrm{RR}$ & Risque Relatf \\
\hline RSPO & Récupérateur Sanguin Per Opératoire \\
\hline SHOT & Serious Hazrd of Transfusion \\
\hline TACO & Transfusion Associated Congestive Overload \\
\hline TAP & Transfusion autologue programmé \\
\hline TCA & Temps de céphaline activé \\
\hline TGF & Tumor Growth Factor \\
\hline TH & Transfusion Homologue \\
\hline TP & Temps prothrombine (temps de quick) \\
\hline $\mathrm{TPa}$ & Tissu Plasminogen Activator \\
\hline TRALI & Transfusion Related Acute Lung Injury \\
\hline TS & Temps de saignement \\
\hline TT & Taux thrombine \\
\hline
\end{tabular}


TCMH Teneur corpusculaire moyenne en hémoglobine

UI Unité Internationale

VST Volume sanguine total 


\section{TABLES ET FIGURES}

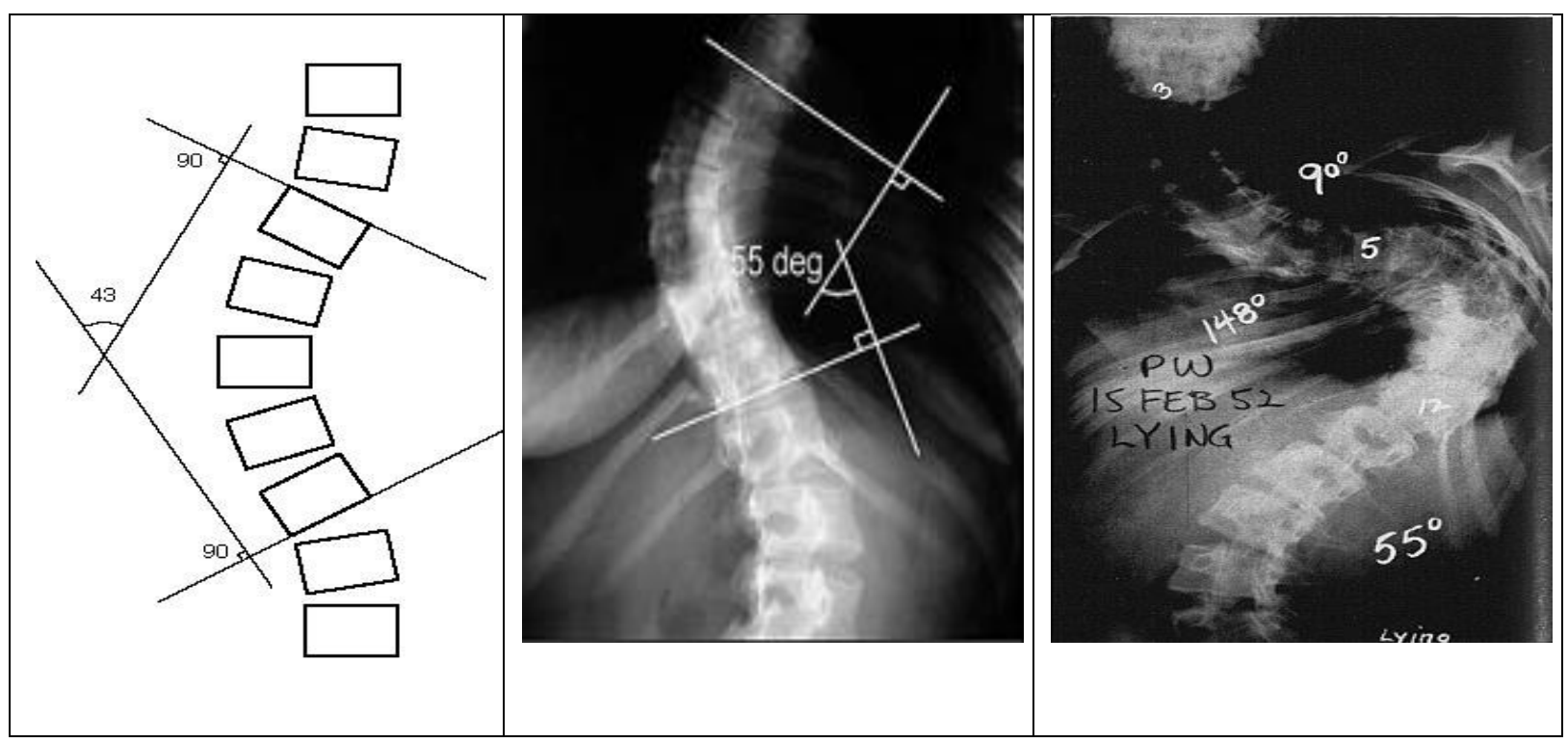

Figure 1: Calcul de l'angle de Cob

Angle exprimé en degrés qui caractérise une courbure formé par une ligne tangente au plateau supérieur de la vertèbre limite supérieure et une ligne tangente au plateau inférieur de la vertèbre limite inférieure.

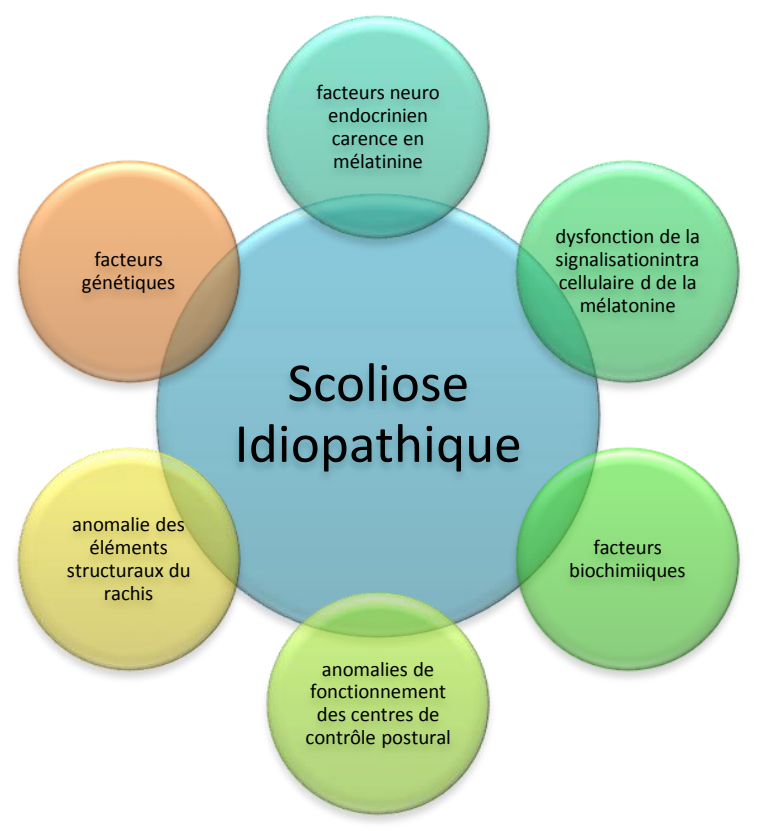

Figure 2: Etiologies de la scoliose idiopathique 

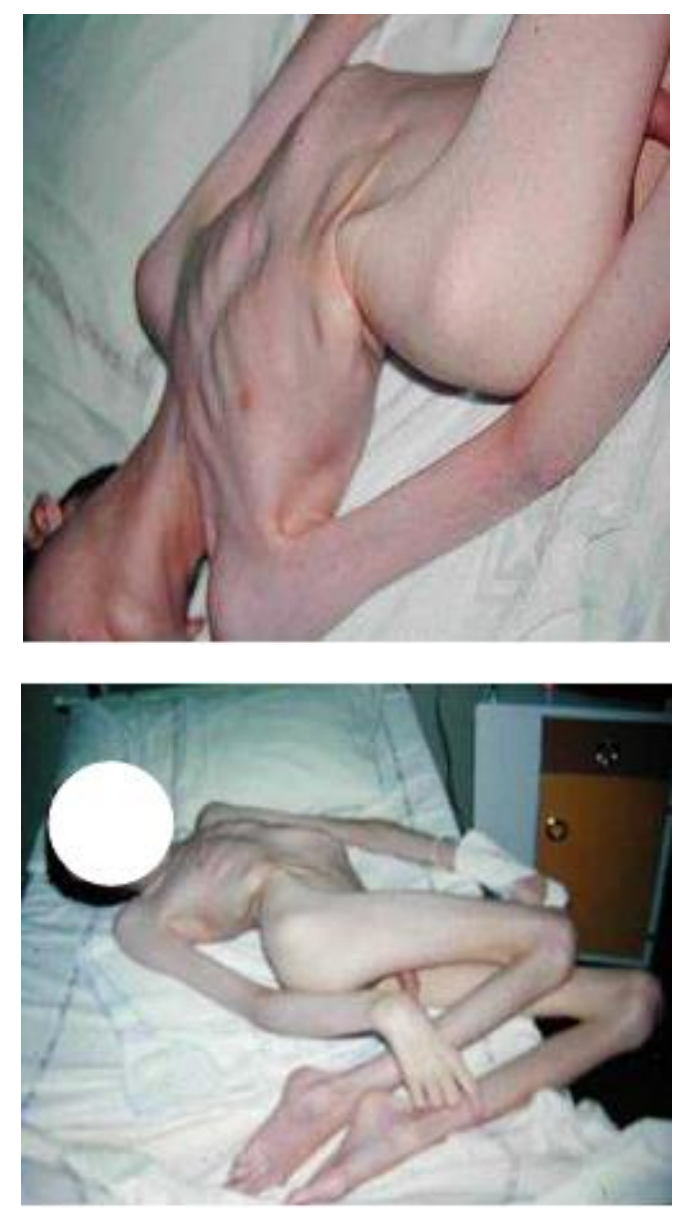

Figure 3: Paralysie cérébrale

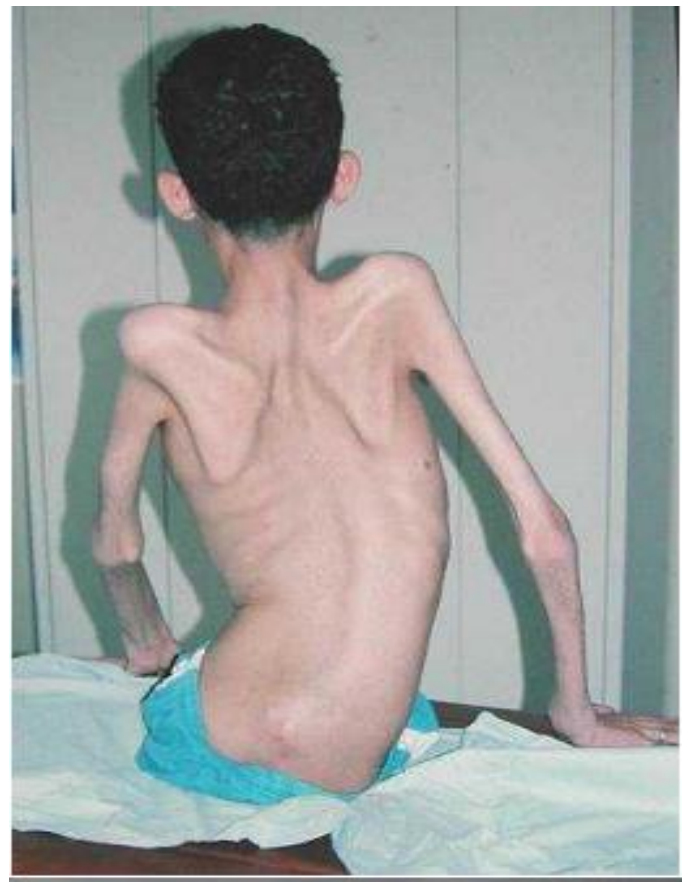

Figure 4: Amyotrophie spinale infantile
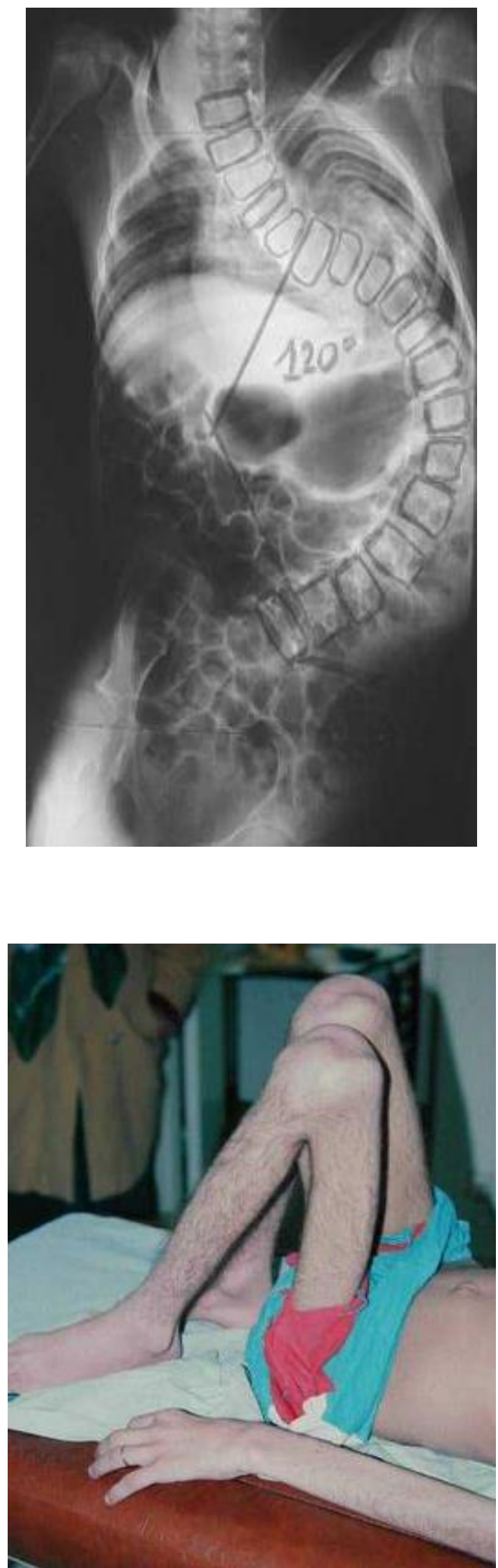

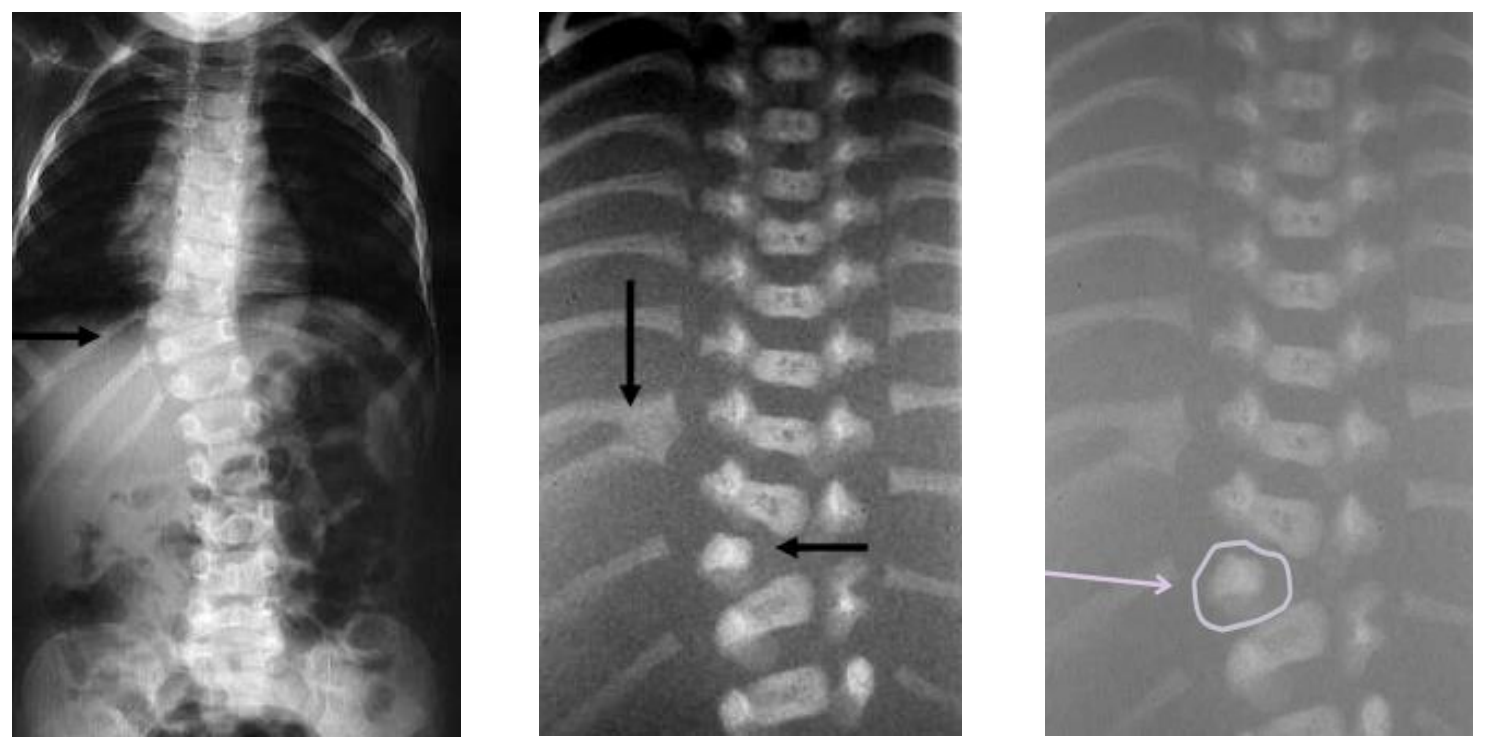

Figure 5: Scoliose congénitale

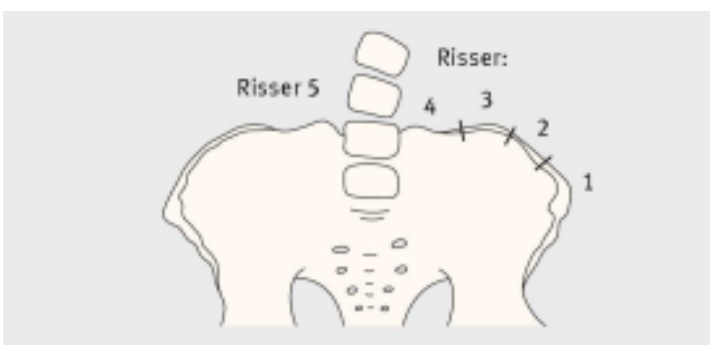

Figure 6: Score de Risser : illustration des 6 stades de Risser permettant d'évaluer l'âge osseux

Test de Risser : indice de maturité osseuse de fin de croissance. Apparition et accolement du cartilage de croissance de la crête iliaque respectivement de dehors en dedans et de dedans en dehors. Risser 0 : absence de cartilage $\Rightarrow$ immaturité : Risser I : cartilage apparu au 1/3 externe ; Risser II : cartilage apparu au 2/3 externes ; Risser III : cartilage apparu sur toute la crête iliaque ; Risser IV : cartilage accolé à la partie interne de la crête iliaque ; Risser V : cartilage complètement accolé à la crête iliaque $\Rightarrow$ maturité = adulte
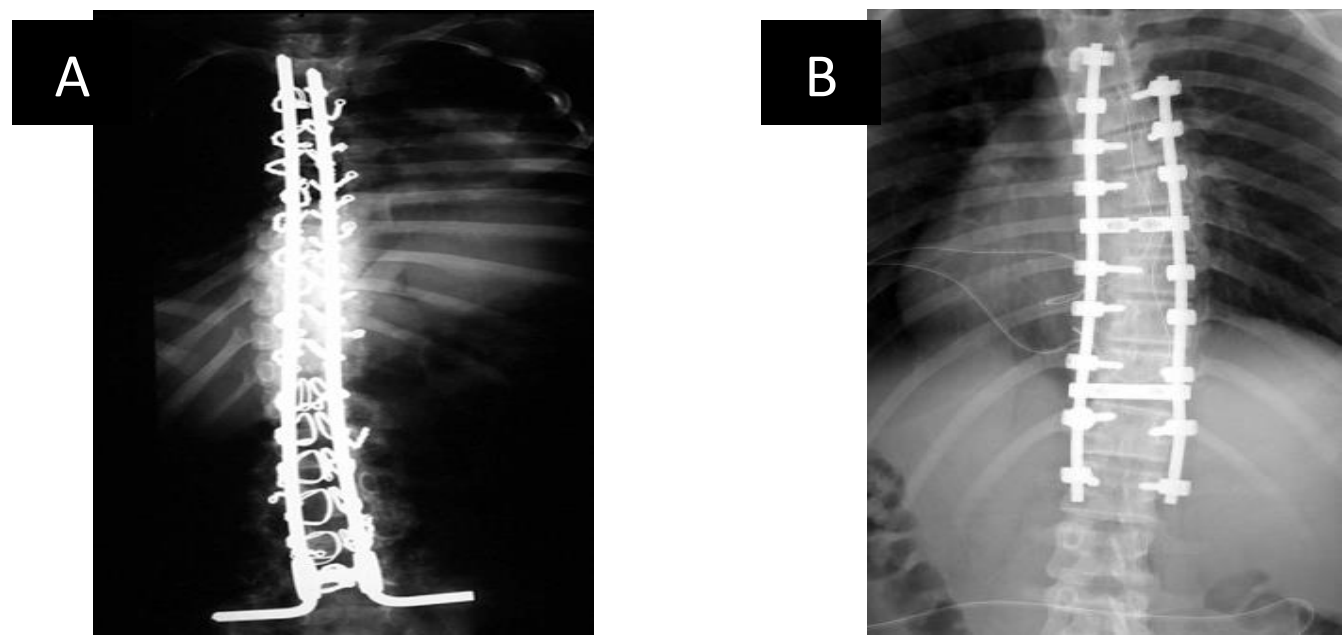

Figure 7: Les techniques d'arthrodèse par voie postérieure: A: Luque et Gavelston; B:Cotrel-Dubousset 
Tableau 1: Etiologies de la scoliose pédiatrique

Idiopathique

(70\% des cas)

Neuromusculaire

(15\% des cas)

\section{Congénitale}

Mésenchymateuse

Anomalie de la

minéralisation osseuse

Tumorale

Traumatique

Infectieuse
Infantile ( $<4$ ans)

$$
\text { Juvenile (entre } 4 \text { et } 10 \text { ans) }
$$$$
\text { De l'adolescent ( }>10 \text { ans) }
$$

Deficit neurologique

Encéphalopathies, pathologies cérébro-

médullaires, syringomyélie, poliomyélite

Myopathique

Dystrophie musculaire, neurofibromatose, ataxie

de Friedrich, amyotrophie spinale

Anomalie de development du cordon spinal ou d'une vertèbre

Arthrite rhumatoïde, syndrome de Marfan

Ostéogénèse imparfaite, ostéoporose, maladie de Paget.

\section{Primaire ou secondaire}

Fracture, radiothérapie, chirurgie

Tuberculose, ostéomyélite

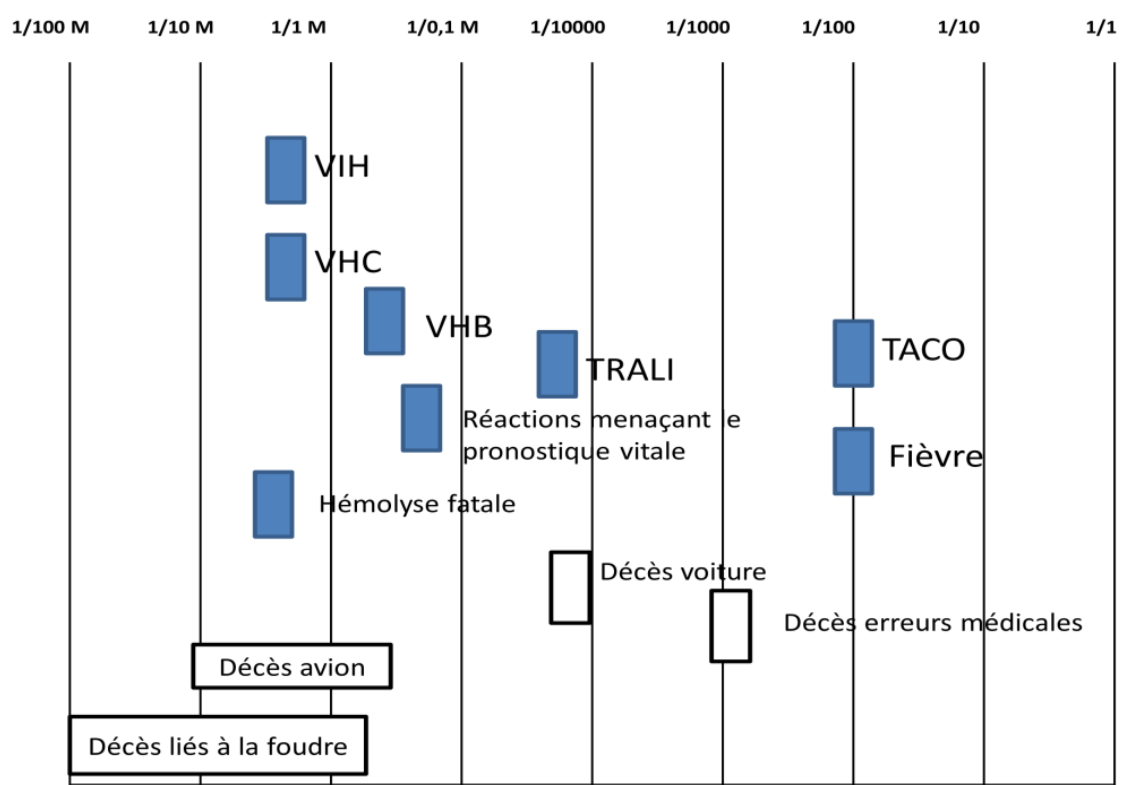

RISQUES TRANSFUSIONNELS EN 2012 (Carson et coll.)

Échelle logarithmique, en bleu: risque pour un concentré globulaire transfusé, en blanc: risque de décès par personne et par évènement; TACO: transfusion-associated circulatory overload; TRALI: transfusion-related acute lung injury;

Figure 8: Risque transfusionnel en 2012 
Tableau 2: Nombre de décès secondaire à la transfusion en 2012 en France au Royaume Uni et aux Etats Unis

Nombre de décès

France $n=13 \quad$ Royaume Uni $n=9 \quad$ Etats Unis $n=38$

(ANSM 2012) ～(SHOT 2012)

(FDA 2012)

\section{Hémolyse post transfusionnelle}

TRALI

Réaction de GVH liée à la transfusion

Anaphylaxie

Infection bactérienne liée à la transfusion

TACO

Autres

$\begin{array}{|lll|}4 & 1 & 8 \\ 1 & - & 17 \\ - & 1 & - \\ - & - & 2 \\ 2 & - & 3 \\ 5 & 6 & 8 \\ 1 & 1 & -\end{array}$

TRALI : transfusion related acute lung injury; TACO : transfusion associated circulatory overload, ANSM : agence nationale de sécuréité du médicament et des produits de santé ; SHOT : Serious Hazard of Transfusion, FDA : food and drug association ;GVH :Graft Versus Host.

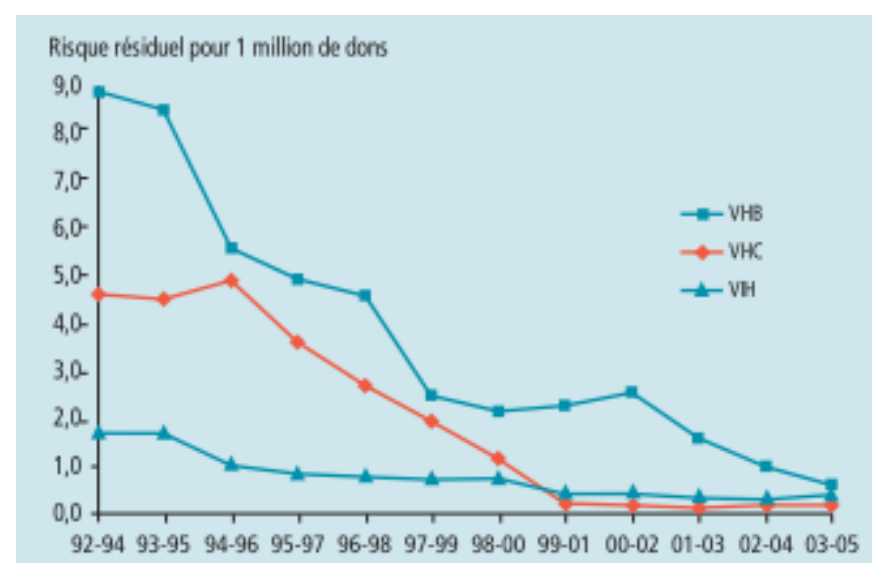

Figure 9: Evolution du risque résiduel de transmission d'infections virales par transfusion entre 1992 et 2005 en France (données de l'institut national de veille sanitaire).

Tableau 3: Effets indésirables liés aux transfusions. Incidence sur la période de 2006-2010

\begin{tabular}{|c|c|c|c|}
\hline Effets indésirables peu sévères & $\begin{array}{l}\text { Incidence pour } \\
100000 \text { PSL }\end{array}$ & Effets indésirables graves & $\begin{array}{l}\text { Incidence pour } \\
100000 \text { PSL }\end{array}$ \\
\hline Allo-immunisation & 62 & \multirow{5}{*}{$\begin{array}{l}\text { Accidents de surcharge } \\
\text { Allergies } \\
\text { TRALI } \\
\text { Incompatibilité immunologique } \\
\text { de type ABO } \\
\text { Infection bactérienne }\end{array}$} & 2,6 \\
\hline Reactions fébriles non-hémolytiques & 51 & & 1,5 \\
\hline Allergies & 47 & & 0,7 \\
\hline \multirow[t]{2}{*}{ Incompatibilité immunologique } & \multirow[t]{2}{*}{9,3} & & 0,4 \\
\hline & & & 0,2 \\
\hline
\end{tabular}




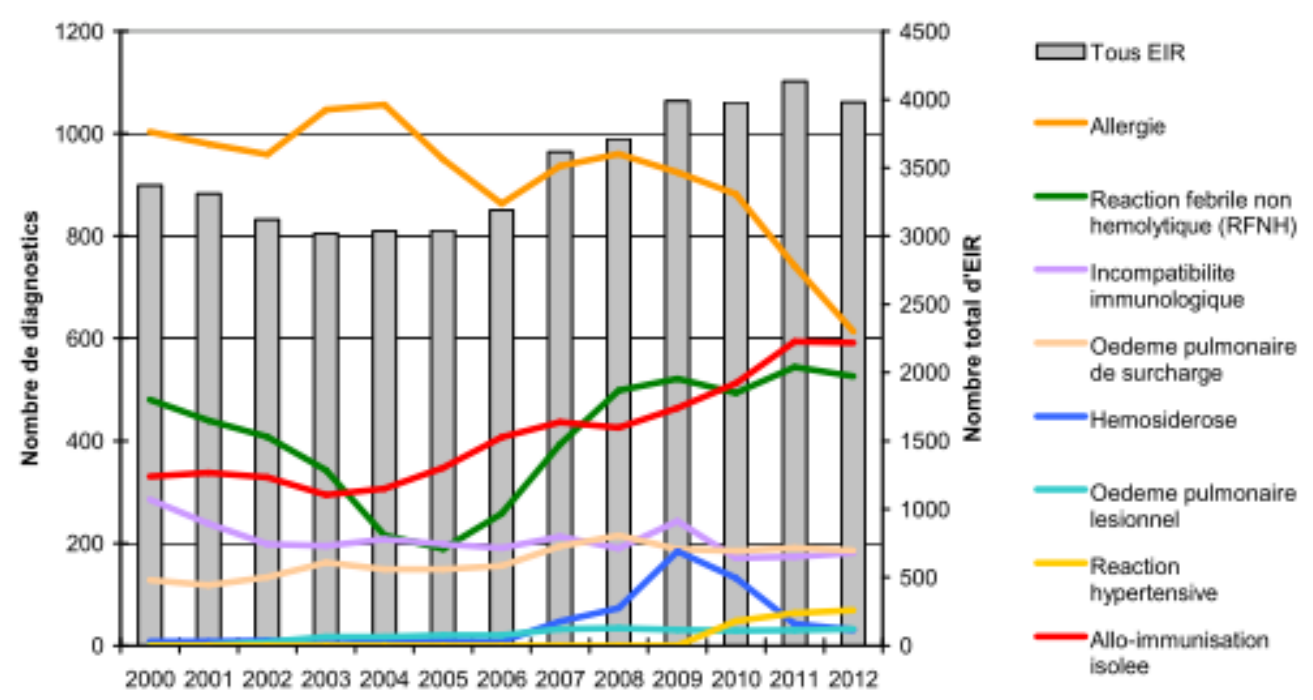

Figure 10:Evolution des principaux effets indésirables chez le receveur de produits sanguins labiles.

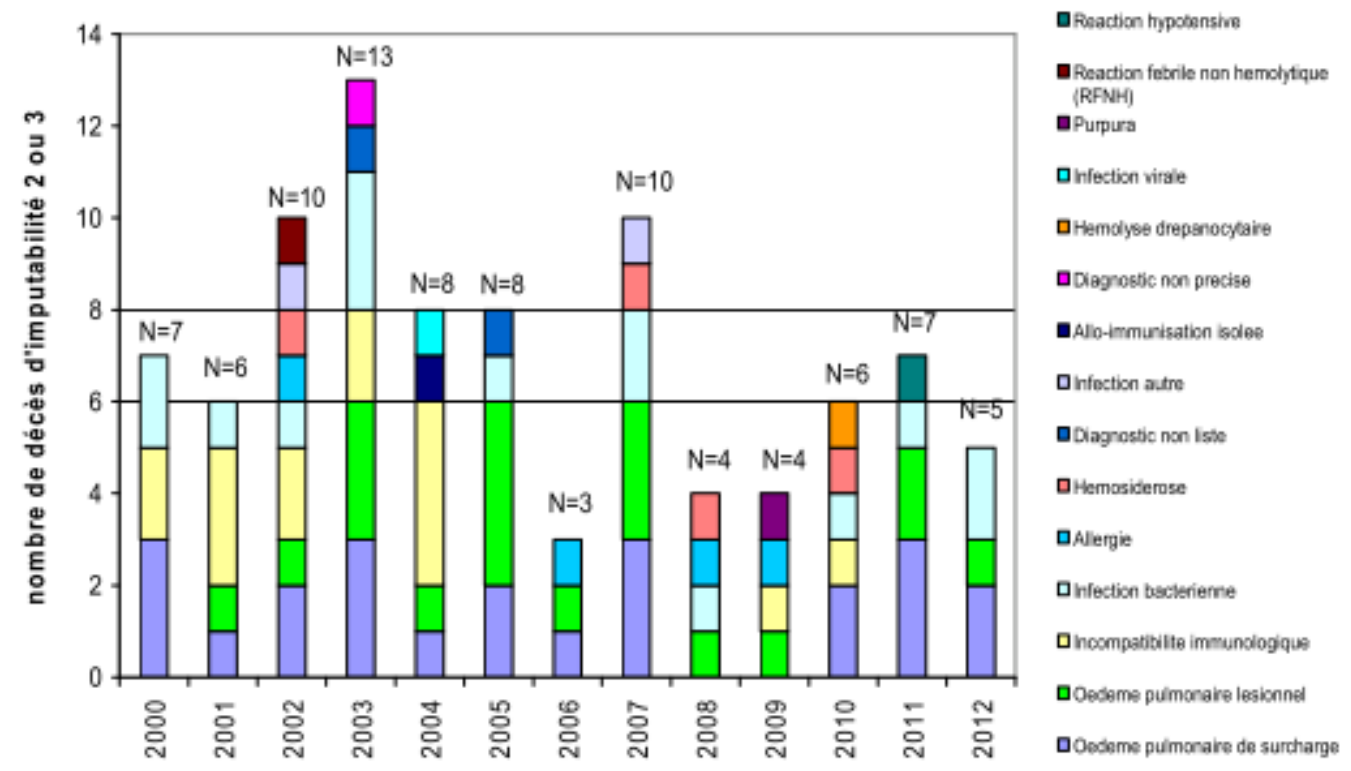

Figure 11: Evolution des causes de décès du receveur de produits sanguins labiles 
Tableau 4: Caractérisques de la population

Caractéristiques de la population $(n=147)$

Moyenne (ET) ou Nombre (\%)

\begin{tabular}{l|l|}
\hline Age (Année) & $15+/-3$ \\
Poids & $50+/-14$ \\
Indice de Masse Corporelle (IMC) & $19+/-4$ \\
Angle de Cobb & $58+/-16$ \\
Type de scoliose & $117(79,6 \%)$ \\
Scoliose idiopathique & $17(11,6 \%)$ \\
Scoliose d'origine neuromusculaire & $8(5,4 \%)$ \\
Scoliose secondaire à une Myopathie & $9(6,1 \%)$ \\
Scoliose secondaire à une Encéphalopathie & $9(6,1 \%)$ \\
Scoliose congénitale & $4(2,7 \%)$ \\
Scoliose post traumatique & $17(11,6 \%) / 37(27,2 \%) / 87$ (63,3 \%) \\
Score ASA 1/2/3 (American Sociaty of Anesthesiology) & $137(93,2 \%)$ \\
EPO (érythropoiétine) & $147(100 \%)$ \\
Acide Tranexamique & $13+/-3$ \\
Nombre d'étage fusionné & $11(7,5 \%)$ \\
Fusion sacrée & $39(26,5 \%)$ \\
Gibbectomie & $227+/-65$ \\
Durée de la chirurgie &
\end{tabular}

Tableau 5: Transfusion et remplissage péri-opératoire

Variables Pré opératoire Post opératoire Péri opératoire

\begin{tabular}{|c|c|c|c|}
\hline $\mathrm{Hb}(\mathrm{g} / \mathrm{dL})$ & $14,6+/-1,3$ & $10,8+/-1,3$ & \\
\hline Cristalloides (mL/kg/h) & $17+/-10$ & - & \\
\hline Colloides (mL/kg) & $10+/-10$ & - & \\
\hline $\mathrm{RSPO}(\mathrm{mL})$ & $129+/-240$ & - & \\
\hline RSPO (N (\%)) & $54(36,5 \%)$ & - & \\
\hline Sang homologue $(\mathrm{mL})$ & $77+/-213$ & $17+/-160$ & $95+/-265$ \\
\hline Sang homologue (\%) & $25(17 \%)$ & $4(2,7)$ & $27(18,4 \%)$ \\
\hline
\end{tabular}


Tableau 6: Résultats de l'analyse univariée des facteurs associés à la transfusion péri opératoire

Variables

Pas de transfusion péri Transfusion péri

opératoire $(n=120)$

opératoire $(n=27)$

$P$ value

\begin{tabular}{|c|c|c|c|}
\hline Age & $15[2-18]$ & $15[12-18]$ & 0.23 \\
\hline Poids & $52[10-96]$ & $40[23-90]$ & $<0.0001$ \\
\hline $\begin{array}{l}\text { IMC (Indice de Masse } \\
\text { Corporelle) }\end{array}$ & $20[10-31]$ & 18 [11 - 31] & 0.002 \\
\hline $\mathrm{IMC}>16$ & 109 (94\%) & $15(57,7 \%)$ & $<0.0001$ \\
\hline Angle de Cobb & $55[26-100]$ & $62[30-120]$ & 0.1 \\
\hline $\begin{array}{c}\text { Score ASA } 3 \text { (American Society } \\
\text { Anesthesiology) }\end{array}$ & $6(5 \%)$ & $11(40,7 \%)$ & $<0.0001$ \\
\hline $\mathrm{Hb}$ pré opératoire $(\mathrm{g} / \mathrm{dL})$ & 15 [10.80 - 16.8] & $14.6[10,2-18]$ & 0.21 \\
\hline scoliose neuromusculaire (17) & $4(3,3 \%)$ & $13(48,1 \%)$ & $<0.0001$ \\
\hline scoliose idiopathique (117) & $106(88,3)$ & $11(40,7 \%)$ & $<0.0001$ \\
\hline Scoliose congénitale (9) & $7(6,6 \%)$ & $2(10 \%)$ & 0.4 \\
\hline Scoliose post traumatique (4) & $4(3,3 \%)$ & $0(0 \%)$ & 0.3 \\
\hline EPO (Erythropoïétine) & $113(94,2 \%)$ & $24(88,9 \%)$ & 0.3 \\
\hline Nombre d'étage fusionné & $13[3-17]$ & $16[11-17]$ & $<0.0001$ \\
\hline Nombre d'étage fusionné > 15 & $5(4.2 \%)$ & $14(51,9 \%)$ & $<0.0001$ \\
\hline Fixation sacrée & $2(1,7 \%)$ & $9(33,3 \%)$ & $<0.0001$ \\
\hline Gibbectomie & $28(23,3 \%)$ & $11(40,7 \%)$ & 0.06 \\
\hline Cristalloides (mL/kg/h) & $15[2,5-90]$ & $17[2,5-40]$ & 0.07 \\
\hline Colloïdes & $59(57,5 \%)$ & $25(92,6 \%)$ & $<0.0001$ \\
\hline Colloides $(\mathrm{mL} / \mathrm{kg})$ & $9[0-34]$ & $16[0-63]$ & $<0.0001$ \\
\hline Durée de la chirurgie (min) & $210[80-330]$ & $285[140-520]$ & $<0.0001$ \\
\hline $\begin{array}{c}\text { Durée de la chirurgie }>255 \\
\qquad \min \end{array}$ & $21(17,5 \%)$ & 17 (63 \%) & $<0.0001$ \\
\hline
\end{tabular}


Tableau 7: Résultats de l'analyse multivariée des facteurs associés à la transfusion péri opératoire

\begin{tabular}{|c|c|c|c|}
\hline Variables & OR & IC 95\% & $P$ value \\
\hline Nombre étage fusionné > 15 & 5.821 & $0.848-39.975$ & 0.073 \\
\hline IMC > 16 (Indice deMasse Corporelle) & 0.144 & $0.024-0.864$ & 0.034 \\
\hline Scoliose neuromusculaire & 11.702 & $1.578-86.756$ & 0,016 \\
\hline Colloides & 15.578 & $1.429-169.846$ & 0.024 \\
\hline Durée de la chirurgie $>255$ min & 7.496 & $2-28.115$ & 0.003 \\
\hline Intercept & 0.039 & & 0.004 \\
\hline
\end{tabular}


Tableau 8: Résumé des études portant sur les différentes techniques d'épargne transfusionnelle en chirurgie de la scoliose pédiatrique.

\begin{tabular}{|c|c|c|c|c|c|c|c|c|c|c|}
\hline Auteur & Année & Intervention & Population & $\begin{array}{l}\text { Stratégie d'épargne } \\
\text { transfusionelle }\end{array}$ & $\begin{array}{l}\text { volume des pertes } \\
\text { sanguines (mL) (moy (et)) }\end{array}$ & $\begin{array}{l}\text { Incidence transfusion } \\
\text { (\% ;mL (moy (et)) }\end{array}$ & $\begin{array}{l}\text { Nombre étage } \\
\text { fusionné }\end{array}$ & $\begin{array}{l}\text { Durée de la } \\
\text { chirurgie (min) }\end{array}$ & $\begin{array}{l}\text { Facteur de } \\
\text { risque de } \\
\text { saignement }\end{array}$ & $\begin{array}{l}\text { Facteur de risque } \\
\text { de transfusion }\end{array}$ \\
\hline Copley (69) & 1999 & Hmd & $861(43 / 43)$ & HypoT, RSPO, TAP & & $79 \%(2 \mathrm{TH}) ; 37 \%(1 \mathrm{TH})$ & $10,2 / 10,7$ & $288 / 256$ & & \\
\hline Bess (102) & 2006 & TAP & $123 \mathrm{I}(104 ; 19)$ & & $\begin{array}{l}900(500) / 905(602) ; \\
\% 23,5(13,4) / 22,6(16,6) ;\end{array}$ & & $8(3,3) / 8(3,4)$ & & & $\begin{array}{l}\text { TAP, Hte pré op ; } \\
\text { NEF }\end{array}$ \\
\hline Vitale (44) & 1998 & EPO & $\begin{array}{l}178(85 \mathrm{i} ; 59 \mathrm{~N} ; 29 \mathrm{C}) \\
(80 / 98)\end{array}$ & & & $\begin{array}{l}\text { I:4\%/23,5\%; } \\
\text { N:55\%/43,6\%; } \\
\text { C:12,5\%/19\% }\end{array}$ & $9,17 / ; 8,89$ & & & $\mathrm{~N}$;Cobb ;NEF \\
\hline Vitale (45) & 2007 & EPO & $61 \mathrm{~N}(35 / 26)$ & RSPO & $919(651) / 866(588)$ & $57 \% / 50 \%$ & $12,1(3,6) / 11,4(4,6)$ & $438(126) / 402(120)$ & & NEF ; Dur C \\
\hline $\begin{array}{l}\text { kobrinsky } \\
\text { (87) }\end{array}$ & 1987 & Desmo & $\begin{array}{l}35(21 \mathrm{l} ; 14 \mathrm{~N}) \\
(17 / 18) \\
\end{array}$ & & $\begin{array}{l}\text { 1134/1681; } \\
\text { V:104/146 }\end{array}$ & Ui : $2,5 / 3,36$ & $11,3(2) / 11,3(1,3)$ & $178 / 177$ & & \\
\hline Guay (88) & 1992 & Desmo & $30 \mathrm{I}(15 / 15)$ & TAP (8nonT ;7T) & $\begin{array}{l}2101(884) / 1975(905) \\
\% 67(28,8) / 57,4(26,5)\end{array}$ & Ui : $3,7(2,1) / 3,5(2,2)$ & $9(1,6) / 9,7(1,3)$ & $222(42) / 246(72)$ & & \\
\hline Letts (89) & 1998 & Desmo & $30 N(16 / 14)$ & & $\begin{array}{l}2615(1214) / 2131(885) ; \\
\text { V:176 (82)/151 (61) }\end{array}$ & Ui: $5 / 4,6$ & $14,1(1,6) / 14,9(0,7)$ & $403 / 382$ & & \\
\hline alanay (155) & 1998 & Desmo & $\begin{array}{l}35(26 \mathrm{I} ; 9 \mathrm{C}) \\
(18 / 22)\end{array}$ & & $950(950) / 975(811)$ & & $12 / 11,5$ & $241 / 202$ & & \\
\hline $\begin{array}{l}\text { Neilipovitz } \\
\text { (46) }\end{array}$ & 2001 & AT & $40(22 / 18)$ & RSPO, НypoT & $2703(1292) / 2453(1526)$ & $1254(542) / 874(790)$ & $15[7-18] / 14[8-17]$ & $414(78) ; 420(90)$ & & \\
\hline Cole (72) & 2003 & AP & $44 \mathrm{~N}(21 / 23)$ & RSPO & $545(311,9) / 929,9(771,7)$ & Ui: $1,1(1) / 2,2(1,7)$ & $14,5(5,8) / 12,2(3,6)$ & $\begin{array}{l}371(128) / 340 \\
(94,7)\end{array}$ & & \\
\hline Sethna (80) & 2005 & AT & $\begin{array}{l}44(22 \mathrm{l} ; 22 \mathrm{~N}) \\
(23 / 21)\end{array}$ & НуроТ/TAP & $\begin{array}{l}\text { 1,230 (535)/2,085 (1,188); } \\
\text { I:1,072 (425)/1,420 (644); } \\
\text { N+C+A:1,408 (605)/2,690 (1,266) }\end{array}$ & $\begin{array}{l}615(460) / 940 \\
(718) ; 60 \% / 71 \% \\
1: 438(308) / 445(209) ; \\
N+C+A: 808(531) / 1391(723)\end{array}$ & $14(9-16) / 13(7-18)$ & $366(108) / 366$ (108) & & \\
\hline Shapiro (81) & 2007 & AT & $56 \mathrm{~N}(20 / 36)$ & НypoT & $\begin{array}{l}3382(1795) / 1944(789) \\
\%: 47(28) / 112(67)\end{array}$ & $512(470) / 955(718)$ & $\begin{array}{l}14,3(13-16) / 14,7 \\
(13-16)\end{array}$ & $446(77) / 459(83)$ & & \\
\hline kasiman (73) & 2008 & AP & $31 \mathrm{~N}(14,17)$ & Нурот & $\begin{array}{l}715 / 2110 \\
\mathrm{~kg}: 23,3 / 60,2\end{array}$ & Ui: $1,25 / 3,16$ & $14,4 / 15,3$ & $314 / 420$ & & \\
\hline $\begin{array}{l}\text { Thompson } \\
\text { (78) }\end{array}$ & 2008 & AAC & $96 \mathrm{~N}(34 / 62)$ & RSPO & $2194(1626) / 1125(715)$ & $\begin{array}{l}88 \% / 69 \% ; \\
1548(962) / 660(589)\end{array}$ & $14(2) / 15(2)$ & \begin{tabular}{|l|}
$337,7(86) / 369$ \\
$(84,3)$ \\
\end{tabular} & & \\
\hline $\begin{array}{l}\text { Dhawale } \\
\text { (79) }\end{array}$ & 2012 & AT,AAC & $84 \mathrm{~N}(40 ; 44)$ & & $\begin{array}{l}1683(1117) / 2684(1712) ; \\
\text { V :100 }(67,4) / 158(98,5) ; \\
\text { kg :47,8 }(29,6) / 87,6(59,9) ; \\
\% 70(40) / 120(80)\end{array}$ & 1346 (1099)/1333 (878) & $16,7(0,7) / 16,7(0,8)$ & $\begin{array}{l}381(95,5) / 372 \\
(108)\end{array}$ & & \\
\hline Kolban (90) & 2006 & FVIIla & $52 ।(26)$ & $\mathrm{Hmd}$ & $\begin{array}{l}1513(610,3) / 1081,4(373,2) ; \\
\% 40,7(16,4) / 30,7(11,2)\end{array}$ & $46 \% / 15,3 \%$ & $11,7(1,2) / 11,8(1,7)$ & $186(36) / 192(48)$ & & \\
\hline Weiss (94) & 2007 & RSPO & $\begin{array}{l}95(71 \mid ; 24 N) \\
(58 / 37)\end{array}$ & & $781[120-4200] / 656[75-3600]$ & & $11[5-17] / 13[7-17]$ & & & \\
\hline Bowen (93) & 2010 & RSPO & $54 \mid(21,33)$ & Нурот & $\mathrm{kg}: 27,6(18,3) / 13,2(6,5)$ & $55 \% / 6 \%$ & & $383(80,4) / 346(53)$ & & $\begin{array}{l}\text { Dur C;RSPO ; } \\
\text { pertes sg }\end{array}$ \\
\hline
\end{tabular}




\begin{tabular}{|c|c|c|c|c|c|c|c|c|c|c|}
\hline $\begin{array}{l}\text { Eschertzuber } \\
(40)\end{array}$ & 2008 & RM & $421(14 / 14 / 14)$ & RSPO & $41,4(18,8) / 37,5(6,9) / 76,9(15,3)$ & & & & & \\
\hline Lesniak (39) & 2013 & RM & $256 I(126 / 126)$ & & $\begin{array}{l}1793(964) / 655,8(323) \\
\mathrm{kg}: 34,2(20,1) / 12,8(6,4)\end{array}$ & $\begin{array}{l}96 \% / 23,8 \% \\
701.4(492.5) / 293.7(170.9) \\
\end{array}$ & $13.1(0.9) /: 12.6(0.8)$ & $222(36) / 216(30)$ & & \\
\hline Guay (47) & 1994 & & $290(1421 ; 98 \mathrm{~N} ; 49 \mathrm{C})$ & EPO & & $21,30 \%$ & 10,5 & & & EPO;N ;sacrum \\
\hline Vitale (49) & 2002 & & $25(11 \mathrm{~N} ; 14 \mathrm{I})$ & $\operatorname{TAP}(3 \mathrm{I})$ & $\%$ : N49 (25-111)//20 (2-52) & $\begin{array}{l}\text { N 100\%// 5,8\%; } \\
\text { Kg N 16.3 (3.2-55.4) } \\
\text { I } 0 \text { (0-10.8) }\end{array}$ & & $\begin{array}{l}\text { N16 (9-17)/ } \\
\text { I11 (4-14) }\end{array}$ & & \\
\hline $\begin{array}{l}\text { Kannan } \\
(126)\end{array}$ & 2002 & & $163(18 \mathrm{~N}, \mathrm{I}+\mathrm{C}+\mathrm{A} 145)$ & & & & $\mathrm{N}: 12(3) / 1+\mathrm{C}+\mathrm{A}: 9(3)$ & & $\mathrm{N}$ & \\
\hline Meert ((48) & 2002 & & 301 & Hmd, TAP ( (22) & $\begin{array}{l}\text { 1971( (831); } \\
\%: 61.5((27,6)\end{array}$ & $\begin{array}{l}59 \% \\
1481((787) \\
\end{array}$ & $9,3((1,4)$ & $246((36)$ & $\begin{array}{l}\text { Dur C ; } \\
\text { NEF }\end{array}$ & \\
\hline Edler (124) & 2003 & & $14 \mathrm{I}, 15 \mathrm{Nsp} ; 15 \mathrm{Npa}$ & RSPO & $1523 / 2667 / 3446$ & & $12,1 / 15 / 15,6$ & $162,4 / 215 / 217,4$ & & \\
\hline Modi (42) & 2010 & & $107(53 \mathrm{I}, 35 \mathrm{~N}, 19 \mathrm{~A})$ & $\begin{array}{l}\text { TAP,Hmd, } \\
\text { RSPO,HypoT }\end{array}$ & $\mathrm{kg}: 22(4-72)$ & $\begin{array}{l}63(59) ; \\
\text { Kg: } 17(3-65) ; 1: 0(0-43) ; \\
\text { N:22 (0-65) }\end{array}$ & $13(4-20)$ & $456(180-864)$ & & $\mathrm{N} ; \mathrm{Pds} ; \mathrm{NEF}$ \\
\hline Hassan (50) & 2011 & & $110(28 \mathrm{~N} ; 60 \mathrm{l} ; 18 \mathrm{~A})$ & AT,RSPO,EPO & $\begin{array}{l}\text { I:833 (462)/N :1523 (1144); } \\
\text { par kg: I16 (9)/N39 (39) }\end{array}$ & $\begin{array}{l}14,2 \% ; \mathrm{N}: 36 \% ; \\
\mathrm{I}: 1,7 \% ; \mathrm{A}: 22 \%\end{array}$ & $10(3) / 15(2)$ & $301(90) / 348(79)$ & & $\begin{array}{l}\text { pertes sg,NEF; } \\
\text { Pds,âge }\end{array}$ \\
\hline
\end{tabular}




\section{BIBLIOGRAPHIE}

1. Bird S, McGill N. Blood conservation and pain control in scoliosis corrective surgery: an online survey of UK practice: Blood conservation and pain control in scoliosis corrective surgery. Pediatr Anesth. 2011 Jan;21(1):50-3. Disponible sur: http://doi.wiley.com/10.1111/j.1460-9592.2010.03443.x. Consulté le : 2013-12-14 21:18:22

2. Kafer ER. Respiratory and cardiovascular functions in scoliosis and the principles of anesthetic management. Anesthesiology. 1980 Apr;52(4):339-51.Disponible sur: http://pubs.asahq.org/article.aspx?volume=52\&page=339. Consulté le mardi 4 novembre 2014, 12:02:14

3. Weinstein SL, Dolan LA, Cheng JCY, Danielsson A, Morcuende JA. Adolescent idiopathic scoliosis. Lancet. 2008 May 3;371(9623):1527-37.Disponible sur: http://www.thelancet.com/pdfs/journals/lancet/PIIS0140-6736(08)60658-3.pdf. Consulté le 4 novembre 2014, 12:02:08

4. Weiss H-R, Negrini S, Rigo M, Kotwicki T, Hawes MC, Grivas TB, et al. Indications for conservative management of scoliosis (guidelines). Scoliosis. 2006 May 8;1:5. Disponible sur: http://www.ncbi.nIm.nih.gov/pmc/articles/PMC1479370/.Consulté le 2014-06-10 23:41:37

5. Kesling KL, Reinker KA. Scoliosis in twins. A meta-analysis of the literature and report of six cases. Spine. 1997 Sep 1;22(17):2009-14; discussion 2015. Disponible sur: http://journals.Iww.com/spinejournal/pages/articleviewer.aspx?year=1997\&issue=09 010\&article=00014\&type=abstract. Consulté le 11/06/2014

6. Ogura Y, Takahashi Y, Kou I, Nakajima M, Kono K, Kawakami N, et al. A replication study for association of 53 single nucleotide polymorphisms in a scoliosis prognostic test with progression of adolescent idiopathic scoliosis in Japanese. Spine. $2013 \mathrm{Jul}$ 15;38(16):1375-9. Disponible sur: http://journals.Iww.com/spinejournal/pages/articleviewer.aspx?year=2013\&issue=07 $150 \&$ article $=00009 \&$ type $=$ abstract. Consulté le 04/08/2014

7. McGregor TL, Gurnett CA, Dobbs MB, Wise CA, Morcuende JA, Morgan TM, et al. Common polymorphisms in human lysyl oxidase genes are not associated with the adolescent idiopathic scoliosis phenotype. BMC Med Genet. 2011 Jul 8;12:92. Disponible sur: http://www.ncbi.nlm.nih.gov/pmc/articles/PMC3154146/. Consulté le 04/08/2014

8. Ryzhkov II, Borzilov EE, Churnosov MI, Ataman AV, Dedkov AA, Polonikov AV. Transforming Growth Factor Beta 1 is a Novel Susceptibility Gene for Adolescent Idiopathic Scoliosis. Spine. 2013 Feb 26; Disponible sur: http://journals.Iww.com/spinejournal/pages/articleviewer.aspx?year=2013\&issue=05 200\&article $=00014 \&$ type=abstract. Consulté le 04/08/2014 
9. Zhang H-Q, Lu S-J, Tang M-X, Chen L-Q, Liu S-H, Guo C-F, et al. Association of estrogen receptor beta gene polymorphisms with susceptibility to adolescent idiopathic scoliosis. Spine. 2009 Apr 15;34(8):760-4. Disponible sur:

http://journals.Iww.com/spinejournal/pages/articleviewer.aspx?year=2009\&issue=04 150\&article $=00003 \&$ type $=$ abstract. Consulté le 04/08/2014

10. Esposito T, Uccello R, Caliendo R, Di Martino GF, Gironi Carnevale UA, Cuomo S, et al. Estrogen receptor polymorphism, estrogen content and idiopathic scoliosis in human: a possible genetic linkage. J Steroid Biochem Mol Biol. 2009 Aug;116(1-2):56-60.

Disponible sur: http://www.sciencedirect.com/science/article/pii/S0960076009001393. Consulté le 04/08/2014

11. Kou I, Takahashi Y, Johnson TA, Takahashi A, Guo L, Dai J, et al. Genetic variants in GPR126 are associated with adolescent idiopathic scoliosis. Nat Genet. 2013 Jun;45(6):676-9. Disponible sur: http://www.nature.com/ng/journal/v45/n6/full/ng.2639.html. Consulté le $29 / 06 / 2014$

12. Takahashi Y, Kou I, Takahashi A, Johnson TA, Kono K, Kawakami N, et al. A genomewide association study identifies common variants near LBX1 associated with adolescent idiopathic scoliosis. Nat Genet. 2011 Dec;43(12):1237-40. Disponible sur: http://www.nature.com/ng/journal/v43/n12/full/ng.974.html. Consulté le $29 / 06 / 2014$

13. Miyake A, Kou I, Takahashi Y, Johnson TA, Ogura Y, Dai J, et al. Identification of a susceptibility locus for severe adolescent idiopathic scoliosis on chromosome 17q24.3. PloS One. 2013;8(9):e72802. Disponible sur:

http://journals.plos.org/plosone/article?id=10.1371/journal. pone.0072802. Consulté le $04 / 08 / 2014$

14. Poon AMS, Cheung KMC, Lu DS, Leong JCY. Changes in melatonin receptors in relation to the development of scoliosis in pinealectomized chickens. Spine. 2006 Aug 15;31(18):2043-7. Disponible sur:

http://journals.Iww.com/spinejournal/pages/articleviewer.aspx?year=2006\&issue=08 $150 \&$ article=00005\&type=abstract. Consulté le 11/06/2014

15. Beuerlein M, Wilson J, Moreau M, Raso VJ, Mahood J, Wang X, et al. The critical stage of pinealectomy surgery after which scoliosis is produced in young chickens. Spine. 2001 Feb 1;26(3):237-40. Disponible sur:

http://journals.Iww.com/spinejournal/pages/articleviewer.aspx?year=2001\&issue=02 010\&article $=00007 \&$ type=abstract. Consulté le 11/06/2014.

16. Hensinger RN. Congenital scoliosis: etiology and associations. Spine. 2009 Aug 1;34(17):1745-50. Disponible sur:

http://journals.lww.com/spinejournal/pages/articleviewer. aspx?year=2009\&issue=08 010\&article $=00003 \&$ type $=$ abstract. Consulté le 11/06/2014 
17. McMaster MJ, Ohtsuka K. The natural history of congenital scoliosis. A study of two hundred and fifty-one patients. J Bone Joint Surg Am. 1982 Oct;64(8):1128-47. Disponible sur: http://jbjs.org/content/64/8/1128.long. Consulté le 11/06/2014

18. Campbell RM. Spine deformities in rare congenital syndromes: clinical issues. Spine. 2009 Aug 1;34(17):1815-27. Disponible sur: http://journals.Iww.com/spinejournal/pages/articleviewer.aspx?year=2009\&issue=08 010\&article $=00012 \&$ type $=$ abstract. Consulté le 04/08/2014

19. Weinstein SL, Ponseti IV. Curve progression in idiopathic scoliosis. J Bone Joint Surg Am. 1983 Apr;65(4):447-55. Disponible sur: http://www.jbjs.org/cgi/pmidlookup?view=long\&pmid=6833318. Consulté le $11 / 06 / 2014$

20. Risser JC. The Iliac apophysis; an invaluable sign in the management of scoliosis. Clin Orthop. 1958;11:111-9.Disponible sur: http://www.ncbi.nlm.nih.gov/pubmed/13561591. Consulté le 04/08/2014

21. Lonstein JE, Carlson JM. The prediction of curve progression in untreated idiopathic scoliosis during growth. J Bone Joint Surg Am. 1984 Sep;66(7):1061-71. Disponible sur: http://www.jbjs.org/cgi/pmidlookup?view=long\&pmid=6480635. Consulté le $11 / 06 / 2014$

22. Weinstein SL, Dolan LA, Spratt KF, Peterson KK, Spoonamore MJ, Ponseti IV. Health and function of patients with untreated idiopathic scoliosis: a 50-year natural history study. JAMA J Am Med Assoc. 2003 Feb 5;289(5):559-67. Disponible sur http://jama.jamanetwork.com/article.aspx?articleid=195893. Consulté le 11/06/2014

23. Ramirez N, Johnston $\mathrm{CE}$, Browne $\mathrm{RH}$. The prevalence of back pain in children who have idiopathic scoliosis. J Bone Joint Surg Am. 1997 Mar;79(3):364-8. Disponible sur: http://jama.jamanetwork.com/article.aspx?articleid=195893. Consulté le 04/08/2014

24. Nachemson A. A long term follow-up study of non-treated scoliosis. Acta Orthop Scand. 1968;39(4):466-76. Disponible sur: http://www.ncbi.nlm.nih.gov/pubmed/5726117. Consulté le 11/06/2014

25. Barsdorf Al, Sproule DM, Kaufmann P. Scoliosis surgery in children with neuromuscular disease: findings from the US National Inpatient Sample, 1997 to 2003. Arch Neurol. 2010 Feb;67(2):231-5.Disponible sur: http://archneur.jamanetwork.com/article.aspx?articleid=799324. Consulté le $11 / 05 / 2014$

26. Rowe DE, Bernstein SM, Riddick MF, Adler F, Emans JB, Gardner-Bonneau D. A metaanalysis of the efficacy of non-operative treatments for idiopathic scoliosis. J Bone Joint Surg Am. 1997 May;79(5):664-74. Disponible sur: http://www.jbjs.org/cgi/pmidlookup?view=long\&pmid=9160938. Consulté le $11 / 06 / 2014$ 
27. Nachemson AL, Peterson LE. Effectiveness of treatment with a brace in girls who have adolescent idiopathic scoliosis. A prospective, controlled study based on data from the Brace Study of the Scoliosis Research Society. J Bone Joint Surg Am. 1995 Jun;77(6):815-22. Disponible sur: http://www.jbjs.org/cgi/pmidlookup?view=long\&pmid=7782353. Consulté le 04/08/2014

28. Noonan KJ, Weinstein SL, Jacobson WC, Dolan LA. Use of the Milwaukee brace for progressive idiopathic scoliosis. J Bone Joint Surg Am. 1996 Apr;78(4):557-67. Disponible sur: http://www.jbjs.org/cgi/pmidlookup?view=long\&pmid=8609134. Consulté le 04/08/2014

29. Weinstein SL, Dolan LA, Wright JG, Dobbs MB. Effects of bracing in adolescents with idiopathic scoliosis. N Engl J Med. 2013 Oct 17;369(16):1512-21. Disponible sur http://www.nejm.org/doi/pdf/10.1056/NEJMoa1307337. Consulté le 04/08/2014

30. Weiss H-R. Is there a body of evidence for the treatment of patients with Adolescent Idiopathic Scoliosis (AIS)? Scoliosis. 2007 Dec 31;2:19. Disponible sur: http://www.ncbi.nlm.nih.gov/pmc/articles/PMC2266701/. Consulté le 11/06/2014

31. Cotrel $Y$, Dubousset J. A new technic for segmental spinal osteosynthesis using the posterior approach. Orthop Traumatol Surg Res OTSR. 2014 Feb;100(1):37-41. Disponible sur: http://www.sciencedirect.com/science/article/pii/S1877056813002946. Consulté le 04/08/2014.

32. Thomas DV. Anesthesia in operations for scoliosis. Anesth Analg. 1957 Jun;36(3):34-7. Disponible sur: http://journals.Iww.com/anesthesiaanalgesia/Citation/1957/05000/Anesthesia_IN_OPERATIONS_FOR_SCOLIOSIS_.5.aspx. Consulté le 25/06/2014

33. Shapiro G, Green DW, Fatica NS, Boachie-Adjei O. Medical complications in scoliosis surgery. Curr Opin Pediatr. 2001 Feb;13(1):36-41. Disponible sur: http://journals.Iww.com/copediatrics/pages/articleviewer .aspx ?year=2001\&issue=02000\&article=00006\&type=a bstract. Consulté le 14/05/2014

34. Reames DL, Smith JS, Fu K-MG, Polly DW Jr, Ames CP, Berven SH, et al. Complications in the surgical treatment of 19,360 cases of pediatric scoliosis: a review of the Scoliosis Research Society Morbidity and Mortality database. Spine. 2011 Aug 15;36(18):148491. Disponible sur:

http://journals.lww.com/spinejournal/pages/articleviewer.aspx?year=2011\&issue=08 $150 \&$ article $=00010 \&$ type $=$ abstract. Consulté le 11/06/20147

35. Bernard JM, Péréon $Y$, Fayet G, Guihéneuc P. Effects of isoflurane and desflurane on neurogenic motor- and somatosensory-evoked potential monitoring for scoliosis surgery. Anesthesiology. 1996 Nov;85(5):1013-9. Disponible sur: http://pubs.asahq.org/article.aspx?volume=85\&page=1013. Consulté le 25/06/2014 
36. Gall O, Aubineau JV, Bernière J, Desjeux L, Murat I. Analgesic effect of low-dose intrathecal morphine after spinal fusion in children. Anesthesiology. 2001 Mar;94(3):447-52. Disponible sur:

http://pubs.asahq.org/article.aspx?volume=94\&page=447. Consulté le 21/04/2014

37. Bianconi M, Ferraro L, Ricci R, Zanoli G, Antonelli T, Giulia B, et al. The Pharmacokinetics and Efficacy of Ropivacaine Continuous Wound Instillation After Spine Fusion Surgery: Anesth Analg. 2004 Jan;166-72. Disponible sur : http://content.wkhealth.com/linkback/openurl?sid=WKPTLP:landingpage\&an $=000005$ 39-200401000-00044. Consulté le 25/06/2014

38. Blumenthal S 2005 Double Epidural Catheter with Ropivacaineversus.pdf. Disponible sur: http://pubs.asahq.org/article.aspx?volume=102\&page=175. Consulté le 25/06/2014

39. Lesniak AB, Tremblay $P$, Dalens BJ, Aucoin M, Mercier P. Intrathecal morphine reduces blood loss during idiopathic scoliosis surgery: retrospective study of 256 pediatric cases. Bosenberg A, editor. Pediatr Anesth. 2013 Mar;23(3):265-70. Disponible sur: http://doi.wiley.com/10.1111/pan.12096. Consulté le 14/12/2013

40. Eschertzhuber S, Hohlrieder M, Keller C, Oswald E, Kuehbacher G, Innerhofer P. Comparison of high- and low-dose intrathecal morphine for spinal fusion in children. Br J Anaesth. 2008 Apr;100(4):538-43. Disponible sur : http://bja.oxfordjournals.org/content/100/4/538.full.pdf+html. Consulté le 09/03/2015.

41. Shapiro F, Sethna N. Blood loss in pediatric spine surgery. Eur Spine J. 2004 Aug 13;13(S01):S6-17. Disponible sur: http://link.springer.com/10.1007/s00586-004-0760y. Consulté le 2013-12-14 21:18:28

42. Modi HN, Suh S-W, Hong J-Y, Song S-H, Yang J-H. Intraoperative blood loss during different stages of scoliosis surgery: A prospective study. Scoliosis. 2010;5(1):16. Disponible sur: http://www.biomedcentral.com/content/pdf/1748-7161-5-16.pdf. Consulté le 2013-12-14 21:18:49

43. Dorsey AT, Schwartz RE, Stayer SA, Pasquariello CA. Scoliosis Surgery Determinants of Blood Loss. Anesth Analg. 1993;76(3):684-684. Disponible sur:

http://journals.Iww.com/anesthesiaanalgesia/Citation/1993/03000/Scoliosis_Surgery_.78.aspx. Consulté le 25/06/2014

44. Vitale MG, Stazzone EJ, Gelijns AC, Moskowitz AJ, Roye DP Jr. The effectiveness of preoperative erythropoietin in averting allogenic blood transfusion among children undergoing scoliosis surgery. J Pediatr Orthop Part B. 1998 Jul;7(3):203-9. Disponible sur: http://www.ncbi.nlm.nih.gov/pubmed/9702670. Consulté le 20/04/2014

45. Vitale MG, Roye BD, Ruchelsman DE, Roye DP. Preoperative use of recombinant human erythropoietin in pediatric orthopedics: a decision model for long-term outcomes. Spine J. 2007 May;7(3):292-300. Disponible sur: 
http://linkinghub.elsevier.com/retrieve/pii/S1529943006002312. Consulté le 2013-1214 21:19:13

46. Neilipovitz DT, Murto K, Hall L, Barrowman NJ, Splinter WM. A randomized trial of tranexamic acid to reduce blood transfusion for scoliosis surgery. Anesth Analg. 2001;93(1):82-7. disponible sur: http://journals.Iww.com/anesthesiaanalgesia/pages/articleviewer .aspx ?year $=2001 \&$ issue $=07000 \&$ article $=00018 \&$ type $=a b$ stract. Consulté le 14/12/2013

47. Guay J, Haig M, Lortie L, Guertin MC, Poitras B. Predicting blood loss in surgery for idiopathic scoliosis. Can J Anaesth J Can Anesth. 1994 Sep;41(9):775-81. Disponible sur :

http://download.springer.com/static/pdf/307/art\%253A10.1007\%252FBF03011583.p df?auth66=1425895646_2ac53e18b2519774de4f54122ff22cbb\&ext=.pdf. Consulté le $09 / 03 / 2014$

48. Meert KL, Kannan S, Mooney JF. Predictors of red cell transfusion in children and adolescents undergoing spinal fusion surgery. Spine. 2002 Oct 1;27(19):2137-42. Disponible sur :

http://journals.Iww.com/spinejournal/pages/articleviewer.aspx?year=2002\&issue=10 010\&article=00012\&type=abstract. Consulté le 19/04/2014

49. Vitale MG, Levy DE, Park MC, Choi H, Choe JC, Roye Jr DP. Quantifying risk of transfusion in children undergoing spine surgery. Spine J. 2002;2(3):166-72. Disponible sur :

http://www.sciencedirect.com/science/article/pii/S1529943002001742.Consulté le 2013-12-14 21:19:16

50. Hassan N, Halanski M, Wincek J, Reischman D, Sanfilippo D, Rajasekaran S, et al. Blood management in pediatric spinal deformity surgery: review of a 2-year experience: BLOOD MANAGEMENT IN PEDIATRIC SPINAL FUSION. Transfusion (Paris). 2011 Oct;51(10):2133-41. Disponible sur : http://doi.wiley.com/10.1111/j.15372995.2011.03175.x. Consulté le 2013-12-14 21:18:31

51. Musallam KM, Tamim HM, Richards T, Spahn DR, Rosendaal FR, Habbal A, et al. Preoperative anaemia and postoperative outcomes in non-cardiac surgery: a retrospective cohort study. Lancet. 2011 Oct 15;378(9800):1396-407. Disponible sur : http://www.thelancet.com/pdfs/journals/lancet/PIIS0140-6736(11)61381-0.pdf. Consulté le 05/08/2014

52. Beattie WS, Karkouti K, Wijeysundera DN, Tait G. Risk associated with preoperative anemia in noncardiac surgery: a single-center cohort study. Anesthesiology. 2009 Mar;110(3):574-81. Disponible sur : http://anesthesiology.pubs.asahq.org/article.aspx?articleid=1923874. Consulté le 05/08/2014

53. Nuttall GA, Horlocker TT, Santrach PJ, Oliver Jr WC, Dekutoski MB, Bryant S. Predictors of blood transfusions in spinal instrumentation and fusion surgery. Spine. 2000;25(5):596-601. Disponible sur : 
http://journals.Iww.com/spinejournal/pages/articleviewer.aspx?year=2000\&issue=03 010\&article $=00010 \&$ type $=$ abstract. Consulté le 06/11/2014

54. Lavoie J. Blood transfusion risks and alternative strategies in pediatric patients:

Pediatric transfusion risks and alternatives. Pediatr Anesth. 2011 Jan;21(1):14-24.

Disponible sur: http://doi.wiley.com/10.1111/j.1460-9592.2010.03470.x. Consulté le 2013-12-14 21:18:34

55. InVS. Bulletin épidémiologique hebdomadaire [Internet]. 2006. Disponible sur: http://www.invs.sante.fr/beh/2006/51_52/beh_51_52_2006.pdf. Consulté le 05/08/2014

56. Royal College of Pathologists. Annual Report 2009 [Internet]. 2009. Disponible sur: http://www.shotuk.org/wp-content/uploads/2010/07/SHOT2009.pdf. Consulté le 05/08/2014

57. Slappendel R, Dirksen R, Weber EWG, van der Schaaf DB. An algorithm to reduce allogenic red blood cell transfusions for major orthopedic surgery. Acta Orthop Scand. 2003 Oct;74(5):569-75. Disponible sur : http://informahealthcare.com/doi/pdf/10.1080/00016470310017974. Consulté le $11 / 06 / 2003$

58. Carson JL, Grossman BJ, Kleinman S, Tinmouth AT, Marques MB, Fung MK, et al. Red blood cell transfusion: a clinical practice guideline from the AABB*. Ann Intern Med. 2012 Jul 3;157(1):49-58. Disponible sur :

http://annals.org/article.aspx?articleid=1206681. Consulté le 13/07/2014

59. Li G, Rachmale S, Kojicic M, Shahjehan K, Malinchoc M, Kor DJ, et al. Incidence and transfusion risk factors for transfusion-associated circulatory overload among medical intensive care unit patients. Transfusion (Paris). 2011 Feb;51(2):338-43. Disponible sur : http://onlinelibrary.wiley.com/doi/10.1111/j.1537-

2995.2010.02816.x/abstract;jsessionid=6D0789C8DE625091F14ABB06F0C6B2AD.f01t 03. Consulté le $13 / 07 / 2014$

60. Popovsky MA, Audet AM, Andrzejewski C. Transfusion-associated circulatory overload in orthopedic surgery patients: a multi-institutional study. Immunohematol Am Red Cross. 1996;12(2):87-9. Disponible sur :

http://www.ncbi.nlm.nih.gov/pubmed/15387748. Consulté le 13/07/2014

61. ANSM. Rapport d'activité hémovigilance 2012 [Internet]. 2012. Disponible sur: http://ansm.sante.fr/var/ansm_site/storage/original/application/b893629101bd8fdb1 Od446fabf34768b.pdf. Consulté le 05/08/2014

62. Royal College of Pathologists. Annual SHOT repport 2012 [Internet]. 2012. DIsponible sur: http://www.shotuk.org/wp-content/uploads/SHOT-Annual-Report-2012.pdf. Consulté le 05/08/2014.

63. FDA. Fatalities Reported to FDA Following Blood Collection and Transfusion [Internet]. 2012. Disponible sur: 
http://www.fda.gov/biologicsbloodvaccines/safetyavailability/reportaproblem/transf usiondonationfatalities/ucm346639.htm. Consulté le 05/08/2014

64. Lienhart A, Auroy $Y$, Péquignot $F$, Benhamou D, Warszawski J, Bovet $M$, et al. Survey of anesthesia-related mortality in France. Anesthesiology. 2006 Dec;105(6):1087-97. Disponible sur: http://pubs.asahq.org/article.aspx?volume=105\&page=1087. Consulté le $05 / 08 / 2014$

65. Bryson GL, Laupacis A, Wells GA. Does acute normovolemic hemodilution reduce perioperative allogeneic transfusion? A meta-analysis. The International Study of Perioperative Transfusion. Anesth Analg. 1998 Jan;86(1):9-15. Disponible sur: http://journals.Iww.com/anesthesiaanalgesia/pages/articleviewer.aspx ?year $=1998 \&$ issue $=01000 \&$ article $=00003 \&$ type $=a b$ stract. Consulté le 17/07/2014

66. Segal JB, Blasco-Colmenares E, Norris EJ, Guallar E. Preoperative acute normovolemic hemodilution: a meta-analysis. Transfusion (Paris). 2004;44(5):632-44. Disponible sur: http://onlinelibrary.wiley.com/doi/10.1111/j.1537-2995.2004.03353.x/full. Consulté le 2014-06-25 00:20:18

67. McNeill TW, DeWald RL, Kuo KN, Bennett EJ, Salem MR. Controlled hypotensive anesthesia in scoliosis surgery. J Bone Joint Surg Am. 1974 Sep;56(6):1167-72. Disponible sur: http://www.jbjs.org/cgi/pmidlookup?view=long\&pmid=4436353. Consulté le 11/06/2014

68. Lim YJ, Kim CS, Bahk JH, Ham BM, Do SH. Clinical trial of esmolol-induced controlled hypotension with or without acute normovolemic hemodilution in spinal surgery. Acta Anaesthesiol Scand. 2003 Jan;47(1):74-8. Disponible sur :

http://onlinelibrary.wiley.com/doi/10.1034/j.1399-6576.2003.470113.x/abstract. Consulté le 11/06/2014

69. Copley LA, Richards BS, Safavi FZ, Newton PO. Hemodilution as a method to reduce transfusion requirements in adolescent spine fusion surgery. Spine. 1999 Feb 1;24(3):219-22; discussion 223-4. Disponible sur : http://journals.Iww.com/spinejournal/pages/articleviewer.aspx?year=1999\&issue=02 010\&article $=00005 \&$ type $=$ abstract. Consulté le 11/06/2014

70. Zonis Z, Seear M, Reichert C, Sett S, Allen C. The effect of preoperative tranexamic acid on blood loss after cardiac operations in children. J Thorac Cardiovasc Surg. 1996 May;111(5):982-7. disponible sur: http://www.jtcvsonline.org/article/S00225223(96)70374-4/pdf. Consulté le 19/04/2014

71. Reid RW, Zimmerman AA, Laussen PC, Mayer JE, Gorlin JB, Burrows FA. The efficacy of tranexamic acid versus placebo in decreasing blood loss in pediatric patients undergoing repeat cardiac surgery. Anesth Analg. 1997 May;84(5):990-6. Disponible sur: http://journals.Iww.com/anesthesiaanalgesia/pages/articleviewer .aspx ?year $=1997 \&$ issue $=05000 \&$ article $=00008 \&$ type $=a b$ stract. Consulté le 22/04/2014 
72. Cole JW, Murray DJ, Snider RJ, Bassett GS, Bridwell KH, Lenke LG. Aprotinin reduces blood loss during spinal surgery in children. Spine. 2003 Nov 1;28(21):2482-5.

Disponible sur :

http://journals.Iww.com/spinejournal/pages/articleviewer.aspx?year=2003\&issue=11 010\&article=00010\&type=abstract. Consulté le 24/04/2014

73. Kasimian S, Skaggs DL, Sankar WN, Farlo J, Goodarzi M, Tolo VT. Aprotinin in pediatric neuromuscular scoliosis surgery. Eur Spine J. 2008 Sep 27;17(12):1671-5. Disponible sur: http://link.springer.com/10.1007/s00586-008-0790-y. Consulté le 2013-12-14 21:18:19

74. Cooper JR Jr, Abrams J, Frazier OH, Radovancevic R, Radovancevic B, Bracey AW, et al. Fatal pulmonary microthrombi during surgical therapy for end-stage heart failure: possible association with antifibrinolytic therapy. J Thorac Cardiovasc Surg. 2006 May;131(5):963-8. Disponible sur: http://www.jtcvsonline.org/article/S00225223(06)00085-7/pdf. Consulté le 25/06/2014

75. Fergusson DA, Hébert PC, Mazer CD, Fremes S, MacAdams C, Murkin JM, et al. A comparison of aprotinin and lysine analogues in high-risk cardiac surgery. $\mathrm{N}$ Engl J Med. 2008;358(22):2319-31. Disponible sur :

http://www.nejm.org/doi/full/10.1056/NEJMoa0802395. Consulté le 2014-06-25 00:20:09

76. Mangano DT, Miao Y, Vuylsteke A, Tudor IC, Juneja R, Filipescu D, et al. Mortality associated with aprotinin during 5 years following coronary artery bypass graft surgery. JAMA J Am Med Assoc. 2007 Feb 7;297(5):471-9. Disponible sur : http://jama.jamanetwork.com/article.aspx?articleid=205404. Consulté le 21/04/2014

77. Henry DA, Carless PA, Moxey AJ, O'Connell D, Stokes BJ, Fergusson DA, et al. Antifibrinolytic use for minimising perioperative allogeneic blood transfusion. Cochrane Database Syst Rev. 2011;(3):CD001886. Disponible sur : http://onlinelibrary.wiley.com/doi/10.1002/14651858.CD001886.pub4/abstract. Consulté le 11/06/2014

78. Thompson GH, Florentino-Pineda I, Poe-Kochert C, Armstrong DG, Son-Hing J. Role of Amicar in surgery for neuromuscular scoliosis. Spine. 2008 Nov 15;33(24):2623-9. Disponible sur :

http://journals.Iww.com/spinejournal/pages/articleviewer.aspx?year=2008\&issue=11 150\&article=00009\&type=abstract. Consulté le 21/04/2014

79. Dhawale AA, Shah SA, Sponseller PD, Bastrom T, Neiss G, Yorgova P, et al. Are antifibrinolytics helpful in decreasing blood loss and transfusions during spinal fusion surgery in children with cerebral palsy scoliosis? Spine. 2012 Apr 20;37(9):E549-55. Disponible sur :

http://journals.lww.com/spinejournal/pages/articleviewer.aspx?year=2012\&issue $=04$ 200\&article $=00020 \&$ type $=$ abstract. Consulté le 19/04/2014

80. Sethna NF, Zurakowski D, Brustowicz RM, Bacsik J, Sullivan LJ, Shapiro F. Tranexamic acid reduces intraoperative blood loss in pediatric patients undergoing scoliosis 
surgery. Anesthesiology. 2005;102(4):727-32. disponible sur : http://pubs.asahq.org/article.aspx?volume=102\&page=727. Consulté le 04/12/2013

81. Shapiro F, Zurakowski D, Sethna NF. Tranexamic acid diminishes intraoperative blood loss and transfusion in spinal fusions for duchenne muscular dystrophy scoliosis. Spine. 2007 Sep 15;32(20):2278-83. Disponible sur : http://journals.Iww.com/spinejournal/pages/articleviewer.aspx?year=2007\&issue=09 150\&article $=00021 \&$ type $=$ abstract. Consulté le 19/04/2014

82. Yagi M, Hasegawa J, Nagoshi N, lizuka S, Kaneko S, Fukuda K, et al. Does the intraoperative tranexamic acid decrease operative blood loss during posterior spinal fusion for treatment of adolescent idiopathic scoliosis? Spine. 2012 Oct 1;37(21):E1336-42. Disponible sur : http://journals.Iww.com/spinejournal/pages/articleviewer.aspx?year=2012\&issue $=10$ 010\&article $=00015 \&$ type $=$ abstract. Consulté le 11/06/2014

83. Tzortzopoulou A, Cepeda MS, Schumann R, Carr DB. Antifibrinolytic agents for reducing blood loss in scoliosis surgery in children. Cochrane Database Syst Rev. 2008;(3):CD006883. Disponible sur : http://onlinelibrary.wiley.com/doi/10.1002/14651858.CD006883.pub2/abstract. Consulté le 20/03/2014

84. Laupacis A, Fergusson D. Drugs to minimize perioperative blood loss in cardiac surgery: meta-analyses using perioperative blood transfusion as the outcome. The International Study of Peri-operative Transfusion (ISPOT) Investigators. Anesth Analg. 1997 Dec;85(6):1258-67. Disponible sur : http://journals.Iww.com/anesthesiaanalgesia/pages/articleviewer .aspx ?year $=1997 \&$ issue $=12000 \&$ article $=00014 \&$ type $=a b$ stract. Consulté le 13/06/2014

85. Levi M, Cromheecke ME, de Jonge E, Prins MH, de Mol BJ, Briët E, et al. Pharmacological strategies to decrease excessive blood loss in cardiac surgery: a meta-analysis of clinically relevant endpoints. Lancet. 1999 Dec 4;354(9194):1940-7. Disponible sur: http://www.thelancet.com/journals/lancet/article/PIIS01406736(99)01264-7/abstract. Consulté le 13/07/2014

86. Carless PA, Henry DA, Moxey AJ, O'Connell D, McClelland B, Henderson KM, et al. Desmopressin for minimising perioperative allogeneic blood transfusion. Cochrane Database Syst Rev. 2004;(1):CD001884. Disponible sur : http://onlinelibrary.wiley.com/doi/10.1002/14651858.CD001884.pub2/abstract. Consulté le 21/04/2014

87. Kobrinsky NL, Letts RM, Patel LR, Israels ED, Monson RC, Schwetz N, et al. 1-Desamino8-D-arginine vasopressin (desmopressin) decreases operative blood loss in patients having Harrington rod spinal fusion surgery. A randomized, double-blinded, controlled trial. Ann Intern Med. 1987 Oct;107(4):446-50. Disponible sur : http://annals.org/article.aspx?articleid=702179. Consulté le 04/07/2014

88. Guay J, Reinberg C, Poitras B, David M, Mathews S, Lortie L, et al. A trial of desmopressin to reduce blood loss in patients undergoing spinal fusion for idiopathic 
scoliosis. Anesth Analg. 1992 Sep;75(3):405-10. Disponible sur:

http://journals.Iww.com/anesthesia-

analgesia/pages/articleviewer .aspx?year $=1992 \&$ issue $=09000 \&$ article $=00016 \&$ type $=a b$ stract. Consulté le 21/04/2014

89. Letts $M$, Pang E, D'Astous J, Jarvis J, Lawton L, Luke B, et al. The influence of desmopressin on blood loss during spinal fusion surgery in neuromuscular patients. Spine. 1998 Feb 15;23(4):475-8. Disponible sur : http://www.ncbi.nlm.nih.gov/pubmed/9516704. Consulté le 21/04/2014

90. Kolban M, Balachowska-Kosciolek I, Chmielnicki M. Recombinant coagulation factor VIla-a novel haemostatic agent in scoliosis surgery? Eur Spine J. 2005 Aug 17;15(6):944-52. Disponible sur: http://link.springer.com/10.1007/s00586-005-10045. Consulté le 2013-12-14 21:19:19

91. HAS. Récupération de sang périopératoire (RSPO) suivie de son administration par voie intraveineuse [Internet]. 2006. Disponible sur: http://www.hassante.fr/portail/upload/docs/application/pdf/rspo_synth.pdf. Consulté le 05/08/2014

92. Carless PA, Henry DA, Moxey AJ, O'Connell D, Brown T, Fergusson DA. Cell salvage for minimising perioperative allogeneic blood transfusion. Cochrane Database Syst Rev. 2010;(4):CD001888. Disponible sur:

http://onlinelibrary.wiley.com/doi/10.1002/14651858.CD001888.pub4/abstract. Consulté le 21/04/2014

93. Bowen RE, Gardner S, Scaduto AA, Eagan M, Beckstead J. Efficacy of intraoperative cell salvage systems in pediatric idiopathic scoliosis patients undergoing posterior spinal fusion with segmental spinal instrumentation. Spine. 2010 Jan 15;35(2):246-51. Disponible sur : http://journals.Iww.com/spinejournal/pages/articleviewer.aspx?year=2010\&issue=01 150\&article=00020\&type=abstract. Consulté le 11/06/2014

94. Weiss JM, Skaggs D, Tanner J, Tolo V. Cell Saver: is it beneficial in scoliosis surgery? J Child Orthop. 2007 Oct;1(4):221-7. Disponible sur : http://www.ncbi.nlm.nih.gov/pmc/articles/PMC2656732/. Consulté le 25/06/2014

95. Dahmani S, Orliaguet GA, Meyer PG, Blanot S, Renier D, Carli PA. Perioperative blood salvage during surgical correction of craniosynostosis in infants. $\mathrm{Br} J$ Anaesth. 2000 Oct;85(4):550-5. Disponible sur: http://bja.oxfordjournals.org/content/85/4/550.long. Consulté le 14/07/2014

96. Golab HD, Scohy TV, de Jong PL, Takkenberg JJM, Bogers AJJC. Intraoperative cell salvage in infants undergoing elective cardiac surgery: a prospective trial. Eur J CardioThorac Surg Off J Eur Assoc Cardio-Thorac Surg. 2008 Aug;34(2):354-9. Disponible sur: http://ejcts.oxfordjournals.org/content/34/2/354.full.pdf+html. Consulté le $14 / 07 / 2014$

97. García-Erce JA, Muñoz M, Bisbe E, Sáez M, Solano VM, Beltrán S, et al. Predeposit autologous donation in spinal surgery: a multicentre study. Eur Spine J Off Publ Eur 
Spine Soc Eur Spinal Deform Soc Eur Sect Cerv Spine Res Soc. 2004 Oct;13 Suppl 1:S34-9. Disponible sur: http://link.springer.com/article/10.1007\%2Fs00586-0040726-0. Consulté le 14/07/2014

98. Forgie MA, Wells PS, Laupacis A, Fergusson D. Preoperative autologous donation decreases allogeneic transfusion but increases exposure to all red blood cell transfusion: results of a meta-analysis. International Study of Perioperative Transfusion (ISPOT) Investigators. Arch Intern Med. 1998 Mar 23;158(6):610-6. Disponible sur: http://archinte.jamanetwork.com/article.aspx?articleid=191643. Consulté le 14/07/2014

99. Hibino N, Nagashima M, Sato H, Hori T, Ishitoya H, Tomino T. Preoperative autologous blood donation for cardiac surgery in children. Asian Cardiovasc Thorac Ann. 2008 Jan;16(1):21-4. Disponible sur: http://aan.sagepub.com/cgi/pmidlookup?view=long\&pmid=18245700. Consulté le $14 / 07 / 2014$

100. Lauder GR. Pre-operative predeposit autologous donation in children presenting for elective surgery: a review. Transfus Med Oxf Engl. 2007 Apr;17(2):75-82. Disponible sur: http://onlinelibrary.wiley.com/doi/10.1111/j.1365-3148.2006.00716.x/abstract. Consulté le 14/07/2014

101. Schved J-F. [Do we need autologous blood donation?]. Ann Fr Anesthèsie Rèanimation. 2004 May;23(5):468-73. Disponible sur: http://www.emconsulte.com/article/25477/alertePM. Consulté le 14/07/2014

102. Bess RS, Lenke LG, Bridwell KH, Steger-May K, Hensley M. Wasting of preoperatively donated autologous blood in the surgical treatment of adolescent idiopathic scoliosis. Spine. 2006 Sep 15;31(20):2375-80. Disponible sur: http://journals.Iww.com/spinejournal/pages/articleviewer.aspx?year=2006\&issue=09 150\&article=00019\&type=abstract; Consulté le 11/06/2014

103. Colomina MJ, Bag J, Pellis F, Godet C, Villanueva C. Preoperative erythropoietin in spine surgery. Eur Spine J. 2004 Jun 9;13(S01):S40-9. Disponible sur : http://link.springer.com/10.1007/s00586-004-0754-9. Consulté le 2013-12-14 21:19:10

104. Vitale MG, Privitera DM, Matsumoto H, Gomez JA, Waters LM, Hyman JE, et al. Efficacy of preoperative erythropoietin administration in pediatric neuromuscular scoliosis patients. Spine. 2007 Nov 15;32(24):2662-7. Disponible sur : http://journals.lww.com/spinejournal/pages/articleviewer. aspx?year=2007\&issue=11 $150 \&$ article $=00005 \&$ type $=$ abstract. Consulté le 20/04/2014

105. Pillonel J, Laperche S, Etablissement Français du sang. Trends in risk of transfusiontransmitted viral infections (HIV, HCV, HBV) in France between 1992 and 2003 and impact of nucleic acid testing (NAT). Euro Surveill Bull Eur Sur Mal Transm Eur Commun Dis Bull. 2005 Feb;10(2):5-8. Disponible sur : http://www.ncbi.nlm.nih.gov/pubmed/15735313. Consulté le 14/07/2014 
106. Long TR, Stans AA, Shaughnessy WJ, Joyner MJ, Schroeder DR, Wass CT. Changes in red blood cell transfusion practice during the past quarter century: a retrospective analysis of pediatric patients undergoing elective scoliosis surgery using the Mayo database. Spine J. 2012 Jun;12(6):455-62. Disponible sur : http://linkinghub.elsevier.com/retrieve/pii/S1529943012002732. Consulté le 2013-1214 21:18:37

107. Booke M, Reich A. Autotransfusion and blood-sparing techniques in infants and children. Curr Opin Anaesthesiol. 2000 Jun;13(3):303-6. Disponible sur : http://journals.Iww.com/coanesthesiology/pages/articleviewer.aspx ?year $=2000 \&$ issue $=06000 \&$ article $=00012 \&$ ty pe=abstract. Consulté le 11/06/2014

108. Laupacis A, Fergusson D. Erythropoietin to minimize perioperative blood transfusion: a systematic review of randomized trials. The International Study of Peri-operative Transfusion (ISPOT) Investigators. Transfus Med Oxf Engl. 1998 Dec;8(4):309-17. Disponible sur: http://onlinelibrary.wiley.com/doi/10.1046/j.1365-

3148.1998.00171.x/abstract. Consulté le 11/06/2014

109. Goodnough LT, Maniatis A, Earnshaw P, Benoni G, Beris P, Bisbe E, et al. Detection, evaluation, and management of preoperative anaemia in the elective orthopaedic surgical patient: NATA guidelines. Br J Anaesth. 2011 Jan;106(1):13-22. Disponible sur: http://bja.oxfordjournals.org/content/106/1/13.full.pdf+html. Consulté le 05/08/2014

110. Goodnough LT, Rudnick S, Price TH, Ballas SK, Collins ML, Crowley JP, et al. Increased preoperative collection of autologous blood with recombinant human erythropoietin therapy. N Engl J Med. 1989 Oct 26;321(17):1163-8. Disponible sur : http://www.nejm.org/doi/full/10.1056/NEJM198910263211705. Consulté le $20 / 04 / 2014$

111. Goodnough LT, Monk TG, Andriole GL. Erythropoietin therapy. N Engl J Med. 1997 Mar 27;336(13):933-8. Disponible sur : http://www.nejm.org/doi/full/10.1056/NEJM199703273361307. Consulté le $11 / 06 / 2014$

112. Sonzogni V, Crupi G, Poma R, Annechino F, Ferri F, Filisetti P, et al. Erythropoietin therapy and preoperative autologous blood donation in children undergoing open heart surgery. Br J Anaesth. 2001 Sep;87(3):429-34. disponible sur : http://bja.oxfordjournals.org/content/87/3/429.long. Consulté le 21/04/2014

113. Price TH, Goodnough LT, Vogler WR, Sacher RA, Hellman RM, Johnston MF, et al. Improving the efficacy of preoperative autologous blood donation in patients with low hematocrit: a randomized, double-blind, controlled trial of recombinant human erythropoietin. Am J Med. 1996 Aug 26;101(2A):22S - 27S. Disponible sur : http://www.ncbi.nlm.nih.gov/pubmed/8928704. Consulté le 15/07/2014

114. Shapiro GS, Boachie-Adjei O, Dhawlikar SH, Maier LS. The use of Epoetin alfa in complex spine deformity surgery. Spine. 2002 Sep 15;27(18):2067-71. Disponible sur: 
http://journals.Iww.com/spinejournal/pages/articleviewer.aspx?year=2002\&issue=09 150\&article=00019\&type=abstract. Consulté le 19/04/2014

115. Roye DP Jr. Recombinant human erythropoietin and blood management in pediatric spine surgery. Orthopedics. 1999 Jan;22(1 Suppl):s158-60. Disponible sur : http://www.ncbi.nlm.nih.gov/pubmed/9927120. Consulté le 20/04/2014

116. Laupacis A, Feagan B, Wong C. Effectiveness of perioperative recombinant human erythropoietin in elective hip replacement. COPES Study Group. Lancet. 1993 Aug 7;342(8867):378. disponible sur: http://www.ncbi.nlm.nih.gov/pubmed/8101624. Consulté le 05/08/2014

117. Goldberg MA. Perioperative epoetin alfa increases red blood cell mass and reduces exposure to transfusions: results of randomized clinical trials. Semin Hematol. 1997 Jul;34(3 Suppl 2):41-7. Disponible sur: http://www.ncbi.nlm.nih.gov/pubmed/9253783. Consulté le 05/08/2014

118. Rosencher N, Poisson D, Albi A, Aperce M, Barré J, Samama CM. Two injections of erythropoietin correct moderate anemia in most patients awaiting orthopedic surgery. Can J Anaesth J Can Anesth. 2005 Feb;52(2):160-5. Disponible sur : http://download.springer.com/static/pdf/305/art\%253A10.1007\%252FBF03027722.p df?auth66=1425899705_706028ed3ee7231ba0a8421e77f1ccb4\&ext=.pdf. Consulté le $05 / 08 / 2014$

119. Lidder PG, Sanders G, Whitehead E, Douie WJ, Mellor N, Lewis SJ, et al. Pre-operative oral iron supplementation reduces blood transfusion in colorectal surgery - a prospective, randomised, controlled trial. Ann R Coll Surg Engl. 2007 May;89(4):41821. Disponible sur:

http://www.ingentaconnect.com/content/rcse/arcs/2007/00000089/00000004/art00 019?token $=00561$ ee $4044984 d$ 3baa2635a666f3a7b6c424051425b6b464c3e6b254926 4f655d375c6b6876305021922e. Consulté le 05/08/2014

120. Andrews CM, Lane DW, Bradley JG. Iron pre-load for major joint replacement. Transfus Med Oxf Engl. 1997 Dec;7(4):281-6. Disponible sur : http://www.ncbi.nlm.nih.gov/pubmed/9510925. Consulté le 05/08/2014

121. Park CK. The effect of patient positioning on intraabdominal pressure and blood loss in spinal surgery. Anesth Analg. 2000 Sep;91(3):552-7. Disponible sur : http://journals.Iww.com/anesthesiaanalgesia/pages/articleviewer.aspx ?year $=2000 \&$ issue $=09000 \&$ article $=00009 \&$ type $=a b$ stract. Consulté le 25/06/2014

122. Nuttall GA, Horlocker TT, Santrach PJ, Oliver WC, Dekutoski MB, Bryant S. Use of the surgical blood order equation in spinal instrumentation and fusion surgery. Spine. 2000 Mar 1;25(5):602-5. Disponible sur : http://journals.Iww.com/spinejournal/pages/articleviewer.aspx?year=2000\&issue=03 010\&article $=00011 \&$ type $=$ abstract. Consulté le 05/08/2014 
123. Brecher ME, Monk T, Goodnough LT. A standardized method for calculating blood loss. Transfusion (Paris). 1997 Oct;37(10):1070-4. disponible sur :

http://onlinelibrary.wiley.com/doi/10.1046/j.1537-

2995.1997.371098016448.x/abstract. Consulté le 05/08/2014

124. Edler A, Murray DJ, Forbes RB. Blood loss during posterior spinal fusion surgery in patients with neuromuscular disease: is there an increased risk? Pediatr Anesth. 2003;13(9):818-22. disponible sur http://onlinelibrary.wiley.com/doi/10.1046/j.14609592.2003.01171.x/full. Consulté le 2013-12-14 21:18:25

125. Gibson PRJ. Anaesthesia for correction of scoliosis in children. Anaesth Intensive Care. 2004;32:548-59. disponible sur: http://anes-

som.ucsd.edu/Intranet/Peds_Resources/Ortho_Back/Peds\%20scoliosis\%20review.pdf. Consulté le 2014-07-22 18:17:03

126. Kannan S, Meert KL, Mooney JF, Hillman-Wiseman C, Warrier I. Bleeding and coagulation changes during spinal fusion surgery: a comparison of neuromuscular and idiopathic scoliosis patients. Pediatr Crit Care Med J Soc Crit Care Med World Fed Pediatr Intensive Crit Care Soc. 2002 Oct;3(4):364-9. disponible sur :

http://journals.Iww.com/pccmjournal/pages/articleviewer.aspx?year=2002\&issue $=10$ 000\&article=00007\&type=abstract. Consulté le 25/06/2014

127. Brenn BR, Theroux MC, Dabney KW, Miller F. Clotting parameters and thromboelastography in children with neuromuscular and idiopathic scoliosis undergoing posterior spinal fusion. Spine. 2004 Aug 1;29(15):E310-4. Disponible sur : http://journals.Iww.com/spinejournal/pages/articleviewer.aspx?year=2004\&issue $=08$ 010\&article=00024\&type=abstract. Consulté le 21/04/2014

128. Allam AM, Schwabe AL. Neuromuscular Scoliosis. PM\&R. 2013 Nov;5(11):957-63. Disponible sur http://linkinghub.elsevier.com/retrieve/pii/S1934148213002888. Consulté le 2014-07-22 18:17:39

129. Rosencher N, Conseiller C, Woimant G, Eyrolle L, Vassilieff N, Belbachir A, et al. [Preoperative hemodilution by erythrocytapheresis with homologous blood saving in total hip arthroplasty]. Ann Fr Anesthèsie Rèanimation. 1996;15(1):13-9. Disponible sur :

http://www.ncbi.nlm.nih.gov/pubmed/?term=Preoperative+hemodilution+by+erythr ocytapheresis+with+homologous+blood+saving+in+total+hip+arthroplasty\%5D. Consulté le 02/08/2014

130. De Jonge $E$, Levi $M$, Berends F, van der Ende AE, ten Cate JW, Stoutenbeek CP. Impaired haemostasis by intravenous administration of a gelatin-based plasma expander in human subjects. Thromb Haemost. 1998 Feb;79(2):286-90. disponible sur: http://th.schattauer.de/en/contents/archive/issue/910/manuscript/4400.html. Consulté le 02/08/2014

131. Bergqvist D. Dextran and haemostasis. A review. Acta Chir Scand. 1982;148(8):633-40. Disponible sur: http://www.ncbi.nlm.nih.gov/pubmed/6189321. Consulté le 02/08/2014 
132. Treib J, Baron JF, Grauer MT, Strauss RG. An international view of hydroxyethyl starches. Intensive Care Med. 1999 Mar;25(3):258-68. Disponible sur : http://link.springer.com/article/10.1007/s001340050833. Consulté le 02/08/2014

133. Damon L, Adams M, Stricker RB, Ries C. Intracranial bleeding during treatment with hydroxyethyl starch. N Engl J Med. 1987 Oct 8;317(15):964-5. Disponible sur : http://www.nejm.org/doi/full/10.1056/NEJM198710083171517. Consulté le $02 / 08 / 2014$

134. Langeron O, Doelberg $\mathrm{M}$, Ang ET, Bonnet $\mathrm{F}$, Capdevila $\mathrm{X}$, Coriat $\mathrm{P}$. Voluven, a lower substituted novel hydroxyethyl starch (HES 130/0.4), causes fewer effects on coagulation in major orthopedic surgery than HES 200/0.5. Anesth Analg. 2001 Apr;92(4):855-62. Disponible sur: http://journals.Iww.com/anesthesiaanalgesia/pages/articleviewer .aspx?year $=2001 \&$ issue $=04000 \&$ article $=00011 \&$ type $=a b$ stract. Consulté le 002/08/2014

135. Haisch G, Boldt J, Krebs C, Suttner S, Lehmann A, Isgro F. Influence of a new hydroxyethylstarch preparation (HES 130/0.4) on coagulation in cardiac surgical patients. J Cardiothorac Vasc Anesth. 2001 Jun;15(3):316-21. disponible sur : http://www.jcvaonline.com/article/S1053-0770(01)11538-7/pdf. Consulté le 02/08/2014

136. Neff TA, Doelberg M, Jungheinrich C, Sauerland A, Spahn DR, Stocker R. Repetitive large-dose infusion of the novel hydroxyethyl starch 130/0.4 in patients with severe head injury. Anesth Analg. 2003 May;96(5):1453-9, table of contents. Disponible sur: http://journals.Iww.com/anesthesiaanalgesia/pages/articleviewer .aspx ?year $=2003 \&$ issue $=05000 \&$ article $=00037 \&$ type $=a b$ stract. Consulté le 02/08/2014

137. Franz A, Bräunlich P, Gamsjäger T, Felfernig M, Gustorff B, Kozek-Langenecker SA. The effects of hydroxyethyl starches of varying molecular weights on platelet function. Anesth Analg. 2001 Jun;92(6):1402-7. Disponible sur: http://journals.Iww.com/anesthesiaanalgesia/pages/articleviewer.aspx ?year $=2001 \&$ issue $=06000 \&$ article $=00008 \&$ type $=a b$ stract. Consulté le 02/08/2014

138. Mittermayr M, Streif W, Haas T, Fries D, Velik-Salchner C, Klingler A, et al. Hemostatic changes after crystalloid or colloid fluid administration during major orthopedic surgery: the role of fibrinogen administration. Anesth Analg. 2007 Oct;105(4):905-17, table of contents. Disponible sur: http://journals.Iww.com/anesthesiaanalgesia/pages/articleviewer.aspx ?year=2007\&issue $=10000 \&$ article $=00004 \&$ type $=a b$ stract. Consulté le 02/08/2014

139. Godier A, Durand M, Smadja D, Jeandel T, Emmerich J, Samama CM. Maize- or potatoderived hydroxyethyl starches: is there any thromboelastometric difference?: Thromboelastographic comparison of two different HES. Acta Anaesthesiol Scand. 2010 Nov;54(10):1241-7. disponible sur: http://doi.wiley.com/10.1111/j.13996576.2010.02306.x. Consulté le 2014-07-31 22:26:06 
140. Schramko A, Suojaranta-Ylinen R, Kuitunen A, Raivio P, Kukkonen S, Niemi T. Hydroxyethylstarch and gelatin solutions impair blood coagulation after cardiac surgery: a prospective randomized trial. Br J Anaesth. 2010 Jun 1;104(6):691-7. Disponible sur: http://bja.oxfordjournals.org/lookup/doi/10.1093/bja/aeq084. Consulté le 2014-07-31 22:25:33

141. Kozek-Langenecker SA, Jungheinrich C, Sauermann W, Van der Linden P. The effects of hydroxyethyl starch 130/0.4 (6\%) on blood loss and use of blood products in major surgery: a pooled analysis of randomized clinical trials. Anesth Analg. 2008 Aug;107(2):382-90. Disponible sur: http://journals.Iww.com/anesthesiaanalgesia/pages/articleviewer .aspx ?year $=2008 \&$ issue $=08000 \&$ article $=00008 \&$ type $=a b$ stract. Consulté le 02/08/2014

142. Raja SG, Akhtar S, Shahbaz Y, Masood A. In cardiac surgery patients does Voluven(R) impair coagulation less than other colloids? Interact Cardiovasc Thorac Surg. 2011 Jun 1;12(6):1022-7. Disponible sur : http://icvts.oxfordjournals.org/cgi/doi/10.1510/icvts.2010.263939. Consulté le 201407-31 22:25:36

143. Hartog CS, Reuter D, Loesche W, Hofmann M, Reinhart K. Influence of hydroxyethyl starch (HES) 130/0.4 on hemostasis as measured by viscoelastic device analysis: a systematic review. Intensive Care Med. 2011 Nov;37(11):1725-37. Disponible sur : http://link.springer.com/10.1007/s00134-011-2385-z. Consulté le 2014-07-31 22:26:03

144. Skhirtladze K, Base EM, Lassnigg A, Kaider A, Linke S, Dworschak M, et al. Comparison of the effects of albumin 5\%, hydroxyethyl starch 130/0.4 6\%, and Ringer's lactate on blood loss and coagulation after cardiac surgery. Br J Anaesth. 2014 Feb;112(2):25564. Disponible sur: http://bja.oxfordjournals.org/content/112/2/255.full.pdf+html. Consulté le 02/08/2014

145. Rasmussen KC, Johansson PI, Højskov M, Kridina I, Kistorp T, Thind P, et al. Hydroxyethyl starch reduces coagulation competence and increases blood loss during major surgery: results from a randomized controlled trial. Ann Surg. 2014;259(2):24954. Disponible sur : http://journals.Iww.com/annalsofsurgery/Abstract/2014/02000/Hydroxyethyl_Starch _Reduces_Coagulation_Competence.9.aspx. Consulté le 2014-07-31 22:25:27

146. Schneider SM, Veyres $P$, Pivot $X$, Soummer A-M, Jambou P, Filippi J, et al. Malnutrition is an independent factor associated with nosocomial infections. Br J Nutr. 2004 Jul;92(1):105-11. Disponible sur : http://journals.cambridge.org/download.php?file=\%2FBJN\%2FBJN92_01\%2FS000711 4504001357a.pdf\&code=e077e27d7b7909b4f111c69b82140018. Consulté le $03 / 08 / 2014$

147. Jain G, Mukerji G, Dixit A, Manshani N, Yadav YR. The impact of nutritional status on the outcome of Indian patients undergoing neurosurgical shunt surgery. Br J Nutr. 2007 Nov;98(5):944-9. Disponible sur : http://journals.cambridge.org/download.php?file=\%2FBJN\%2FBJN98_05\%2FS000711 
4507749218a.pdf\&code=e077e27d7b7909b43592b187924f0996. Consulté le $03 / 08 / 2014$

148. Radman M, Mack R, Barnoya J, Castañeda A, Rosales M, Azakie A, et al. The effect of preoperative nutritional status on postoperative outcomes in children undergoing surgery for congenital heart defects in San Francisco (UCSF) and Guatemala City (UNICAR). J Thorac Cardiovasc Surg. 2014 Jan;147(1):442-50. Disponible sur : http://www.jtcvsonline.org/article/S0022-5223(13)00326-7/pdf. Consulté le 03/08/2014

149. Mehta NM, Bechard LJ, Cahill N, Wang M, Day A, Duggan CP, et al. Nutritional practices and their relationship to clinical outcomes in critically ill children-An international multicenter cohort study*: Crit Care Med. 2012 Jul;40(7):2204-11. Disponible sur: http://content.wkhealth.com/linkback/openurl?sid=WKPTLP:landingpage\&an $=000032$ 46-201207000-00026. Consulté le 2014-08-07 12:50:00

150. Buzby GP, Mullen JL, Matthews DC, Hobbs CL, Rosato EF. Prognostic nutritional index in gastrointestinal surgery. Am J Surg. 1980 Jan;139(1):160-7. Disponible sur : http://www.americanjournalofsurgery.com/article/0002-9610(80)90246-9/pdf. COnsulté le 03/08/2014

151. Wiskin AE, Owens DR, Cornelius VR, Wootton SA, Beattie RM. Paediatric nutrition risk scores in clinical practice: children with inflammatory bowel disease. J Hum Nutr Diet Off J Br Diet Assoc. 2012 Aug;25(4):319-22. Disponible sur : http://onlinelibrary.wiley.com/doi/10.1111/j.1365-277X.2012.01254.x/abstract. Consulté le 03/08/2014

152. Davidson ZE, Truby H. A review of nutrition in Duchenne muscular dystrophy. J Hum Nutr Diet Off J Br Diet Assoc. 2009 Oct;22(5):383-93. Disponible sur : http://onlinelibrary.wiley.com/doi/10.1111/j.1365-277X.2009.00979.x/abstract. Consulté le 03/08/2014

153. Somerville $\mathrm{H}, \mathrm{O}^{\prime}$ loughlin $\mathrm{E}$. Gastrostomy feeding in cerebral palsy: enough and no more. Dev Med Child Neurol. 2010 Dec 1;52(12):1076-1076. disponible sur : https://onlinelibrary-wiley-com.frodon.univ-paris5.fr/doi/10.1111/j.14698749.2010.03805.x/abstract. Consulté le 2014-08-03 12:00:38

154. Arrowsmith F, Allen J, Gaskin K, Somerville H, Clarke S, O'Loughlin E. The effect of gastrostomy tube feeding on body protein and bone mineralization in children with quadriplegic cerebral palsy. Dev Med Child Neurol. 2010 Nov;52(11):1043-7. Disponible sur: http://onlinelibrary.wiley.com/doi/10.1111/j.14698749.2010.03702.x/abstract. Consulté le 03/08/2014

155. Alanay A, Acaroglu E, Ozdemir O, Erçelen O, Bulutçu E, Surat A. Effects of deamino-8$D$-arginin vasopressin on blood loss and coagulation factors in scoliosis surgery. $A$ double-blind randomized clinical trial. Spine. 1999 May 1;24(9):877-82. Disponible sur: 
http://journals.Iww.com/spinejournal/pages/articleviewer .aspx?year=1999\&issue=05 010\&article=00008\&type=abstract. Consulté le 21/04/2014 


\title{
RESUME DE LA THESE EN FRANCAIS
}

Introduction : L'optimisation des stratégies d'épargne transfusionnelle au cours de la chirurgie de la scoliose pédiatrique est toujours une question de recherche. L'objectif de cette thèse était la recherche des facteurs prédictifs de transfusion au cours de cette chirurgie après mise en place d'un protocole avec érythropoiétine et acide tranexamique.

Matériel et méthode : Il s'agissait d'une étude rétrospective, monocentrique. Les facteurs prédictifs étudiés étaient l'âge, l'indice de masse corporel(IMC), l'étiologie de la scoliose, le score ASA, l'angle de Cobb, le nombre d'étage fusionné, la réalisation d'une fusion sacrée, d'une gibbectomie, la durée de la chirurgie et le type de soluté de remplissage administré. Etait évaluées les transfusions le jour de la chirurgie et les 5 jours suivant. Une analyse uni puis multivariée étaient effectuées.

Résultats : 147 patients étaient inclus dans l'analyse, 27 d’entre eux étaient transfusés au cours de la chirurgie. Les facteurs indépendants associés au risque transfusionnel étaient un IMC supérieur à 16(0.144[0.024-0.864]), une origine neuromusculaire de la scoliose (11.7[1.58-86.76]), l'administration de colloides (15.58[1.43-169.8]) et une durée de la chirurgie de plus de $255 \mathrm{~min}(7.49[2-28.12])$.

Discussion: Une origine neuromusculaire reste toujours un surrisque de transfusion, de nouvelles strategies doivent être élaborés spécifiquement pour ces patients. L'IMC doit être évalué systématiquement et optimisé pour cette chirurgie. Les colloides ne devraient pas être les solutés de référence en l'absence d'autres études affirmant leurs inocuités.

\section{TITRE DE LA THESE EN ANGLAIS}

Predictive factors of homologous transfusion during Scoliosis Surgery in Children losses

\author{
with Erythropoietin (rEPO) and antifibrinolytic therapy (AFT) as saving strategies.
}

\section{RESUME DE LA THESE EN ANGLAIS}

Introduction: Major bleeding is one the major complications during pediatric scoliosis surgery. The aim of this study was to determine the factors associated with the perioperative allogenic transfusion after having implemented Erythropoietin and antifibrinolytic therapy as saving strategies.

Material and Methods: the study consists on a retrospective analysis of factors associated with the perioperative (defined as the intraoperative and the first 5 postoperative days) probability of homologous red cell transfusion. Predictors analyzed were: age, Body Mass Index (BMI), origin of scoliosis, Cobb's angle, ASA status, preoperative hemoglobin, techniques of blood saving used, number of level fused, sacral fusion and gibbectomy, duration of the surgery and intra operative fluids. Statistical analyses were performed using uni and multivariate analysis.

Results: 147 patients were included into the analysis, and 27 were transfused during the perioperative period. Perioperative factors independently associated with perioperative homologous transfusion during scoliosis surgery in children were a Body Mass Index over 16(0.144[0.024-0.864]), the neuromuscular etiology of scoliosis (11.7[1.58-86.76], intraoperative Colloids(15.58[1.43-169.8]) and the duration of surgery above 255 $\mathrm{mn}$ (7.49[2-28.12]).

Discussion: A neuromuscular origin was still associated with an higher level of transfusion. New strategies must be developed specifically for these patients. Body Mass index was independently associated with this risk suggesting the importance of nutrition. Finally, colloids were independently associated with the risk of transfusion. The real benefice of macromolecules must be questioned.

Mots clés: épargne transfusionnelle, chirurgie, scoliose, pédiatrie, érythropoiétine, anti-fibrinolytique, anesthésie

Key words: blood saving strategies, scoliosis, surgery, children, erythropoietin, antifibrinolytic, anesthesiology

Faculté de médecine PARIS DESCARTES, PARIS V, 15 rue de l'école de médecine F-75270 PARIS CEDEX 06 www.medecine.univ-paris5.fr 